\title{
Hommes armés, femmes aguerries
}

\section{Rapports de genre}

en situations de conflit armé

\section{Textes réunis par Fenneke Reysoo}

Les colloques genre de l'IUED: Collection Yvonne Preiswerk
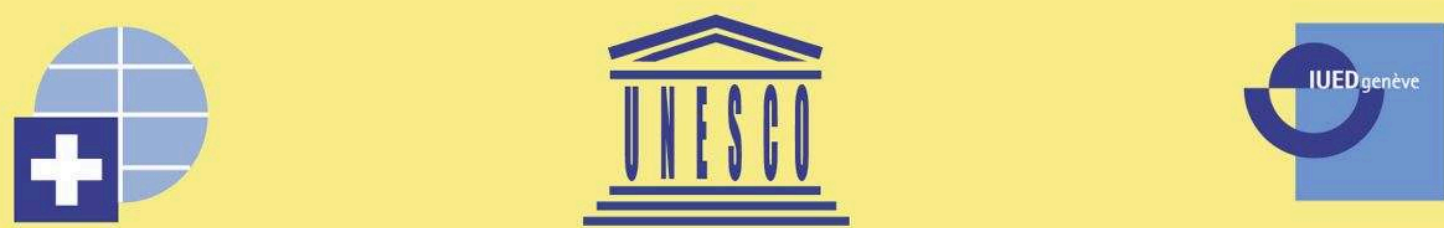

Commission nationale suisse pour l'Unesco, Berne

DDC, Direction du développement et de la coopération

Département fédéral des affaires étrangères, Berne

IUED, Institut universitaire d'études du développement, Genève

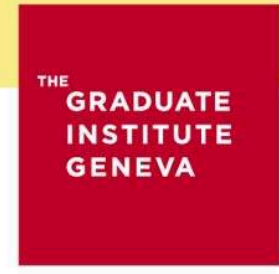

-

INSTITUT DE HAUTES

ÉTUDES INTERNATIONALES

ET DU DÉVELOPPEMENT

GRADUATE INSTITUTE

OF INTERNATIONAL AND

DEVELOPMENT STUDIES

NOUVELLE ÉDITION

\section{GENRE ET DÉVELOPPEMENT | RENCONTRES}




\section{Hommes armés, femmes aguerries}

Rapports de genre en situations de conflit armé

\section{Fenneke Reysoo (dir.)}

DOI : 10.4000/books.iheid.6123

Éditeur: Graduate Institute Publications

Lieu d'édition : Genève

Année d'édition : 2001

Date de mise en ligne : 5 juillet 2016

Collection : Genre et développement. Rencontres

EAN électronique : 9782940503773

\section{Q OpenEdition}

Books

https://books.openedition.org

Édition imprimée

EAN (Édition imprimée) : 9782882470430

Nombre de pages : 250

Référence électronique

REYSOO, Fenneke (dir.). Hommes armés, femmes aguerries : Rapports de genre en situations de conflit armé. Nouvelle édition [en ligne]. Genève : Graduate Institute Publications, 2001 (généré le 08 décembre 2022). Disponible sur Internet : <http://books.openedition.org/iheid/6123>. ISBN : 9782940503773. DOI : https://doi.org/10.4000/books.iheid.6123. 


\section{RÉSUMÉS}

La guerre est un moment de rupture sociale profonde. Toutes les normes et valeurs sont remises en question, transgressées ou inversées. Ce livre montre comment les conflits affectent les hommes et les femmes, de manière différente et comment ces bouleversements se perpétuent (ou non) par la suite. La multiplication des responsabilités des femmes en temps de guerre et leur adaptabilité à des situations difficiles font souvent d'elles les forces motrices dans les processus de reconstruction sociale après un conflit. 


\section{Hommes armés, femmes aguerries. Rapports de genre en situation de conflit armé}

Textes réunis par Fenneke Reysoo

DDC/Unesco/IUED, Genève, 2001, 250 p.

\section{Table des matières}

Jean-Luc Maurer

Ouverture

Fenneke Reysoo

Situations de conflit armé comme champs d'analyse des rapports de genre

\section{A leurs risques et périls}

Eugénie Rokhaya Aw-Ndiaye

Rapports hommes-femmes : les crises en Afrique sont-elles des ferments du changement?

Amneh Badran

Palestinian-Israeli Women's Initiatives and Power Relations

\section{Dispositifs d'alerte et signes précurseurs}

Susanne Schmeidl

Gender and Early Warning

Fanta Coulibaly Coumaré

Les situations de conflits armés entre exploitants des ressources naturelles en zone soudanosahélienne, cas du Mali

Monika Kaempf

Impact of War on Women

Magdala Velazquez Toro

Unas reflexiones feministas en torno a la guerra, la paz, y las mujeres, desde una perspectiva de género

\section{Les douleurs invisibles après conflit}

Dinora Aguiñada Deras

Una mirada feminista sobre la participación de las mujeres en la guerra

Goretti Ndacayisaba

Impact d'un conflit sur les relations hommes-femmes : le cas du Burundi 
Alla Kuvatova

Gender Issues in Tajikistan : Consequences and Impact of the Civil War

Annemiek Richters

Gender Violence, Health and Healing in Situations of Ethno-national Conflicts : the Cases of the Former Yugoslavia and Tajikistan

\section{Les chemins vers la paix : résistances et pacifismes}

Micheline Centlivres-Demont

Hommes combattants, femmes discrètes : aspects des résistances subalternes dans le conflit et l'exil afghan

Clara Inés Mazo LÓpez

Una mirada al conflicto armado colombiano desde la palabra, las acciones, las propuestas y los símbolos construidos por las mujeres

Christiana George

Engendering the Peace Process in Africa

\section{Abstracts \\ Resúmenes}


JEAN-LuC MAURER

\section{OUVERTURE}

Bonjour à tout le monde,

Tout d'abord bienvenue à tou-te-s les participant-e-s, qui sont venue-s pour prendre part à ce colloque que l'IUED organise maintenant chaque année sur les questions de genre dans le développement.

C'est le septième colloque organisé par l'IUED. Le premier a eu lieu en 1993, et je dois dire que nous en sommes très heureux, d'autant plus que notre institut ne s'était pas particulièrement singularisé par son empressement à se saisir des questions de genre. Nous avions en quelque sorte un peu loupé le virage des études de genre dans les années 1980. C'est la raison pour laquelle, quand j'ai pris la direction de l'institut en 1992, j'ai demandé à notre collègue Yvonne Preiswerk - que vous connaissez tous, qui nous a malheureusement brutalement quittés au printemps 1999, et qui était une anthropologue émérite, spécialisée dans les sociétés alpines - de voir comment elle pouvait essayer de nous faire recoller à cette problématique, étant entendu que les difficultés budgétaires qui étaient les nôtres ne nous permettaient pas d'ouvrir illico presto un poste sur la thématique.

Grâce à Yvonne, et j'aimerais de nouveau ici saluer sa mémoire, nous avons pu commencer à développer des activités dans ce domaine, notamment en organisant le colloque auquel vous venez participer 
aujourd'hui. Le travail qu'avait fait Yvonne, et les personnes qui travaillaient avec elle, était tellement remarquable que quand elle nous a quittés, et après que nous eûmes fait notre deuil de cette collègue chère à nos cœurs, nous avons décidé de perpétuer la tradition qu'elle avait établie, en ouvrant un poste de chargé-e de cours à temps partiel - nous n'avions pas de plus grandes marges à ce momentlà - cette fois-ci entièrement dédié à la question de genre. Il était évident qu'un tel poste serait occupé par un ou une anthropologue. Ce fut une anthropologue, Fenneke Reysoo, qui a été choisie. Bien sûr je la salue. Je ne saurais dire combien nous sommes heureux qu'elle ait pu rejoindre l'équipe de l'IUED. Je la remercie de tout le travail qu'elle a fait, avant même d'être entrée véritablement en fonction, pour préparer le colloque de cette année.

Peut-être un mot sur l'approche qui est la nôtre en matière d'études de genre. C'est une approche horizontale, transversale, qui nous amène à traiter des problèmes de manière interdisciplinaire: dans les enseignements de base de sociologie, d'anthropologie, d'économie et d'écologie; et également dans les enseignements sectoriels, sur la santé, le développement rural, le développement urbain, l'éducation et les développements régionaux. C'est donc aussi l'approche que nous aimerions avoir dans le colloque.

Chaque année, nous avons traité un thème différent. De mémoire, je mentionne les questions du rôle des femmes dans le développement urbain, d'entrepreunariat et de créativité, d'économie, et la problématique de la santé. L'année dernière, nous avons essayé, avec Anne Zwahlen et quelques autres personnes, de continuer l'idée qu'avait lancée Yvonne avant qu'elle nous quitte: parler des hommes dans les études de genre avec comme problématique la construction sociale de la masculinité. Comme vous le savez, chaque année le colloque donne lieu à la publication d'un ouvrage. Le dernier, "Quel genre d'homme?», vient de sortir dans cette collection qui porte maintenant le nom de "Collection Yvonne Preiswerk», et j'aimerais remercier Christine Verschuur ici présente, qui a été la pierre angulaire de cette aventure et qui a assuré la transition difficile entre le moment où Yvonne nous a quittés et aujourd'hui. 
Cette année, le thème du colloque est centré sur la problématique des conflits «Hommes armés, femmes aguerries». C'est une idée qui a été discutée entre les collègues responsables des études de genre à l'institut, notamment Fenneke Reysoo. L'institut a une grande expérience dans le domaine des «conflits» et surtout des rapports entre les sociétés en conflit et les problèmes de développement, et de la transition difficile qu'il peut y avoir à la fin d'un conflit pour réinitier une dynamique de développement. Je mentionne juste ici que nous sommes engagés depuis très longtemps en Afrique centrale. Nous sommes au Burundi depuis une vingtaine d'années dans des opérations qui à l'origine étaient des opérations de développement et qui sont devenues des opérations de résolution de conflits en quelque sorte. Nous avons aussi une longue expérience au Moyen-Orient à travers quelques collègues qui sont des spécialistes de la région. Nous sommes fortement impliqués en Amérique du Sud dans la problématique de la recherche d'une solution pacifique au conflit colombien. Nous avons d'autres expériences dans d'autres régions du monde, je pourrais mentionner le travail fait à Haïti pendant longtemps, au Cambodge, également, etc. Bref, nous sommes très intéressés par ces problèmes. Dans les restructurations qui sont en cours à l'institut, nous espérons d'ailleurs pouvoir déboucher sur une nouvelle organisation des activités de recherche autour de trois ou quatre grands axes majeurs interdisciplinaires. Il est à peu près certain que l'un de ces axes sera centré sur la problématique des conflits, de leur résolution à la reconstruction, puis à la reprise de processus de développement.

Avec le temps, ce colloque est devenu la seule manifestation régulière en Suisse sur la problématique «genre et développement», c'est en quelque sorte devenu un point de repère que tous les gens qui travaillent sur ces questions connaissent et fréquentent.

J'aimerais maintenant remercier nos partenaires dans cette aventure: la DDC qui soutient l'institut depuis sa création, de manière générale et sur des projets particuliers comme celui-ci; la Commission nationale suisse pour l'UNESCO à laquelle participait 
notre collègue Yvonne Preiswerk et qu'elle avait su intéresser dès le départ à cette manifestation; et EFI - espace femmes international - qui nous a aidés à finaliser la problématique et à nous mettre en contact avec des organisations de femmes dans le Sud.

Ce colloque s'ouvre en un jour qui n'est pas très propice à la cause des femmes. Vous avez probablement entendu la nouvelle arrivée des USA hier soir. M. Bush n'a pas attendu très longtemps avant de se lancer dans la politique qu'il avait annoncée. Symboliquement, il a décidé de couper tous les moyens à toutes les organisations américaines et internationales de planning familial qui prônent l'avortement. Il est certain que cela constitue une atteinte aux libertés des femmes. Mais ce n'est guère surprenant. Je compte au nombre de ceux qui pensent que les choses risquent malheureusement $\mathrm{d}^{\prime}$ aller plus mal avant qu'elles n'aillent mieux. Nous nous employons toutefois contre vents et marées dans notre institut et à travers un colloque comme celui-ci à ce qu'elles s'améliorent. Il ne faut en effet jamais désespérer. C'est par ce genre de travail opiniâtre que tôt ou tard le balancier de la mondialisation néoliberale triomphante et exacerbée qui affecte nos sociétés reviendra peut-être dans le sens de la raison et de l'équité. 
FENNEKe ReYsoo

\section{SITUATIONS DE CONFLIT ARMÉ COMME CHAMPS D'ANALYSE DES RAPPORTS DE GENRE}

\section{PRÉLIMINAIRE}

Les conflits armés font la une de l'actualité. Il s'avère que la plupart des conflits actuels sont des guerres civiles. Les rôles des hommes et des femmes dans ces conflits sont généralement présentés dans les médias comme une simple dichotomie: les hommes sont des acteurs actifs, les femmes des victimes passives de la violence de la guerre. Cependant, la réalité de guerre est beaucoup plus complexe et demande à être nuancée.

Des recherches, en nombre croissant depuis une décennie, nous font prendre conscience que la vie «normale» des gens vivant dans les zones de conflits armés est complètement bouleversée. Les un-e-s partent aux armes tandis que les autres assurent la survie dans des conditions très précaires et dangereuses. Beaucoup de femmes, de par leur rôle social de gardiennes de la famille et de dispensatrices des soins de base, doivent en temps de guerre également générer des revenus pour assurer la survie de leur famille. Cette multiplication de leurs responsabilités et leur adaptabilité à des situations difficiles font souvent d'elles les forces motrices dans les processus de reconstruction sociale après un conflit. 


\section{DÉMANTÈLEMENT DES STÉRÉOTYPES «GENRÉS »}

Les intervenantes au colloque, venues de régions aussi diverses que l'Asie centrale, le Moyen-Orient, l'Afrique centrale, l'Amérique latine et l'Europe, parleront justement des transformations des rapports de genre pendant les situations de conflit armé. Cela nous permet de nous demander si les crises sont des «ferments du changement social» (Eugénie Aw-Ndiaye sur la région des Grands Lacs en Afrique), des «douleurs invisibles» (Dinora Aguiñada sur les séquelles de la guerre au Salvador), un reflet des configurations de pouvoir en place (Amneh Badran sur le conflit israélo-palestinien) ou des espaces d'empowerment individuel (comme l'argumente Magdala Velazquez-Toro).

Un tour d'horizon nous apprend que les femmes ont pris les armes lors des conflits de libération en Erythrée, au Sri Lanka, au Mexique, au Nicaragua, en Colombie et au Salvador (Bennett et al., 1995). Le stéréotype des femmes victimes et pacifistes tombe quand nous étudions ces cas-ci. Et que dire de l'image de la femme pacifiste et passive qui a été mobilisée pour participer au génocide rwandais?

Des femmes se sont organisées dans la résistance sans violence, comme les Femmes en noir israéliennes, palestiniennes et yougoslaves. D'autres encore ont organisé des tribunaux pour poursuivre les acteurs de la perpétration de la violence. Malgré les menaces, elles continuent de militer pour les droits humains (Guatemala, Israël, Palestine) et assurent l'éducation de leurs enfants dans des conditions souvent très précaires, comme en témoigne l'intervention de Micheline Centlivres-Demont au sujet de l'Afghanistan.

Au-delà des conflits internes, les femmes ont également été affectées par les interventions externes. Au Cambodge, au Mozambique, en Haïti, la présence de forces armées étrangères et même des casques bleus a induit une augmentation de la prostitution, de la violence sexuelle et de l'incidence du sida. Les interventions humanitaires et 
de paix n'ont pas toujours la délicatesse de tenir compte des besoins et capacités différenciés par genre ou de reconnaître le non-respect des droits humains des femmes. Le projet «Femmes et guerre» du CICR (Monika Kaempf) vise justement à mettre sur pied des actions humanitaires qui tiennent compte de la dimension du genre dans le vécu des populations victimes de guerre.

Quoi qu'il en soit, une constante dans ces conflits armés est la rupture profonde avec la vie sociale de tous les jours. Femmes, hommes, enfants et vieillards se voient confrontés à de nouveaux rôles et responsabilités. Les hommes partent aux armes, sont enlevés ou déportés, se voient assignés aux travaux forcés ou disparaissent on ne sait où. Dans les périodes précédant un conflit, la crainte de la guerre induit souvent des réactions individuelles ou collectives qui peuvent être détectées comme signes d'alerte (Susanne Schmeidl). Un signe d'alerte parmi d'autres est l'augmentation d'actes de violence domestique.

Les épouses, en l'absence de l'homme au foyer, doivent faire fonctionner le ménage, en générant des revenus, en assurant la subsistance, tout en dispensant des soins et le soutien affectivo-moral. Elles doivent prendre des décisions dans des domaines traditionnellement masculins et se voient obligées de se mouvoir dans des espaces étrangers ou interdits à elles en temps normal (Alla Kuvatova pour le Tadjikistan et Goretti Ndacayisaba pour le Burundi). Cela les expose à des dangers et contribue à une situation d'insécurité généralisée et stressante. Aussi bouleversantes que soient ces expériences, l'ironie est que «l'histoire nous apprend que les femmes ont quelque chose à gagner lors des guerres. Elles se voient responsables de plus de tâches en l'absence de leurs maris, mais elles s'approprient aussi plus de libertés et de nouveaux pouvoirs», et aussi qu' «il est un fait qu'elles reperdent généralement ces acquis après la situation de conflit, lorsque les hommes revendiquent à nouveau leur autorité au sein de la société et de la famille» (Richters 1996 : 15). 
Cependant, ces «activités de femmes» et ce que ces activités signifient pour elles n'ont pas vraiment fait l'objet d'études détaillées. Le colloque sera alors un espace d'échanges, de réflexions et de débats sur les rôles respectifs des hommes et des femmes lors de la gestation de conflits et sur les effets des conflits sur les rapports de genre aux niveaux aussi bien symbolique (Micheline Centlivres-Demont, Magdala Velazquez-Toro) et structurel (Susanne Schmeidl, Goretti Ndacayisaba, Alla Kuvatova, Eugénie Aw-Ndiaye, Clara Mazo-Lopez, Fanta Coulibaly) qu'individuel (Annemiek Richters, Dinora Aguiñada).

\section{LA GUERRE COMME RUPTURE SOCIALE}

La guerre comme un moment de rupture sociale profonde est donc un champs d'analyse des rapports de genre. Toutes les normes et valeurs «sûres» y sont remises en question, transgressées ou inversées. Au niveau le plus apparent, comme nous venons de le voir, il s'agit des rôles et responsabilités différenciés par genre. Les interventions sur le Burundi, le Rwanda, le Congo Brazzaville et le Tadjikistan parleront de cette nouvelle configuration sociale après une période de conflit et des besoins spécifiques qui en résultent.

Dans la période de reconstruction socio-économique, la pénurie d'emploi est une menace réelle pour la population active féminine. Les femmes sont souvent licenciées au profit des hommes (Serbie). Nous nous souvenons qu'après la Seconde Guerre mondiale, plusieurs pays européens avaient formulé une politique restrictive quant à la participation des femmes mariées sur le marché du travail.

Les énormes pertes en vies humaines ont fait que les femmes sont devenues l'objet de politiques pronatalistes (territoires occupés). En Irak, l'utilisation de méthodes contraceptives fut interdite lors des années de guerre entre l'Irak et l'Iran. Le corps des femmes devint ainsi l'enjeu de l'intérêt nationaliste.

Les veuves, et surtout les veuves de guerre, ont une position sociale vulnérable. Elles n'ont pas seulement la responsabilité de leur 
famille, mais doivent trouver un emploi et donc jouer un rôle traditionnellement masculin. Dans un certain nombre de sociétés, elles sont marginalisées. On les aborde avec suspicion ou on les évite, car une veuve pourrait prendre le mari d'une femme mariée (Sri Lanka, Guatemala) (Bennett et al., 1995). Dans d'autres pays, elles se voient contraintes à se remarier contre leur gré selon une logique de polygamie ou de lévirat (Tadjikistan, Afghanistan). Les couples ou familles ethniquement mixtes doivent recomposer leurs liens de famille malgré des ruptures douloureuses et des souvenirs atroces (Rwanda, Burundi, Croatie, ex-Yougoslavie).

Les hommes en guerre doivent prouver leur masculinité et «ritualisent» parfois leur virilité et leur domination sur les femmes. Participer à la guerre peut dans certains contextes devenir le rite d'initiation dans la communauté des vrais hommes (voir Peteet [1994] sur les adolescents participant à l'intifada: les cicatrices sur le corps sont un signe de virilité). La résistance islamique afghane au régime communiste n'a pas fait appel à des combattantes, sous prétexte que "nous n'avons pas de femmes combattantes; Dieu soit loué, nous avons suffisamment d'hommes» (Shah Bazgar, cité par Micheline Centlivres-Demont). Magdala Velazquez-Toro nous apprend que les jeunes recrues apprennent à «tuer ce qui est féminin en eux».

Plus à l'actualité - et reproduisant le stéréotype - sont les hommes qui s'adonnent à des actes d'agression et de violence. Ils violent les femmes afin de les humilier et d'humilier les hommes du groupe auquel elles appartiennent. L'incidence du viol présente une corrélation positive avec l'affaiblissement ou la déstabilisation du pouvoir des hommes. Le viol est la symbolisation et le topos du déshonneur de l'Autre. En Inde, suite aux conflits violents en 1984, un grand nombre de femmes hindoues violées se sont suicidées. Devenues la honte de leur famille et l'incarnation de l'impureté, elles n'avaient plus d'avenir. Les femmes portant un enfant d'un violeur ennemi doivent composer avec la contradiction «incorporée» de la haine-amour. «Les femmes parlementaires au Rwanda se sont organisées en forum et ont fait voter des lois essentielles. Le viol est 
ainsi devenu, dans la loi concernant le jugement des génocideurs, un crime de première catégorie» (Eugénie Aw-Ndiaye). Rendre justice dans la période postconflictuelle est d'importance cruciale pour les individus et les communautés afin de leur permettre de reprendre le fil de leur vie. Peu d'études ont dressé le vécu des hommes dont l'honneur est bafoué.

La maternité et la sexualité sont souvent au centre de l'enjeu symbolique d'un conflit. En situation de guérilla, comme au Salvador, Dinora Aguiñada analyse comment le fait de tomber enceinte représentait un acte de trahison à la cause. Les méthodes contraceptives étaient distribuées en masse, et des services d'avortement dispensés. La maternité et la sexualité étaient délibérément investies de nouveaux signifiants.

\section{L'OPÉRATIONNALITÉ SYMBOLIQUE DU CONCEPT DE GENRE}

L'avancement académique des études genre nous a fait prendre conscience qu'au-delà des rapports sociaux entre hommes et femmes, le «genre» en tant que construction symbolique de la masculinité et de la féminité a un pouvoir autonome pour structurer les relations sociales. Cette dimension du concept genre connaît toute sa légitimité au sein de la recherche fondamentale, mais n'a malheureusement pas encore été intégrée dans les recherches opérationnelles.

Un des apports des études genre est le changement paradigmatique et la découverte que le «genre» - qu'on le veuille ou non - structure tous les rapports sociaux. Ce pouvoir (ou cette opérationnalité) du concept de genre a été minutieusement appliqué à l'étude de la guerre ethnique en ex-Yougoslavie par l'anthropologue yougoslave Dubravka Zarkov, en 1999. Dans sa thèse de doctorat, intitulée From "Media War» to "Ethnic War». The Feminine Body and the Production of Ethnicity in Former Yugoslavia (1986-1994), elle 
démontre comment les notions et normes de genre et de sexualité furent utilisées pour produire l'ethnicité.

En analysant les images dans les médias, les actes de violence de la guerre, ainsi que les narrations des femmes et des hommes qui ont vécu la guerre au quotidien, elle découvre comment les antagonismes ethniques ont été produits (parfois ex nihilo). Elle argumente que les ingrédients de cette production sont les notions et normes de genre et de sexualité. Les représentations «genrées» et «sexuées» des différences ethniques font que le conflit devient une expérience «incorporée» (embodied).

"Cette incorporation vécue [experienced embodiment] maintient le conflit [vivant...] Nous avons horreur des viols et des tortures, des exécutions et des évictions commis par les Uns, mais nous avons une certaine compréhension pour les mêmes crimes commis par les Autres, parce que nous voyons dans les premiers les actes sans merci des agresseurs masculins, et dans les derniers les victimes féminines qui ne demandent que la revanche. Sans les notions de masculinité et de féminité, nous ne serions jamais capables de distinguer entre les crimes. [...] Nous assignons ainsi un sexe aux groupes ethniques entiers. » (Zarkov 1999 : épilogue, ma traduction.)

Pour comprendre sa démarche, donnons-lui encore la parole: «J'ai démontré que dans [mon] corpus des médias croates et serbes, la représentation des victimes concerne une symbolisation des corps lésés masculins et féminins du Soi (ethnique) comme de l'Autre (ethnique). Toutefois, la victimisation du Soi est un processus différent de la victimisation de l'Autre. Dans la presse croate, la victimisation du Soi - la Croatie - était un Soi féminisé. L'impuissance de la victime à se défendre n'avait pas comme but de l'humilier, mais rendait un statut de héros au défenseur, le soldat croate. En revanche, la victimisation de l'Autre concernait un Autre complètement déshonoré. Le corps déshumanisé d'une musulmane violée et le corps castré d'un musulman pouvaient être montrés, car ils n'appartenaient pas au corps nouveau-né de la Croatie. Cette représentation [de la renais- 
sance croate] ne se permettait pas de montrer le corps lésé du Soi. Dans la presse serbe, en revanche, la victimisation du Soi était importante pour la production de la "serbicité". Le corps enceint de la femme serbe violée symbolisait l'offense du corps viril et fécond de l'homme serbe. [...] La guerre des médias ne situait pas les ennemis seulement de l'autre côté de la frontière ethnique, mais identifiait également des traîtres au sein du groupe propre. Quand la guerre éclata en Slovénie en 1991, les hommes serbes qui contestaient furent étiquetés "homosexuels". En 1992, les féministes croates furent accusées de "violer" la Croatie.» (Zarkov 1999 : épilogue, ma traduction.)

Afin qu'un conflit armé soit effectif, il faut produire l'Autre-ennemi. Et qui dit produire dit un matériau de base, une méthode de manufacture, un-e ou des manufacturier-ière-s, des consommateur-trice-s et quelqu'un-e qui paie pour tout cela. Plusieurs interventions nous montrent que pour produire l'image de l'Autre-ennemi, il faut disposer d'ingrédients efficaces afin de produire une image de Soi qui se vende bien: mythes nationaux, histoire de la nation ou d'un peuple, héros nationaux, pour ne nommer que quelques-uns des produits qui ont séduit plus d'un consommateur. Qui sont les héros et les guerriers, qui les violeurs et les violés? Qu'est-ce qui rend les lignes de démarcation si efficientes? Zarkov offre la réponse: les notions de féminité et de masculinité et la norme de l'hétérosexualité. Ce sont les ingrédients de base sans lesquels l'ethnicité (ou l'image de l'ennemi) ne se produirait pas.

L'opérationnalité symbolique du concept de genre est une dimension des rapports entre femmes et hommes qui devrait être prise en compte dans toute étude ou intervention de terrain avant, pendant et après un conflit. D'autant plus que cette dimension symbolique peut être le détonateur et le facteur d'envenimement d'un conflit.

- Le 10 décembre 1990 parut dans le quotidien rwandais Kangura le texte des «Dix commandements du Hutu». Ce manifeste commençait ainsi: «Chaque Hutu doit être conscient que toute femme tutsi travaille dans l'intérêt de son groupe ethnique. C'est 
pour cela que tout Hutu qui se marie avec une Tutsi, qui a une amie tutsi ou qui emploie une Tutsi comme secrétaire est un traître. [... plus loin] Femmes hutus, soyez vigilantes et essayez de raisonner vos époux, frères et fils.» En 1990, ce manifeste fut ignoré, son importance d'opérationnalité symbolique sous-estimée. Nous savons ce qui s'est passé quatre ans après.

- En automne 1987, la presse serbe au Kosovo accusait les hommes albanais kosovars de violer les femmes serbes et monténégrines. Un politicien albanais du Kosovo, Fadil Hoxha, proposa de résoudre ce problème de viols interethniques en faisant venir des prostituées. Cette proposition aggrava la situation, car elle suggérait que les femmes serbes et monténégrines étaient des prostituées. Les femmes serbes et monténégrines du Kosovo manifestèrent contre Hoxha en clamant qu'elles étaient des mères et non pas des putes. (Zarkov 1999 : introduction.)

- Une semaine avant le colloque, le 15 janvier 2001, j'entendis à la radio néerlandaise un soldat israélien parler des Palestiniens de l'intifada. Il s'agirait de jeunes hommes frustrés qui n'avaient pas de lieux où aller, pas de bistrots, pas d'accès aux femmes - car elles étaient voilées. Du point de vue de ce soldat, les jeunes combattants de l'intifada se porteraient volontaires comme martyrs afin d'atteindre le plus rapidement possible le paradis avec les vierges éternelles (houris). (Radio VPRO «de Avonden», titre «Het heilige land», par Heere Heeresma.)

Sans les notions de masculinité et de féminité, la distinction entre les Uns et les Autres lors d'un conflit ne serait jamais aussi efficace. Cette distinction permet de produire l'ethnicité par des représentations «genrées» et «sexuées» et introduit de ce fait une hiérarchisation sociale légitime, le «masculin» étant incontestablement supérieur au «féminin» (au niveau symbolique bien entendu). Pour conclure, je dirais que les vertus, valeurs et normes de genre sont ainsi mises en exergue afin de permettre d'assigner un sexe aux groupes entiers et de les hiérarchiser entre eux. 


\section{CONCLUSION}

Le colloque des 23 et 24 janvier 2001 fut un événement riche où nous avons partagé expériences de terrain et expériences de recherche fondamentale. Nous avons confirmé que les conflits armés affectent les hommes et les femmes différemment. Nous nous sommes rendu compte que les conflits armés transforment les rapports de genre, sans pour autant oublier qu'il y a une grande variation sur le thème qui nécessite à chaque fois une contextualisation de l'analyse. Cela est impératif même pour un phénomène en apparence aussi universel que la violence contre les femmes. "L'efficacité et l'ampleur de la gender violence ne peuvent se comprendre sans connaître l'organisation sociale, politique et culturelle des sociétés ou communautés en conflit», nous démontre Richters en parlant de l'ex-Yougoslavie et duTadjikistan. On notera qu'une moindre attention a été portée au genre masculin. Ce n'est pas un choix délibéré, mais le reflet de l'état des recherches sur les conflits armés et le genre.

Pour finir, je vous présente quelques points importants du débat:

- Les conflits armés ne peuvent se réduire à la dichotomie entre hommes armés et femmes victimes. Ils induisent une diversification des rôles de genre aussi bien pour les femmes que pour les hommes. Ces changements peuvent parfois résulter en des relations sociales plus équitables après le conflit (exemple du Rwanda, où il y a eu des réformes légales en faveur des femmes), mais aussi induire des processus de «traditionalisation» (au Tadjikistan postsoviétique, en Afghanistan sous le régime des talibans).

- Les interventions sur les dispositifs d'alerte et les négociations de paix ont insisté sur l'importance du dialogue. Le véritable dialogue est trop souvent entravé par l'implication des parties autour de la table de négociations dans la politique interne de leurs communautés (Israël, Palestine, Colombie). La faible parti- 
cipation des femmes au dialogue de la paix correspond souvent à leur faible participation à la vie politique d'une façon générale. Certains indicateurs des dispositifs d'alerte se réfèrent justement à la participation politique des femmes dans les divers pays: «Moins de femmes au Parlement et moins de participation féminine aux votations induisent plus de risques de recours aux armes pour régler une dispute» (Susanne Schmeidl). Les dispositifs d'alerte sont un outil utile et nécessaire pour prévenir l'éclatement de conflits armés. Dans leur mise en application, il manque malheureusement encore les systèmes adéquats de rapportage et de monitoring.

- Les conflits armés déstructurent profondément les sociétés et vont toujours de pair avec des formes de violence atroces. Les cicatrices physiques guérissent relativement vite, mais les cicatrices invisibles sont des plaies beaucoup plus longues à se refermer. En plus, elles s'ouvrent à nouveau dès que d'autres crises surviennent (comme le tremblement de terre en janvier $2001 \mathrm{au}$ Salvador nous l'a révélé). Les stratégies thérapeutiques pour traiter les traumatismes de guerre et les stratégies de reconstitution d'une identité féminine ont été élaborées et mises sur pied par des équipes de spécialistes très compétentes: travail de mémoire, paroles de femmes, organisations de femmes pour dispenser un soutien pluridisciplinaire, pour entrer sur la scène politique ou pour inventer des structures d'auto-appui, pour n'en citer que quelques-unes. Dans de nombreux pays, le potentiel féminin s'affirme dans toute sa dynamique. La Ruta Pacifica en Colombie en est un exemple, bien que ce soit un processus complexe et de longue haleine (Clara Mazo-Lopez). Femmes Africa Solidarité (FAS), dont le siège se trouve à Genève, est une expérience intéressante qui vise à articuler les différents niveaux sociaux: gouvernement, société civile et grass roots (Christiana George).

Conclure un événement si riche en échanges, en réflexions et en débats ne peut se faire sans référence à l'articulation étroite entre justice, développement et paix. A l'unanimité, les intervenantes et 
les organisations qu'elles représentent (Vamos Mujer; Dignas; FAS ; CAFOB; The Jerusalem Link; Tradition \& Modernity; le CICR) œuvrent pour la dignité humaine, le respect des droits humains et la paix.

\section{RÉFÉRENCES}

Bennett, Olivia, Jo Bexley \& Kitty Warnock (ed.)

1995, Arms to Fight, Arms to Protect. Women Speak out about Conflict. London: Panos.

Byrne, Bridget, Rachel Marcus \& Tania Powers-Stevens

1995, Gender, Conflict and Development. Case Studies from Cambodgia, Rwanda, Kosovo, Somalia, Algeria, Guatemala and Eritrea. BRIDGE, Briefings on Development \& Gender. Brighton: Institute of Development Studies, University of Sussex.

Peteet, Julie

1994, "Male Gender and Rituals of Resistance in the Palestinian Intifada: A Cultural Politic of Violence». American Ethnologist, 21(1) : 31-49.

Richters, Annemiek 1996, «My Darling Sugar Sweet Adolf». Hoe vrouwen oorlog voeren. In: War and Peace for Men Only? Reader to the Public Forum in Amsterdam organized by the Netherlands Humanist Committee on Human Rights and Vrouwenberaad Ontwikkelingssamenwerking.

Zarkov, Dubravka

1999, From «Media War» to "Ethnic War». The Feminine Body and the Production of Ethnicity in Former Yugoslavia (1986-1994), Nijmegen: Centre for Women's Studies, Ph. D. dissertation. 
EugÉNIE ROKHAYA Aw-NDIAYE

\section{RAPPORTS HOMMES-FEMMES : LES CRISES EN AFRIQUE SONT-ELLES DES FERMENTS DU CHANGEMENT?}

En situation de conflits, les femmes africaines sont souvent associées au symbo le de la paix, de la réconciliation. Les souffrances spécifiques qui sont les leurs, leur rôle nourricier, liés à leur statut dans les sociétés africaines, expliquent cette image. Or lesfemmes appartiennent à un environnement, à une histoire qui les situent au coeur des conflits. Toutefois, leur vécu les amène à un autre rapport aux hommes et à la société, à un devenir citoyen souvent ignoré des experts $d u$ développement.

Il est si difficile de parler. Les mots ne pourront jamais exprimer ce que nous avons vécu. Comment un récit peut-il exprimer les souffrances, la violence comme arme de guerre? Les viols, les mutilations, le sida. Nous faisons face désormais à la pauvreté, à l'isolement. Nous devons nous occuper des orphelins, mais éga lement des enfants nés $d u$ viol et que nous appelons «les enfants du mauvais souvenir, les enfants des immondices». (Geneviève)

J'ai perdu mes sept enfants. Je suis pourtant ici, je travaille pour un changement global et pour que l'on puisse vivre dans le futur d'une manière différente... Si on part de cette capacité d'adap tation, de la maîtrise que les femmes ont des situations difficiles, il yaura reconstruction. (Dafrosa) 
Le vrai problème, c'est l'autonomie des femmes. (Veneranda)

Donner la parole à Geneviève, donner la parole à Dafrosa, donner la parole à Veneranda, c'est briser le silence qui leur était imposé et qui est la marque de leur exclusion sociale. A travers cette parole, ces paroles, nous avons tenté de comprendre comment les femmes passent d'une "culture de la mort» à la mise en œuvre, douloureuse comme un accouchement, encore silencieuse et traversée de contradictions, d'une culture de la vie et donc d'une transformation sociale. Et pourtant, à travers d'autres paroles, il est possible de voir les femmes faire part d'un environnement, d'une culture qui les fait courroie de transmission de la reproduction, du maintien de la société et de ses valeurs dominantes, largement patriarcales.

Nous sommes en Somalie:

Un fils ramène à sa mère le corps d'un autre fils tué à la guerre. La mère regarde froidement le dernier mâle qui lui reste et lui jette:

- Lâche! Que fais-tu encore ici ? Tu devrais être déjà sur le champ de bataille.

Dans nos imaginaires, dans nos perceptions, dans la littérature, voire dans certaines analyses théoriques féministes ou non, une vision dichotomique prévaut: les femmes artisans de la paix, les hommes acteurs de la guerre. Dans plusieurs traditions africaines, les femmes sont bien associées à la paix, elles sont le symbole de la paix.

Notre champ de réflexion se situera au Rwanda et au Congo Brazzaville. Dans ces deux pays, les crises sont de nature différente mais elles ont toutes une base immédiate commune, l'instrumentalisation de la différence ethnique. Tutsi et Hutu au Rwanda, Gens du Nord («Norvégiens») et Gens du Sud («Nibolek») au Congo Brazzaville.

Les femmes participent de la manipulation idéologique qui fonde et légitime la violence; elles sont perçues, dans ces constructions, comme une extension du bras armé des hommes. Si elles ont subi, 
elles ont aussi participé, elles ont incité à la haine par l'éducation donnée, par l'intériorisation des valeurs dominantes patriarcales, par la peur d'être vues comme traîtres à leur groupe d'appartenance. La pauvreté joue, par ailleurs, un rôle de cristallisation de la haine contre l'Autre.

\section{LES FEMMES PLUS PACIFIQUES QUE LES HOMMES?}

Les femmes africaines sont-elles, cependant, plus pacifiques que les hommes? Dans toutes les régions de l'Afrique, les femmes sont perçues comme des symboles de paix. Ce symbolisme est fortement lié au rôle qu'elles jouent dans la société comme mères et épouses et donc piliers de la famille. C'est cette image, et une pratique qui résulte du processus de socialisation des filles et jeunes femmes qui amènent les femmes à jouer un rôle particulier de rapprochement, de dialogue, de conciliation lors des conflits.

Ainsi, rapportent Dyan Mazurana et Susan McKay:

«En Afrique,... les femmes se sont servies de l'autorité morale que leur confère leur pouvoir de donner la vie (rôle maternel) et de l'entretenir (en tant que mères, épouses et filles) pour revendiquer la paix; des femmes ont utilisé ce genre de tactique en Algérie, en République démocratique du Congo, au Kenya, au Liberia, au Rwanda, en Somalie, en Afrique du Sud et au Soudan (UNESCO 1995a)».

Selon le Collectif Pro-femmes/Twese Hamwe, au Rwanda, traditionnellement, «la femme incarne les valeurs sociales de tolérance, de médiation, de pacification en famille et entre les familles. On l'appelle Nyampinga, c'est-à-dire, le havre de paix, le refuge des fatigués, des voyageurs et de ceux qui sont dans le besoin. Ses bras sont toujours ouverts pour accueillir ceux et celles qui ont recours à elle. La fille et la femme sont aussi appelées Gahuzamiryango c'est-à-dire, celle qui, par son ménage, fait le trait d'union entre différentes familles qui automatiquement deviennent parentes, alliées et amies. 
La femme est en général considérée comme créatrice de valeurs d'unité et de solidarité entre différents groupes, familles et communautés. La femme est appelée aussi Inkingi ya Kanangazi. Elle est le pilier central qui soutient la toiture d'une maison. Cette image illustre le rôle de la femme dans la reproduction biologique et sociale ainsi que son rôle dans la production économique...».

Mais on ne peut déduire de cette perception et de ce rôle que les femmes seraient congénitalement moins violentes que les hommes. Certes, elles portent les enfants, agissent comme nourricières. On les perçoit faibles et dépendantes. Or, les femmes sont issues d'un environnement social, économique, politique qui, dans le cadre des sociétés patriarcales, modèle leur comportement. On attend de ces dernières qu'elles soient loyales envers leur mari, leur groupe. Les femmes n'opèrent que rarement et de manière ouverte, en dehors des cadres de classes, de races, de religions, de convictions politiques, etc.

Lorsqu'elles le font, elles utilisent des stratégies de contournement. L'organisation African Rights note que:

«Presque toutes les sociétés ont leurs histoires de femmes devenues de célèbres combattantes; leur célébrité tenait au fait qu'elles étaient, précisément, des femmes et que l'on ne s'attendait pas à ce qu'elles prennent les armes. Le Rwanda ne constitue pas une exception. Un mythe s'est développé à propos d'une fille du nom de Ndabaga qui, il y a des décennies, a décidé de se battre alors que les hommes de sa communauté avaient été pratiquement anéantis...».

\section{LES FEMMES DANS LA GUERRE}

Des femmes ont été membres de mouvements de guérilla, elles ont lutté pour l'indépendance, l'intégrité territoriale. "Sur la scène africaine, les femmes ont constitué $25 \%$ des forces de la ZANLA au Zimbabwe, 33\% des forces du Tigray (Snyder et Tadesse, 1995) et $5 \%$ des Mau Mau du Kenya (Kanongo, 1987). Ailleurs, les femmes se sont battues avec les hommes en Angola et au Mozambique 
(Snyder et Tadesse, 1995; Urdang, 1989) au Soudan et au Tchad (Doual, 1991; Bwolo, 1991). Dans toutes ces guerres, les femmes étaient impliquées dans le combat, la mobilisation, le travail clandestin, les évacuations et les soins, la production alimentaire et la cuisine, l'administration». En Ouganda, les activités d'intelligence, de collecte et de transport des armes faisaient aussi partie de leurs responsabilités. (...) « Les femmes encouragèrent leurs enfants à partir rejoindre les forces des libérateurs» (Mugambe, 2000).

Toutefois, des femmes ont aussi pris les armes pour défendre les convictions du groupe; elles ont éduqué des enfants et perpétué, par ce biais, des haines séculaires. Dans la vie de tous les jours, le groupe social auquel elles appartiennent peut les amener à perpétuer la violence qu'engendrent les inégalités (Dyan E. Mazurana et Susan R. McKay, 1999).

Au Congo Brazzaville, on note la présence de femmes dans les milices. Peu nombreuses, leur rôle n'a fait l'objet d'aucune étude. Mais elles ont bel et bien perpétué la violence contre d'autres groupes et spécifiquement contre les femmes et les enfants de ce groupe. En ce qui concerne le Rwanda, en revanche, on a pu démontrer le rôle que les femmes ont joué dans la cruauté ordinaire du génocide: là où les collègues, les voisines, les maîtresses et professeurs, les agents de santé, voire des religieuses, ont dénoncé, ont tué; là où des femmes journalistes ont construit, fait la propagande, donné des ordres. Par ailleurs, des femmes de pouvoir ont été à la tête de barrières, de groupes d'interahamwe (groupe paramilitaire hutu accusé d'être responsable du génocide).

«...En ce qui concerne les meurtres de masse, beaucoup de femmes n'ont eu besoin d'aucun encouragement. Certaines ont été poussées par leurs propres positions extrémistes. D'autres percevaient l'extermination des Tutsi comme une possibilité de s'enrichir en expropriant les biens de leurs victimes ou une possibilité de régler des comptes avec des ennemis, réels ou imaginaires... Quel qu'ait été le motif, certaines de ces femmes ont organisé et conduit les attaques qui ont provoqué la mort de centaines de femmes. 
"... Dans la population, la coercition ou la menace ont amené des femmes à tuer, elles étaient dans la foule des attaquants, des femmes ont assassiné leur mari et leurs enfants, des femmes se sont retournées contre leurs voisins. De même dans les écoles et les universités. Des ministres dans les gouvernements intérimaires, des responsables de gouvernement local ont administré la mort, des journalistes en ont été les messagers; des religieuses, des enseignants et des inspecteurs scolaires, des médecins, des infirmières se sont joints aux tueurs» (African Rights, 1995).

\section{DES VIOLENCES SPÉCIFIQUES}

Mais les femmes subissent aussi, lors des crises, des violences spécifiques qui les ramènent encore plus brutalement à leur statut subordonné et à des rapports hommes-femmes violents dans la société. Prendre possession d'une femme par le viol, c'est affirmer, par le prolongement de l'arme, sa virilité, son droit de vie et de mort; prendre possession des femmes du camp adverse, c'est le déposséder de son identité et le vaincre. Les violences sexuelles deviennent donc, dans les cas qui nous préoccupent, une arme systématique de guerre.

Cette violence est souvent dans le prolongement de la violence ordinaire, domestique. Lorsque les armes ont été déposées, quelle que soit la sphère investie, l'observation montre que si le statu quo est insupportable pour de nombreuses femmes, elles se heurtent à la violence structurelle. Et pourtant, elles ont une vision de l'avenir basée sur la réponse aux besoins pratiques amplifiés par la crise. 


\section{LES SPHÈRES DE FONCTIONNEMENT \\ ET D'ORGANISATION DES FEMMES}

Nous choisissons de faire notre analyse sur la base de la parole de femmes d'horizons multiples et à partir de l'observation de trois espaces:

\section{LA SPHÈRE PRIVÉE}

C'est l'espace domestique qui marque le statut des femmes. Il est le lieu de la violence ordinaire contre les femmes. Les violences en temps de guerre ne sont qu'un prolongement extrême de la violence dans le privé. Il définit l'espace privilégié où s'énonce la parole des femmes. Il est l'espace de la famille, l'espace domestique, celui de la mère et de ses enfants, son lieu de femme, mère et épouse et donc le lieu de sa compétence. C'est dans cet espace domestique que s'est jouée aussi la participation des femmes au génocide. Pour les faire participer à ce génocide, aux massacres, il a fallu que l'on aille les chercher là où elles étaient, au foyer. C'est là, dans ce lieu que la tradition leur assigne, qu'on les a persuadées ou forcées à prendre part au génocide. Elles devaient obéir, en tant que femmes, mères et épouses.

Parfois, elles ont elles-mêmes incité leurs maris. De plus, la pauvreté a souvent été un puissant moteur. En effet, la situation économique du pays était catastrophique et beaucoup de Rwandais et Rwandaises vivaient dans la précarité et dans un espace de plus en plus réduit en raison de l'exiguiité des terres, de leur manque de productivité et de la démographie galopante.

C'est aussi parce que comme femmes, elles appartiennent au groupe de leur mari que les femmes des Tutsi ou des Hutu modérés qui s'opposaient au génocide ont été violées, mutilées. A un point extrême, porter l'enfant de leur violeur, de l'assassin de leur mari et de leurs enfants, c'était parachever le génocide. C'est donc sur leur statut de femme, comme déterminant social que le génocide s'est joué autant du côté des tueuses que des victimes. 
Au Congo, c'est au foyer que se fait la socialisation et que la femme apprend à se conformer par la reproduction biologique et sociale aux règles patriarcales. Là, la coutume prend le pas sur la loi positive, là, dans ce microcosme se situe la première violence.

Birgit Brock-Utne associe «la paix véritable à la réalisation d'une paix tant "positive" - l'absence de violence indirecte ou systémique - que "négative" - l'absence de violence individuelle, physique et directe.» (op cit. in. Mazurana \& McKay, 1999). C'est aussi là que la violence extrême, celle de miliciens qui ont exercé leur pouvoir de vie et de mort, l'arme prolongeant leur sexe, a pu provoquer une rupture définitive avec le statu quo social, culturel et politique, vers le suicide, la mort ou alors vers le changement.

\section{LA SPHÈRE COMMUNAUTAIRE}

Premier lieu d'organisation postconflit et de prise de parole, il est l'embryon de conscience citoyenne, en dépit d'une mémoire qui demande à être prise en compte au nom de la justice sociale et pénale. Au Rwanda, cet espace représente le lieu de rencontre des femmes qui s'organisent après le génocide. Leur expérience les a amenées à une réflexion personnelle sur la nécessité de se retrouver pour pleurer ensemble, vaincre ensemble la solitude et survivre. C'est là que va se développer leur capacité à prendre la parole, à s'approprier l'espace extérieur en exerçant des métiers auxquels elles n'avaient pas accès traditionnellement. On voit, par exemple des femmes présentes pour la première fois sur des chantiers comme maçons, menuisiers; ces nouveaux métiers permettent aux femmes d'entrer en dissidence des règles sociales.

Elles y acquièrent des savoirs bâtis sur la souffrance et apprennent, jour après jour, à dire publiquement, à affirmer une nouvelle identité, leurs nouvelles perspectives dans cet espace communautaire qui est le leur. Là commencent les premières stratégies pour nouer le contact avec l'autre, sur la base d'une histoire commune de femmes et pour accéder à la prise de décision, tout au moins au niveau local. 
On observe, par exemple que les femmes parlent, certes de réconciliation, mais elles exigent également, vision stratégique en acte, la reconnaissance de leurs droits et, en particulier, la lutte contre l'impunité.

Au Congo Brazzaville, de nombreuses associations se sont mises en place. Là où ces groupes sont liés à la reconstruction économique pour les femmes, ils constituent de puissants moteurs pour remettre en cause les divisions et la violence et pour contrer les problèmes psychologiques. Enfin, les femmes existent et ont une individualité.

Toutefois, le fait que cette violence soit une composante de l'espace privé congolais ne permet pas à des femmes très vulnérables de remettre en cause le pouvoir qui s'exerce sur elles. Peu de femmes et de groupes pensent qu'ils peuvent faire la différence.

\section{LA SPHÈRE PUBLIQUE}

Elle représente le lieu des institutions nationales, politiques, des organisations de la société civile. C'est dans cet espace que se noue l'avenir politique des femmes. Mais a-t-on su définir une autre conception du pouvoir, celui qui a tué, au nom parfois, parole manipulée, de la démocratie?

Les femmes qui ont accédé à cet espace définissent une nouvelle perspective: elles demandent, par exemple, l'intégration de la problématique de genre dans tous les aspects de la vie nationale. Les institutions qui sont responsables de programmes visant les femmes ont facilité leur participation et la prise en compte de leurs besoins dans différentes instances du pouvoir local. C'est ainsi que les femmes parlementaires, au Rwanda, se sont organisées en forum et ont fait voter des lois essentielles. Le viol est ainsi devenu dans la loi concernant le jugement des génocideurs, un crime de première catégorie. Elles ont également obtenu le vote d'une loi qui assure aux femmes l'héritage et la terre. Cette loi, dans la période actuelle où les femmes ont en charge une grande partie de la reconstruction, est essentielle. 
Mais les femmes sont marginalisées dans cet espace: d'abord le fait qu'elles se regroupent vise, en dépit des contradictions qui les traversent, à minimiser leur isolement, ensuite elles doivent régulièrement adopter des stratégies de contournement pour obtenir l'adhésion des hommes. Au Congo Brazzaville, leurs collègues hommes voient mal comment «de pauvres femmes» peuvent réussir là où eux-mêmes auraient échoué: la paix.

\section{QUEL EST LE LIEN ENTRE CES TROIS ESPACES?}

Observons que les femmes de l'espace privé se retrouvent dans l'espace communautaire. Il nous semble que les choix mêmes auxquels les femmes sont confrontées de manière individuelle, en menant la réflexion ensemble dans l'espace communautaire, en y exerçant une parole libre, critique, située à partir d'événements douloureux, les femmes arrivent à réinterpréter cette tradition. Les femmes, dans cette tradition, sont toujours responsables de la paix et de la vie, mais la réinterprétation donne à la tradition son sens premier: non plus un sens domestique, mais plutôt social et politique. Il s'agit bien là d'une vision critique de la tradition.

Au Rwanda, le passage de l'espace privé à l'espace communautaire, c'est la prise de conscience que, collectivement, elles peuvent par cet exercice libre de la pensée et de la parole, contribuer à la culture de la paix, construire et bâtir, à partir du négatif, une nouvelle société. Au Congo Brazzaville, toutefois, les femmes vivent dans la peur.

A Dolisie, une femme s'exclame:

- Qu'on nous laisse en paix! En allant à nos plantations, nous avons rencontré un groupe de femmes qui venaient d'être violées par des hommes en armes.

Beaucoup d'entre elles ne veulent plus souffrir et remettent en question les divisions. Mais elles ne se sentent pas de pouvoir par rapport à la solution qu'elles identifient comme l'éradication des groupes armés ou alors, «le dialogue entre chefs. Eux là-bas», disent-elles. 
Elles identifient aussi la démocratie à l'expérience que le Congo traverse. Il y a donc lieu de développer leurs savoirs et à les amener à comprendre qu'elles sont part d'une solution réellement démocratique, à la fois comme électrices et comme candidates pour de prochaines élections. Mais les femmes estiment que même si elles étaient candidates, elles n'ont pas les moyens de faire campagne. Par ailleurs, au plan de l'organisation, on découvre que souvent le leadership se trouve à Brazzaville. Les femmes au niveau local n'ont donc pas de contrôle sur l'organisation à laquelle elles appartiennent.

En ce qui concerne l'espace public, il est d'un niveau plus complexe, quant à la définition des politiques. Pour l'heure, il ne s'articule pas encore totalement sur les deux premiers espaces de manière à permettre une participation à la majorité des femmes. Dans l'espace public, c'est-à-dire au niveau des institutions de l'Etat, des organisations intermédiaires et internationales, la parole n'appartient pas encore réellement aux femmes. Dans l'espace communautaire, les femmes ont à leur actif des réalisations qui méritent d'être prises en compte au niveau de ces institutions, si l'on veut que les femmes deviennent des citoyennes à part entière et constituent avec les hommes une masse critique qui rendra cette citoyenneté irréversible.

Il est donc essentiel que leurs formes d'organisation soient intégrées à un vaste mouvement de la société civile. Or, dans les études qui sont faites au Rwanda par les consultants des organisations internationales comme le PNUD (Programme des Nations Unies pour le développement), les femmes ne figurent pas spécifiquement dans ce que l'on appelle le capital social. Par un acte volontariste, la société civile, composante essentielle, avec les institutions nationales, de l'espace public, doit considérer comme constitutifs de la société civile elle-même les regroupements locaux des femmes. Le fossé qui sépare encore l'espace public des deux premiers doit être comblé pour permettre une meilleure circulation de l'information et que se fasse ainsi le lien avec la base. 
Un sage africain disait fort justement:

- Une loi ne suffit pas, car elle ne vient pas à la maison pour discuter avec toi.

Dans les programmes de reconstruction, le concept de réconciliation prend une dimension essentielle; dans la pratique, elle se caractérise souvent par des projets plutôt traditionnels de développement qui permettraient, entre autres, aux groupes communautaires, de prendre appui sur l'économique. Des projets de résolution de conflits sont également mis en avant. Mais, s'arriment-ils sur les besoins exprimés et les initiatives prises par les communautés concernées?

Dans ces projets, où sont les exclu(e)s de la parole et du développement, où sont les femmes et quels sont leurs liens avec les groupes qui les ont dépouillées de toute humanité?

Prenons le cas de la réinsertion des ex-combattants et le ramassage des armes légères au Congo Brazzaville. Il est mentionné dans un projet du PNUD, de développement social et d'intégration des groupes sociaux avec comme domaines d'intérêts la restauration de la paix et la lutte contre la pauvreté. Or les femmes sont particulièrement touchées par ces aspects, victimes des miliciens, elles ont vu leur vie bouleversée autant sur le plan de leur humanité (nous tenons inlassablement à le répéter, car la souffrance des femmes est innommable). Comment leur serait-il possible de vivre avec ces miliciens, même ceux qui appartiennent à leur famille?

Nous voyons les liens et interactions possibles suivants:

- l'aspect réparation (dédommagement, participation à des travaux communautaires, etc.) ;

- l'aspect réconciliation par le biais de symboles forts dans la culture congolaise qui permettent d'avouer le dommage, de le reconnaître et d'obtenir le pardon. A cet égard, le travail de mémoire des femmes est essentiel ; 
- des actions conjointes visant le dialogue entre jeunes et femmes pourraient être organisées sous forme d'activités socioculturelles, par exemple.

Par ailleurs, l'information concernant la perception des femmes, leur construction du sens doit aussi remonter des plus petits villages avec les expériences, les savoirs qui se constituent, et qui demandent à être validés. En effet, «les droits peuvent donner aux femmes le pouvoir (power) de forger leurs vies uniquement s'ils leur permettent également une participation égale dans l'autodétermination civique, car seules les femmes elles-mêmes peuvent décider des aspects pertinents qui définissent l'égalité et l'inégalité dans un domaine donné» (Habermas, 1996).

\section{PAROLES DE FEMMES ET SUBVERSION DU SENS}

Ce que nous cherchons à comprendre, ce sont les conditions pour que le groupe des femmes fasse la différence, en raison justement de la pluralité de pensée de ces dernières. Les femmes, en effet, bien que participant à l'idéologie véhiculée par les différentes ethnies en présence, constituent un groupe spécifique, elles sont métisses et mères. La tradition les lie au symbole de paix. C'est sur la base des besoins pratiques qu'elles recommencent à se rencontrer au Rwanda ou qu'elles ont appris, au Congo, à se rencontrer dans l'espace communautaire avant de réaliser que comme femmes, elles sont toutes manipulées par le pouvoir. Là, elles décident de «bâtir sur leurs douleurs communes» et donc de définir ensemble des intérêts stratégiques. Et un sens commun qui procède de la subversion du sens.

La subversion du sens consiste, précisément, à questionner et à renverser le sens imposé par les tenants du pouvoir, par la culture dominante, elle permet aux «sans-pouvoir» de mettre en place des stratégies pour réinterpréter ce qui fait leur subordination et auxquelles ils participent consciemment ou non. 
Nous avons toujours travaillé à partir de la parole des femmes. Le silence qui est imposé à la plupart des femmes est la marque de leur exclusion. Recueillir leur parole et la fixer par écrit représente une entrée des femmes dans l'histoire de leur pays et une reconnaissance de leur rôle. En reprenant la parole, les femmes peuvent la faire déviante et capable d'innovation, en ce sens elles la subvertissent. On le voit de manière encore embryonnaire au Rwanda; il reste à appuyer ce processus au Congo. Cette écriture de la parole des femmes locales permet aussi de déterminer quel est le lieu du changement, quel est le temps de l'action qui transforme la crise en opportunité, celle d'une réécriture de l'acte de gouverner par des actrices qui étaient largement exclues de l'espace public.

Nous avons, ainsi, une idée des conceptions pratiques que les femmes se font sur la paix et la réconciliation:

- Le droit à la mémoire et le devoir de mémoire, la justice, la réconciliation sont un trio inséparable.

- La justice économique et une conception du développement plus proche des femmes (le bien-être) sont essentielles car la pauvreté a été une puissante incitation à la haine.

- L'acceptation de la pluralité des voix et le débat, la parole, même colérique. Nous traduisons ces deux éléments en termes de citoyenneté.

Ainsi, la culture de la paix devient un impératif, et la citoyenneté un objectif urgent. La citoyenneté peut s'apprendre, l'aptitude à la paix est une disposition de l'esprit, une éthique.

$\mathrm{M}^{\mathrm{me}}$ Emilienne Raoul, parlementaire du Congo Brazzaville, notait les points suivants quant à la paix et la réconciliation:

- elle démonte le processus qui conduit à la réconciliation.

- elle identifie les actions menées par les femmes.

- elle fait le lien entre réconciliation et paix durable.

Le processus de réconciliation inclut l'identification des personnes et groupes à réconcilier et l'analyse du phénomène de la violence car 
c'est l'action sur ces paramètres qui permet l'action sur les individus, les structures économiques, les institutions, etc.

Le processus inclut la reconnaissance du mal et la demande de pardon; en raison de complications, souvent politiques, un médiateur est souvent nécessaire. Le processus inclut la réparation et la célébration de la réconciliation. Et c'est probablement là que l'on oblige l'interlocuteur à mieux comprendre les perceptions des femmes quant à la sécurité. C'est là que l'on peut le mieux appréhender leur vision globale du développement qui n'est pas technique mais intègre aussi le bien-être. C'est là que la question de genre se révèle - sans être imposée - comme un élément essentiel au développement durable.

Mais la question des rapports hommes-femmes ne saurait occulter la diversité des femmes et des hommes dans la société. Les femmes de pouvoir ont intégré la culture dominante du pouvoir et la perspective de genre ne saurait ignorer cet élément fondamental, celui de femmes ennemies d'autres femmes et d'hommes pauvres et marginalisés. Ce serait ignorer une dimension essentielle de la perspective de genre: la structuration de la société et de ce fait son potentiel de transformation. 
AMNEH BADRAN

\section{Palestinian - IsRaeli Women's Peace INITIATIVES AND POWER RELATIONS}

FEMMES PALESTINIENNES ET ISRAÉLIENNES:

INITIATIVES DE PAIX ET RELATIONS DE POUVOIR

Les initiatives de paix des Palestiniennes et des Israéliennes ont commen cé il y a plus de dix ans. Le dialogue des femmes a conduit au premier article politique écrit conjointement.

Le dialogue entre les activistes politiques connues des deux côtés a égale ment ouvert la voie au premier travail institutionnalisé basé sur des principes politiques en développement continuel et a donné naissance à un organisme de liaison et de coopération entre deux associations fémi nines (l'une à Jérusalem Est et l'autre à Jérusalem Ouest): "The Jerusalem Link».

Dire cela ne signifie pas oublier le fait que les relations de pouvoir entre les deux côtés et dans chaque communauté ont toujours régi, à un degré important, le processus de formation des rôles dans la quête des femmes pour une transformation du conflit. En tant que telle, la politique des femmes a été très liée à la politique de leurs partis.

Dans ce texte, basé sur les expériences de "The Jerusalem Link», nous traitons ces thèmes, d'une manière plus ciblée sur le côté palestinien.

Women on both sides of the conflict live in different cultural, economic, social and political conditions. Yet the conflict affects the daily reality of these women in both similar and different ways. 
Decades ago, as Palestinian women activists were strongly involved with the Palestinian people's national political struggle for liberation, Israeli women activists were also very much involved in the quest to achieve equality in a society divided between secularism and religion.

As feminist thought developed across that divide, the roles women saw for themselves expanded. More than ten years ago, prominent political activists broke the taboo of recognizing and meeting those on the other side. Dialogue between political activists and scholars, who met during the first Intifada or uprising, produced the first published joint position paper. Its main article was the recognition of the Palestinian people's right to self-determination. This was a substantial step forward and a substantial step for the bi-national movement for peace making. Dialogue continued, mirroring the power relationships existing between the two sides and within each community.

The Palestinian - Israeli dispute is based on the fact that there is an occupier and an occupied. This fact is reflected at the dialogue table. For example, while Palestinians have tried to re-shift the balance towards one between equals, the Israelis have aimed at finding a compromise with a "flexible" partner. But Palestinians, now without their basic rights and needs, can hardly give up more of these in a compromise.

The Palestinians, who are the weaker party according to the conventional definition of power, demanded concessions from the stronger side on many occasions, saying that it had room to give. The Israeli's readiness to make a change in positions and get closer to the Palestinians' has very much been affected by changes in the political situation whether locally or internationally. For example, the Israelis would be ready to compromise if there was a Palestinian Intifada (uprising) because the price they would pay would increase. But as long as the price for peace is limited, they are more reluctant to compromise as if nothing was pressing. As such, throughout the process of dialogue, both sides had phases of strength and weaknesses. 
The progressive thought of feminists on both sides geared the process of political dialogue towards trust building and creative thinking. Both aimed at moving towards a joint vision for peace making. Agreed-upon political principles constituted the basis for institutionalized cooperation (such as the Jerusalem Link) and joint initiatives. Specific strategies were aimed at the public opinion and personal attitudes of both sides.

Still, not much was achieved. Each side worked within the framework and structures of its own political parties and affiliations. The Palestinians had different and changing strategies for struggle that reflected individuals' political party line. The Israelis made many moves forward and backward, reflecting the ongoing change in political realities and coinciding with their surroundings.

To talk about women's substantive yet limited effect on national politics in the peace building process on both sides, one must speak of each community's internal politics. On the Palestinian side, patriarchal relations dominate. The cultural heritage does not provide fertile ground for women's participation in community and political life. According to traditional values, males are the independent breadwinners, while females are the subordinate caretakers. Of course the Palestinian feminist movement consisting of many factions has challenged this norm. The movement is still developing and has many challenges to overcome.

The Palestinian feminist movement, that represents a plurality of thought from conservative to liberal, has been developing for decades. Still, it has not been able to overcome the traditional nature of the main political establishment, the Palestine Liberation Organization. The PLO praised women's participation in the political struggle, but it did not include or empower women to take part in the decision-making process.

The first Intifada, which erupted in 1987, introduced a progressive political discourse calling for the liberation of the land and people. 
The United Leadership of the Intifada encouraged women to participate in all aspects of the uprising, including demonstrations, local committees, and cooperatives. Women's grassroots organizations and activists were strongly involved.

But despite recognition of their central role, women's contribution to decision making was highly limited. Political parties from left to right had this same position, not least because of their internal lack of real democracy.

The establishment of the Palestinian National Authority in 1994 gave women more of a role - albeit cosmetic - in political decision making. There is one female minister in the cabinet of thirty members appointed by President Yasser Arafat. The minister of Social Affairs, an elected member of the Palestinian Legislative Council, is the wife of assassinated PLO leader, Abu Jihad. Only five of the 88 elected members of the Palestinian Legislative Council are women. One of them is active in the bi-national venture for peace building, the Jerusalem Link.

Lately, the leftist political parties have been enhancing their internal democracy. Women are encouraged to apply for top positions and many have succeeded. Still, conservative and religious parties lag behind.

On the Israeli side, the women's movement is also facing tremendous difficulties in overcoming existing rivalries between secular and religious groups. After years of activism to achieve equality, patriarchy continues to negatively affect women's quest for equality and social justice. No wonder then that the democracy practiced in Israeli parties only produces limited women's representation. Fifteen of the 120 Israeli Knesset members are women. One of them is a Palestinian Israeli, another is Mizrahi (from Arab roots) and 13 Ashkinazi (from European background). Few of these women are active in the Jerusalem Link. Experience has shown that each Bat Shalom board of trustee member represents the position of her party 
in discussion. Decisions made in Bat Shalom are the result of consensus accepted by all.

This process is very similar to what occurs at the Jerusalem Center for Women, the Palestinian partner. This means that both sides are very connected to existing political structures with limited space to maneuver. It also indicates how much internal power relations can affect one side's position in an external power relationship.

No wonder then that the Jerusalem Link is currently in crisis. The Israeli public is moving to the political right. The same can be said of Israeli leftist parties. It took the Israeli "peace camp" over a month before it reacted positively towards the Palestinian Intifada for independence, rejecting the Israeli government's practices. Members of Bat Shalom have made a shift in their positions, from a discourse close to the Zionist mainstream to that of the Zionist left. For example, at the request of the Palestinian members of the Jerusalem Center for Women, the Israeli members managed to present a position on the Palestinian refugees' issue that left the door open for continuing dialogue between the two sides' board members.

The Palestinian side was astonished by the limited involvement of Israel's peace camp during the recent Palestinian Intifada. It took Bat Shalom weeks to react at a time when their counterparts' lives were in danger. Emotion is now very high on the Palestinian side due to the rapid increase in the number of killed and injured. As a result, the Palestinian side gave a clear message to its Israeli counterpart that a measure of trust building must come from their side. All joint projects and activities have been stopped. Boards members and staff of both sides can meet whenever it is necessary. Jerusalem Center for Women now tries to reach an agreement over political principles that leaves no room for misinterpretations. Only then can joint activities be resumed and new strategies be defined by both parties. 
SUSANNE SCHMEIDL

\section{GENDER AND EARLY WARNING}

\section{DÉBUT ET FIN DES CONFLITS}

Cet article soutient que l'introduction du genre dans les conflits naissants amènera à des approches préventives plus réelles et plus utiles, particuliè rement si les signes d'alerte sont compris comme un système flexible sen sible aux diverses situations sur le terrain demandant des solutions sur mesure. Une approche sensible aux questions de genre peut mettre en valeur les modèles de préconflits dans leurs suppositions de base (ce que nous considérons comme important ou non, ainsi que les questions que nous nous posons) et dans leur façonnage (incluant des indicateurs sen sibles aux questions de genre), aussi bien que dans leur mise en cuvre (possibilité d'une plus large variété de réponses). Outre les arguments éta blissant pourquoi l'approche genre peut améliorer le «système d'alerte anticipée» en général et les modèles de préconflits en particulier, cet article suggère aussi des propositions d'indicateurs sensibles au genre.

\section{EARLY WARNING}

Early warning is not only about assessing the possibility of conflict but also identifying the possible resurgence of conflict and the opportunities for peace (FEWER 1999, p. 3).

The major point in early warning information collecting and analysis is not the information and analysis of the crisis in itself, but the 
use of this information and analysis to gain the trust of decision makers and to bring them effective response options (Adelman 1997, p. 6).

\section{DIFFERENT TYPES OF EARLY WARNING INDICATORS}

1. Systemic causes - those referring to general underlying structural and deep-rooted background conditions, e.g. infant mortality, socio-political conditions, economic development.

2. Proximate causes - those relating to specific situational circumstances, e.g. widening income disparity, competition between ethnic groups, popular discontent.

3. Immediate catalysts - idiosyncratic contingent triggers, e.g. electoral fraud, purges against certain sectors of society, sharp price rises.

\section{Proactive “Response”, Conflict Prevention and GENDER CONSIDERATIONS}

- It is suggested that gender mainstreaming would further promote appropriate action. In other words, if policy makers and implementing agencies are aware of the differential impact of conflict on women and men, and understand that women are at risk of rape, military prostitution, economic violence and displacement in war (Tickner 1999 and 1992) the humanitarian response options they propose are more likely to be directed equally (gender sensitively) at both women and men.

- Furthermore, if gender sensitivity exists within policy making and response institutions there is a greater chance that responding agencies will look for, and draw upon local prevention initiatives developed by women. 
- Better gender sensitivity in policy and decision-making could also have an impact on the response processes. Women in such positions could also influence the mandate, structures and processes of warning and response agencies. This must not reinforce the stereotypical image of women as being more inherently peaceful, but merely suggests that women do things differently.

- Stereotypical images of men as strong, aggressive and rational beings, compared to women as emotional, passive and peaceful is detrimental to policy-making processes and to the development of effective and proactive response options. This "gender ideology" undermines women's leadership as it suggests that they lack agency. It also affects men's leadership as it inhibits their possible search for cooperative solutions. Moreover, it delegitimizes peace and cooperative strategies that may be regarded as weak alternatives or idealist. "As a concept, peace will remain a "soft" issue, utopian and unrealistic, as long as it is associated with femininity and passivity" (Tickner 1999, p. 4).

\section{Structural/Systemic CAUSES}

\section{Political Equality}

- Caprioli's research suggests that states with lower percentages of women in parliament are more likely to use military violence to settle disputes. Only few states do currently reach above the 30 percent threshold which is argued to create a "critical mass" in terms of policy impact, which may suggest that this variable may become more powerful as women are increasingly included in political positions.

- Female suffrage was also a significant predictor of state bellicosity. "Given two states, for example, the state having twice the number of years of female suffrage will be nearly five (4.94) times as 
likely to resolve international disputes without military violence" (Caprioli 2000, p. 61).

\section{ECONOMIC EQUALITY}

- The percentage of women in the labor force showed statistical significance in explaining state bellicosity. This can also be construed as suggesting that women's participation in the labor force captures the degree to which women are tied into the public sphere and other forms of participation such as voting or political activism.

\section{SOCIAL EQUALITY}

- An overall measure of female fertility rate, suggests that "women's access to reproductive health services is constrained by their broader social deprivation, including the lack of resources for, or priority to their health, restrictions on social participation, and limited access to information due to illiteracy" (p. 57; see also Sadik 1997). "Those states with high fertility rates, which represent a low status for women, were more likely to use force in international disputes" (Caprioli 2000, p. 63).

- Marshall and Ramsey's research (1999) using the composite measure of Gender Empowerment concurs with the above. There "appears to be a very real and robust relationship between the quality of gender empowerment and the unwillingness to use force" (Marshall and Ramsey 1999, p. 26).

- Other research in related areas (Brumfield 1994, Erchak and Rosenfeld 1994, Levinson 1989 as cited in Caprioli 2000) suggests that "societies with high levels of family violence are more likely to rely on violent conflict resolution and are more likely to be involved in wars compared to societies with lower levels of family violence" (Caprioli 2000, p. 55). The rising level of domestic violence (or general tension) was observed in Ethiopia prior to the outbreak of war with Eritrea (Ludi 1999). 


\section{Proximate Causes}

As suggested previously, minority groups, women and children are often the first affected and targeted in this way.

- Indicators based on violations against women could contribute to improved and "earlier" early warning. For example, the recession in the status of women, discrimination against women, media scapegoating, violations of women's human rights, and virulent attacks on women may be direct precursors of further repression and violent conflict.

The fact that women's human rights may be violated earlier can be connected to the fact that violence against women is often considered as a "private" and not "public" affair, and thus not related to political developments - even if performed systematically. This very subtlety makes the violation of women's human rights (and also that of minorities) a very good indicator for "early" warning.

- Abrupt changes in women's roles in society can also foreshadow human rights abuses and help gauge the level of tolerance in society in general. Increasing restraints on women's roles in Kyrgyzstan, and the decline in women's political participation throughout the former Soviet system for example is a useful indicator (Schmeidl 1999). The imposition or implementation of strict religious laws - particularly those that affect women more directly - is a useful indicator as well. For example in Pakistan the tighter imposition of Sharia laws, giving women far less rights, was a precursor to the overall strengthening of laws and a shift towards a more general conservatism in society.

- Recent studies suggest that youth bulk and particularly a large percentage of unemployed young men be an indicator of potential instability in a society as they form the recruitment ground for militant groups. 
- The media can also play a critical role at this stage. Addressing gender related issues, the portrayal of women in the media can be a key indicator. In Rwanda, as early as 1990, extremist Hutu press and radio, began to target Tutsi women as seductresses ("femmes libres"), spies, and a threat to Hutu society (see Chretien 1995 ; Human Rights Watch 1996).

- Sale of valuables, particularly gold: In societies where women's own security and wealth is based on their possession of gold and other precious materials, the sale of such items is an important indication of the level of desperation and need. Although no systematic studies have been done about women's economic activities in the run-up to conflict, this area is worth further exploration.

\section{IMMEDIATE CATALYSTS}

\section{ExAmple: SeX-SPECIFIC Refugee Migration}

Gender-disaggregated examination of flows of refugees may help prepare better responses (given that women and children represent approximately $75-80 \%$ of camp populations, Schmeidl 1997, 1999) and make better prediction as well. Linking gender and age, we can distinguish three basic waves of refugee movements (Ferris 1987). The first refugees are political exiles, or anticipatory refugees (Kunz 1973). They are politically active and flee at an early point in time foreseeing political turbulence. The second wave consists of urban dwellers, which flee after the initial outbreak of violence. The third wave of refugees (peasants), are a mass movement, composed of people who are caught in the "cross-fire" of rapidly unfolding political violence in their country and therefore flee much later in the conflict. They are the victims of violence with little involvement in the initial conflict. While the first two types of refugees tend to be educated middle-class males, the third tend to be non-educated women and children (Ferris 1987 ; see also d'Adesky 1991). 
In a different situation it was observed that between March and April 1992 women (especially of Muslim origin) left Priador (Bosnia and Herzegovina) by busloads. This was actually 6-8 weeks before the situation deteriorated. Muslims described this as protecting their families from danger, Serbs presented it as clearing the decks so they could prepare for all-out conflict (Last 1997).

While it may not be fully clear if one has to look for all male (Ferris) or all female (last) migration, sex-disaggregated analysis of the fleeing groups can provide a more accurate picture of the state of events and be an effective early warning signal to conflict escalation.

\section{GENDER AND EARLY RESPONSE}

Involvement of women, or gender mainstreaming

- may lead to policy prescriptions aimed at less militarized responses,

- can increase the possibility of obtaining gender-sensitive information giving more appropriate responses to groups at risk, and thus

- may help develop more sensitive and comprehensive approaches to conflict early warning and prevention.

\section{EARLY AND NON-MiLITARY RESPONSES}

- It may be an overgeneralization to aguing that a heavily militarized focus, or the use of military personnel to perform non-military tasks, is linked to an extremely male-dominated decision-making process, but it cannot be denied that military operations are overwhelmingly performed by men. Even in situations where women have been active as fighters or within the ranks of the military, the overwhelming ethos has been male dominated. 
- There is some evidence that the "inclusion of women in the armed forces ... might result in an alteration of the armed forces." This supposition is supported by evidence indicating that the police force has become less violent with an increased number of female officers integrated at all levels, rather than having female officers become more violent (see Carson (1993) in Caprioli 2000, p. 54).

- Evidence from public opinion and voting behavior also suggests that women are less likely to support militaristic response options than men - though the gap is small (Mueller 1973; Lamare 1989 ; Fite, Genest, and Wilcox 1990).

- Apart from an exclusive gender-differences to gender-perspective it has been suggested that "individuals who are more supportive of equality between women and men are also less supportive of violence to resolve conflict. ... In other words, societies that have internalized values that are less gender-based and apply them to their interstate and interpersonal relations should exhibit less militaristic international behavior" (Caprioli 2000, p. 55). This implies the possibility that all people can be educated toward violent or nonviolent approaches and responses to, conflict.

Ultimately however, there is still insufficient data to prove if and how increased numbers of women in relevant decision-making positions would alter the responses of multi-lateral organizations or military operations.

\section{GENDER-SENSITIVE INFORMATION LEADS TO More APPROPRIATE Responses of GROUPS AT RisK}

1. Distribution of food: Research has showed that by arbitrarily assigning men to certain tasks considered as important, refugee camps often distort existing systems of division of labor among men and women (Callamard 1993). For example food produc- 
tion is often considered a reproductive task and thus falls under the women's realm. But in a refugee camp the task of redistributing food is generally performed by men. Thus, relief workers (also largely male) tend to assign this work to men. The effect is two-fold. First, the supplies are often siphoned off and used in exchange for weapons or profit, and second, women's subordination to men increases (Motsisi 1993).

2. Shelter: Another example shows that those men in charge of redistributing plastic sheeting to make huts had sold most of them for profit, while women were concerned about protecting their families during the rainy season. "The implementing partner said more sheeting was coming in. But had they changed the distribution system? No" (Marshall 1995, p. 4).

3. Provision of basic necessities: Other minor changes in planning can also have a major positive impact on assistance provided. The distribution of sanitary napkins is an obvious example. While this distribution to women refugees may seem natural, its poor implementation, by male staff members, is not. Consequently a quarter of some refugee women's lives are sometimes wasted as they are denied access to cloth used for sanitary napkins, and are thus forced into spending a week per month in their shelters, unable to take their children to the clinic or gather firewood (Marshall 1995).

4. Camp layout: Similarly, the physical layout of a refugee camp can also play an important role in the security of refugee women. For example, many of the latrines are built side-by-side for both women and men. But women prefer risking attack in the forest rather than use these closely confined latrines. In other instances, women are forced to forage outside the camp for firewood with no protection from bandits and the militia, placing themselves in situations of possible rape and assault (Marshall 1995). 
5. Limiting Sexual Violence: A 1993 evaluation of the Australian "Women at Risks" scheme concluded that the scheme's low success rate was due to the "acceptance of the rape and sexual abuse of women as valid claim for Refugee Status" (Pittaway 1993). However, as the program was run mainly by men, the issue of rape was minimized as it became apparent that to a large extent they shared the opinion that it is "only rape" and thus not a major issue. Pittaway (1993) further believes that part of the problem, is the idea that "good men" are needed to protect women from "bad men." This portrays women as weak and pathetic, and unable to protect themselves.

\section{CONCLUSION AND RECOMMENDATIONS}

1. Better Early warning: gender specificity and gender sensitivity in the construction of early warning indicators can improve medium and long-term, and in some cases, early prediction by encouraging analysts and decision-makers to pay attention to critical on-the-ground realities and details that might otherwise be missed.

2. Better responses: gender specificity and gender sensitivity when formu lating responses to early warning, leads to a consideration of gender-sensitive information that can result in more realistic and sensible response options, and perhaps less militaristic/violent ones.

More attention is needed in the following areas:

1. Research: it is necessary to further test the relationship of gender and conflict and gender and violence - in different cultural contexts - so that early warning models can reflect on-the-ground realities and focus on long-term warning.

2. Testing of indicators: the search for (and testing of) gender-specific early warning indicators is crucial. Most importantly, we 
need to test whether they indeed improve early warning models by providing contextual sensitivity and "early" warning.

3. Analysis: the impact of gender mainstreaming on response option must be further examined. While it is argued that a gender perspective encourages the diversity of possible response options at different stages of the conflict, more exploration is needed to identify the kind of options and perspectives favored by women, how they differ from male preferences, and if / how these options would affect early warning/response processes.

4. Support to existing systems: Comprehensive and more flexible early warning approaches (see FEWER, FAST) that can incorporate new strategies should be supported in an effort to test the impact of gender mainstreaming.

5. Strengthen training programs: More resources and attention should be given to training programs in international organizations/ governments that work on early warning and early response, so as to introduce/strengthen a gender focus.

6. Increasing gender balance: To speed up gender mainstreaming and the inclusion of women's perspectives in conflict early warning/response processes, programs that encourage the recruitment of women into crucial decision-making positions in international organizations/governments should be supported. 
Fanta Coulibaly Coumaré

\section{LES SITUATIONS DE CONFLITS ARMÉS ENTRE EXPLOITANTS DES RESSOURCES NATURELLES EN ZONE SOUDANO-SAHÉLIENNE: CAS DU MALI}

Cette intervention se propose de réfléchir sur l'utilisation anarchique des ressources naturelles comme principale source de conflit dans les zones sahéliennes. La rareté et la mauvaise gestion des ressources naturelles sont des causes de conflits entre les différents pays sahéliens, mais égale ment entre communautés voisines. Un certain nombre de facteurs (exploitation intensive des sources de combustibles, sécheresses endé miques...) rendent de plus en plus difficiles les conditions de survie. L'introduction de nouvelles technologies énergétiques, de structures décentralisées de gestion et d'implication des femmes peut aider à atté nuer les tensions et prévenir l'éclatement de conflits.

\section{INTRODUCTION}

Cette communication est une réflexion personnelle née du constat que l'utilisation anarchique des ressources naturelles est la principale source de conflits en Afrique et plus particulièrement au Mali, qu'il śagisse du pétrole, du diamant, de l'eau, des terres ou du couvert végétal.

Les systèmes de gestion des maigres ressources du Mali tiennent peu compte des relations de genre pour leur utilisation. Trop souvent, les 
projets sectoriels de développement essaient de répondre aux besoins immédiats des populations sans tenir compte de l'équité et il s'ensuit un déséquilibre social et des conflits.

\section{LE NON-RESPECT DE L'ÉQUITÉ «GENRE » DANS LA GESTION DES RESSOURCES NATURELLES COMME SOURCE DE CONFLITS ARMÉS}

Suite à la disparition des grands blocs Est/Ouest, les conflits armés en Afrique ont aujourd'hui perdu leur caractère idéologique pour ne garder que l'aspect économique. De nos jours, la principale source de conflits est liée à la rareté et à la mauvaise gestion des ressources naturelles.

Les programmes d'ajustement structurel ont également introduit des jeunes diplômés dans le secteur du développement rural. Ce qui a sûrement contribué à augmenter la pression sur les ressources naturelles. Les émigrations vers le sud et les pays côtiers et la prolifération des camps constituent aujourd'hui une menace pour l'écosystème et la paix.

L'exploitation anarchique des ressources naturelles est la principale source de conflits armés au Mali, que ce soit avec des pays voisins ou à l'intérieur du Mali. Les Maliens ont des difficultés à gérer les maigres ressources naturelles. Plus de $80 \%$ de la population vivent du secteur primaire: agriculture, élevage, cueillette et pêche. Une bonne partie des activités économiques sont liées directement à ce secteur sous forme d'approvisionnement en intrants agricoles et/ou commercialisation de la production, de transformation.

Les femmes accèdent peu aux terres cultivables et tirent leurs revenus principalement des produits de cueillette: karité, néré, gomme arabique, bois. La quasi-totalité des familles utilisent le bois et le charbon comme source d'énergie domestique. Avec la création des zones d'irrigation, de pâturage et d'agriculture, certains exploitants sont lésés. 
Il s'ensuit une surexploitation des ressources naturelles, ce qui menace directement notre survie et la paix. Et sans paix il n'y a pas de développement. A deux reprises (1972-1984) une terrible sécheresse a entraîné famine, décimation des troupeaux et exode. La cause du conflit avec le pays frère Burkina Faso a été l'utilisation des bandes de pâturage à la frontière des deux pays.

$\mathrm{Au}$ niveau national, les populations nomades du nord ayant tout perdu dans les terribles sécheresses se sont rebellées contre l'autorité de l'Etat. Ces mouvements terroristes de revendication ont failli déraper vers une guerre civile interethnique entre sédentaires et nomades. Ces conflits ont entraîné un exode massif des femmes et des enfants vers les centres urbains et les pays voisins. Les femmes se sont organisées alors pour exercer des pressions sur les différentes parties impliquées dans le conflit pour les amener à la table de négociations.

Ensuite, elles ont organisé des manifestations culturelles pour gérer l'après-conflit et amener la paix entre les populations. La gestion de ces conflits a déclenché la politique de décentralisation pour donner plus d'autonomie aux collectivités par la création des communes. Les structures de décentralisation et les ONG sont aujourd'hui les principales actrices du développement de ces zones et de la résolution de conflits.

Le Mali est également l'objet de conflits armés sporadiques entre communautés pour l'utilisation des ressources naturelles, entre éleveurs et cultivateurs, entre sédentaires et nomades, pour la gestion des points d'eau, le passage des troupeaux, le pâturage et la terre.

Les familles entrent régulièrement en conflit armé pour la délimitation des champs et des terroirs. Cela se règle généralement par le biais des tribunaux traditionnels ou modernes, mais très souvent après des accrochages meurtriers. 


\section{LES CONSÉQUENCES DES CONFLITS ARMÉS SUR LA SOCIÉTÉ EN GÉNÉRAL}

La famille comme unité sociale de base est la première à souffrir des conflits:

- dispersion des membres de la famille;

- violence sur les plus vulnérables;

- perte des repères pour la socialisation des enfants et la maîtrise des rôles de production et de reproduction.

Les personnes battues, humiliées, injuriées subissent de graves pertes de confiance en soi, d'estime de soi et de confiance en autrui. Avec les déplacements et la précarité des conditions de vie, le sens d'appartenance sociale s'effrite. Il y a plus de difficultés à satisfaire le besoin d'intimité, ce qui engendre la frustration et l'agressivité.

Les conflits entraînent un état psychosocial de violence permanente. La désorganisation sociale suscite un climat d'impunité favorable aux actes de violence et au chaos. On constate que les femmes sont les principales victimes de ces violences.

\section{COMMENT PRÉVENIR LES CONFLITS}

Le fait d'étouffer le conflit n'est pas toujours rentable à long terme. La désignation d'un médiateur peut réduire le temps de conflit et faciliter sa gestion. Mais pour une paix durable, il faut une approche plus humaine des actions de développement qui tienne compte des intérêts stratégiques de chaque sous-groupe:

- répartition équitable des ressources naturelles;

- mise en œuvre des actions de solidarité et de communication entre les différents sous-groupes;

- clarification des règles de gestion pour tous les sous-groupes;

- focalisation du système d'organisation vers le bien-être social et la collaboration; 
- prise de conscience des lois et attitudes discriminatoires;

- reconnaissance de l'apport de chacun et valorisation des rôles de solidarité;

- plus spécialement au Mali, un programme de diffusion massive des énergies renouvelables.

Le solaire, la biomasse et l'éolienne pourraient réduire les risques de conflit armé à long terme. Malheureusement, le développement d'un tel programme est freiné par l'extrême pauvreté de la population. La diffusion de l'énergie renouvelable non seulement préserverait les ressources naturelles, mais favoriserait également le développement d'autres activités grâce à l'électrification et diminuerait la pression des hommes et des animaux sur les ressources naturelles.

Actuellement, les principales sources de revenus des femmes sont menacées par la disparition des forêts. Et il faut noter que plus la pression est forte, plus les récoltes sont rares et plus les plus pauvres n'ont d'autre choix que d'exploiter les maigres ressources de la forêt.

Les programmes de lutte contre la pauvreté et la diffusion massive des énergies nouvelles et renouvelables ainsi que la décentralisation et l'intégration sous-régionale constituent un espoir immense de prévention de conflits armés dans nos zones fragilisées par la sécheresse et l'économie de marché.

L'émigration commence à atteindre un seuil d'intolérance dans beaucoup de pays de la sous-région; les minorités transfrontalières sont très souvent expulsées à seule fin de récupérer leurs terres.

La prévention des conflits passe nécessairement par des stratégies de lutte contre la faim et la pauvreté, ce qui ne sera possible que si les ressources naturelles sont préservées.

En matière de conflit, il vaut mieux prévenir que guérir. Les conflits armés ont laissé des plaies ouvertes, des inimitiés entre pays, communautés, ethnies et familles. 
Par ailleurs, les sécheresses ont provoqué une véritable mutation dans les rôles et les responsabilités des hommes et des femmes au Mali. Les fonctions de la femme ont considérablement augmenté pour assumer la survie de la famille et de la communauté.

\section{CONCLUSION}

L'approche «genre et développement» est une réorientation nécessaire à nos politiques, programmes et projets de développement pour

- la prévention des conflits et la définition d'indications précoces de prévention et d'alerte;

- une approche plus globale et humaine de la problématique du sous-développement, considérant l'être humain dans ses multiples rôles;

- une approche plus participative pour un véritable changement durable des comportements qui perpétuent les mauvaises habitudes et pratiques néfastes;

- une approche systémique qui prenne en compte les facteurs d'influence. 
MONIKA KAEMPF

\section{IMPACT OF WAR ON WOMEN}

Le CICR est une organisation humanitaire indépendante qui se donne pour objectif de protéger et d'assister les victimes de guerres et de tensions internes. Il déploie ses activités dans quatre-vingts pays. La loi humani taire internationale accorde des mesures de protection pour les les femmes égales à celles pour les hommes. Dans certains cas, les besoins spécifiques des femmes induisent des mesures de protection particulières. Cet article présente un nombre d'actions sur le terrain visant particuliè rement les besoins des femmes.

The ICRC visits prisoners of war and persons detained in relation to conflict and political violence throughout the world. More men are detained than women, but because women are a minority in detention situations, they may in fact suffer worse detention conditions then men, not as a deliberate discrimination, but simply because there are not as many prisons for women as for men. Hence women may be housed in a ward of men's prison and in quarters that do not adequately meet their needs.

War and armed conflicts affect all human beings. The seriousness and magnitude of suffering leave no room for complacency. The context in which humanitarian organizations operate needs to be regularly evaluated; it is also necessary to examine whether they adequately respond to the needs of the present victims of armed conflicts, women, men and children. 
International humanitarian law has accorded women, as civilians, the same general protection as men, and recognized that they must be given a special protection in accordance with their specific needs. Yet women do still suffer from violence and are even specifically targeted in situations of armed conflict because they are women.

The ICRC is an independent humanitarian organization which endeavors to bring protection and assistance to victims of armed conflict and internal tension. The ICRC is impartial: its only criteria for action are the needs of the victims. The ICRC is neutral and remains detached from all political issues related to conflict and endeavors to promote dialogue in situations of internal violence, with a view to finding solutions for matters of humanitarian concern. The ICRC, active in 80 countries and with delegations based in 56 of these countries, carries out its mandate throughout the world through its detention and protection activities, its relief and medical assistance programs, its efforts to re- establish family links, and its dissemination activities.

Here are some examples of gender-related activities that the ICRC has led in various fields:

- In Lebanon, the ICRC gave financial assistance to families of detainees in order to facilitate family visits and also assisted the families with administrative procedures. The delegation also provided material assistance to wives of detainees.

- In Bosnia-Herzegovina, the ICRC provided extensive support as an organization that listens to the families of the missing, made representations to the authorities and acted as a neutral intermediary to forward the files of persons missing to the respective authorities, liaised with "missing" commissions and international organizations (like the International Commission for Missing Persons (ICMP) for the former Yugoslavia), and is endeavoring to support families through the various associations set up within the country (recently co-ordinated by a delegate with expertise in psy- 
cho-social activities). In the year 2000, the ICRC published the first "Book of Belongings", containing photos of clothing and personal effects that were found on unidentified dead bodies. Families have recognized items belonging to over 80 missing persons so far, allowing formal identification to begin.

- In Congo-Brazzaville, the ICRC in its dissemination sessions to the armed forces, promotes awareness and implementation of the law of armed conflicts (IHL), including protective measures for women.

- In Algeria since June 1999 the ICRC has been supporting psychological rehabilitation programs for women and children who have been victims of violence (including women who have been victims of rape), which are run by the Algerian National Society in collaboration with the Ministries of Health and Labour. This support is given through funding and provision of equipment and material for the programs, and through the services of a child psychiatrist who provides expertise in matters of staff training and care for the victims. The ICRC will also give a contribution to the equipment of 5 new workshops for women in zones affected by violence, for a total cost of 200,000 CHF, and will continue to provide other material support to the different workshops already set up and to the centers taking care of children.

The intended beneficiaries of this program are around 4,400 children, 600 women and 240 professionals working in the medical and paramedical sectors.

- In Peru, during the year 2000, several women who had been raped have been assisted by the ICRC, through consultation with ICRC medical doctors, and referral to a gynecologist for medical check-up and a psychologist for counseling. The ICRC paid for the medical expenses.

- In Sierra Leone, a vegetable seeds-assistance program is targeted to women's associations whose members are underprivileged 
women such as widows and female heads of households. The program was designed to enhance skills, food security and incomegenerating opportunities for women affected by armed conflict. So far, 11'720 women have received extensive training and cashcrop seeds and tools.

- The ICRC in Afghanistan has developed some small scale agricultural programs for women in their homes, e.g. kitchen gardens, in order to provide some assistance and a potential source of income. The Kitchen Garden Program provides vegetable seeds, fertilizers and tools to families headed by widows and disabled persons in an attempt to decrease dependency on food aid, reduce living costs, create an income and strengthen coping mechanisms.

- In Sri Lanka, the Russian Federation and Rwanda, the ICRC has provided sewing machines and material to develop existing or new clothes workshops as a means of generating income for vulnerable groups, particularly targeting widows or female headed households.

- In Mexico (Chiapas) the ICRC is organizing training courses for traditional midwives in an attempt to ensure that all women, especially in indigenous communities displaced by armed conflict, receive adequate prenatal care.

Furthermore the ICRC has just completed a study initiated in order to better identify ICRC activities carried out in favor of women during armed conflict and to provide a better basis for an analysis of women's situation and of ways to improve the response to women's needs. The study focuses on:

- Identifying women's needs, including access to basic goods and services, such as food, shelter and primary health care as well as, to a certain extent, the strategic needs of women. 
- Drawing up a realistic picture of ICRC's activities with regard to women, and evaluate whether these activities adequately respond to the identified needs.

- Examining of the International Humanitarian Law, in order to assess its coverage of women's needs

- The establishment of guidelines from the findings of the study in order to improve the protection of women and promote their role in society.

For up-dated information about the ICRC's activities with regard to its work and in particular about the women and war project please consult the ICRC web page: www. icrc. org 
Magdala Velasquez Toro

\section{REFLEXIONES FEMINIST AS EN TORNO A LA GUERRA, LA PAZ Y LAS MUJERES, DESDE UNA PERSPECTIVA DE GÉNERO}

L'auteure aborde ici la guerre et la paix d'un point de vue historique et féministe. Elle se livre à une déconstruction du patriarcat et de la sociali sation des hommes dans un certain nombre de sociétés. Ce faisant, elle pro pose des modèles alternatifs des stéréotypes existants sur la masculinité et la féminité. Certains de ces modèles śobservent dans la guerre dite "postmoderne», où les espaces discursifs multiples et flexibles permettent à des individus de trouver une motivation de participation individualisée. La participation à la guerre devient ainsi une question de négociation gran dement basée sur la construction/déconstruction des catégories du genre.

\section{UNA MIRADA DESDE COLOMBIA}

Las siguientes reflexiones feministas en torno a las mujeres, la guerra y la paz, pretende aportar histórica, política y éticamente a los esfuerzos por introducir este tema en el proceso de búsqueda de la paz, de negociación política del conflicto armado y de construcción de una sociedad justa equitativa y democrática Colombia.

El siglo XX concluyó en un clima de desasosiego mundial. Las reflexiones de pensadores acerca del futuro están teñidas 
de insatisfacción y de desconfianza. Al respecto, el historiador Hobsbawm afirma que esto ocurre porque no sólo ha sido "el siglo más mortífero de la historia a causa de la envergadura, la frecuencia y la duración de los conflictos bélicos que lo han asolado sin interrupción -salvo en un período corto durante los años 20-, sino también por las catástrofes humanas, sin parangón posible que ha causado las mayores hambrunas de la historia hasta el genocidio sistemático". Asimismo, afirma que las guerras que se han librado atacan "cada vez más la economía, la infraestructura de los estados y la población civil"11.

El politólogo inglés John Keane del Centro de Estudios de Democracia de Westminster, registra con preocupación que entre las muchas paradojas que ofrece este siglo una es la escasa tendencia de la teoría política contemporánea, incluida la democrática, a reflexionar sobre las causas, los efectos y las consecuencias ético políticas de la violencia. Afirma que "la enorme violencia que ha soportado este siglo sería capaz de hacer un pesimista del más entusiasta de los filósofos, y puesto que los "optimistas escriben mal" (Valéry) y los pesimistas escriben poco, se comprende el silencio de los profesionales de la teoría política que han padecido su crueldad" ${ }^{\prime 2}$.

$\mathrm{Al}$ lado de estas aterradoras características, paradójicamente, durante este siglo, como nunca antes, se lograron estructurar jurídica y políticamente mecanismos, instituciones y estrategias para preservar la dignidad humana de la degradación por la tiranía, la pobreza, la falta de equidad y la muerte violenta ocasionada por las guerras y demás formas de exterminio humano. El paradigma de los derechos humanos y la paz, como elemento fúndante de las relaciones internacionales y de las organizaciones políticas de las diversas sociedades, recorren el mundo, a pesar de que los resultados en la lucha por la humanización de la vida sean poco satisfactorios.

1. Hobsbawm Eric "Historia del Siglo XX." Crítica Grijalbo Mondadori, Buenos Aires, 1998, págs. 22 y 23.

2. Keane John, "Reflexiones sobre la Violencia", Alianza Editorial, S.A. Madrid, 2000, pág 16 y ss. 
En estos últimos cincuenta años, las paradojas de la historia contemporánea del mundo han tenido su expresión en el devenir del país. La guerra que se inició en Colombia como proyecto de transformación social propia de la época de la guerra fría, nos lleva a una conclusión contundente: la maquinaria de la guerra atrapa por igual a todos sus cultores. Socialmente se convierte y posiciona como otra causa estructural más del empobrecimiento, de la desigualdad y la inequidad, y factor potenciador de la degradación humana, tanto de las víctimas de la guerra como de los diferentes actores del conflicto armado. Nuestra reciente historia, advierte tanto la crisis institucional del estado y del proyecto de sociedad que ha prevalecido como del fracaso de la vía armada para la transformación social. Cincuenta años de guerra sin triunfo posible son en sí mismo una derrota, y persistir en ella es una falta de generosidad con las futuras generaciones colombianas como con la humanidad.

Estas reflexiones constituyen un esfuerzo del pensamiento feminista y la experiencia del movimiento social de mujeres con el propósito de aportar elementos al análisis de la compleja realidad nacional y a la difícil búsqueda de alternativas para lograr que la negociación política del conflicto armado sea alentada desde las diversas ópticas de la sociedad civil y que los acuerdos de paz sean radicales y sostenibles.

\section{Herencia histórica de LUCHAS POR LA PAZ}

La lucha por la paz se ha manifestado históricamente a través de expresiones que rechazan el uso de la violencia y en especial el uso de la guerra bajo cualquier perspectiva, califican la guerra defensiva $\mathrm{u}$ ofensiva como éticamente inadmisible e ineficaz para conseguir cualquier tipo de objetivos. Este movimiento ha sido conocido genéricamente como pacifismo y aboga por la utilización de métodos no violentos para enfrentar la agresión externa, la explotación y las injusticias internas. 
Norberto Bobbio habla de que "la paz al que aspira el pacifista no puede ser otra cosa que la paz de satisfacción, o sea una paz que es el resultado de una aceptación consciente, como sólo puede serlo la paz que se instituye entre partes que ya no tienen reivindicaciones recíprocas que formular", caracteriza toda forma de pacifismo por considerar la guerra como mal absoluto y además plantea que los pacifistas no consideran en absoluto que la paz, por sí misma, sirva para resolver todos los problemas que afligen a la humanidad, pero que sí es un bien necesario, pero no suficiente y a lo sumo prioritario. Kant, en "Por la Paz Perpetua", escribía en 1795 que el valor supremo que una convivencia bien ordenada de los individuos debería realizar es la libertad, no la paz, puesto que la paz es solo una condición preliminar para la realización de la libre convivencia ${ }^{3}$.

En la perspectiva histórica se habla de posturas pacifistas desde antes de la era cristiana (Lao Tse en China, Jeremías frente a la agresión babilónica, los griegos, los Evangelios), se sostenían posiciones próximas al rechazo de la violencia y próximas al pacifismo. Los cristianos del primer siglo se oponían a participar en el ejército romano por razones religiosas que les prohibían realizar actos violentos que exigía la milicia, en la edad media la iglesia católica cambió radicalmente de posición. Los comienzos del pacifismo moderno se remontan a los primeros anabaptistas y menonitas. En el marco de las luchas religiosas en Francia del S. XVI, el católico Ettiene de la Boetie defendió las tácticas de resistencia no-violenta contra la tiranía, en el S. XVII los cuáqueros ingleses intentaron aplicar el pacifismo a su organización política y desarrollaron una comunidad desarmada en Pennsylvania, que durante dos generaciones se vio libre de guerras con los indígenas. Durante el Siglo XIX y el XX las teorías racionalistas próximas al pacifismo llegaron a su punto culminante, W. Godwin anarquista primitivo planteaba el carácter inmoral e irracional del llamamiento a la fuerza, incluso contra la injusticia, la violencia revolucionaria era calificada como una contradicción en los términos. Shelley llamaba a los obreros ingleses a

3. Véase Bobbio Norberto, El Problema de la Guerra y las Vías de la Paz, Gedisa 1982. 
luchar contra la explotación por medio de huelga de brazos caídos. Tolstoi fue un gran pensador del pacifismo, apoyado en una interpretación anarquista de los evangelios. Después de la primera guerra mundial se fortaleció el movimiento pacifista, la decepción frente a la guerra como institución produjo hechos como el "juramento de Oxford", por el cual miles de jóvenes ingleses prometían, en la década del 20 y el 30, no volver a combatir por la patria y el rey.

En 1919 surgió un gran movimiento pacifista dirigido por Mohandas K Gandhi, de inspiración religiosa hindú, del Nuevo Testamento y de la obra de León Tolstoi ; movimiento de resistencia no violenta contra el gobierno colonial inglés que se prolongó hasta $1947^{4}$.

\subsection{NEXOS HISTÓRICOS ENTRE EL FEMINISMO Y EL PACIFISMO}

La relación entre pacifismo y feminismo se remonta al Siglo XIX, uno de los casos más destacados es el de la socialista francesa Jeanne Deroin que en 1848 contestaba a los hombres la pregunta respecto a lo que quieren las mujeres "queremos construir un mundo nuevo con vosotros, donde reinen la verdad y la paz, queremos la justicia dentro de todos los espíritus y amor dentro de todos los corazones". Durante la guerra de Crimea en 1854, la feminista sueca Frederika Bremmer, que luchaba por la igualdad de derechos, apeló a las mujeres para formar una liga pacifista, argumentando que "por separado somos débiles y solo podemos conseguir poco, pero si extendemos nuestras manos por todo el mundo podemos coger la tierra en nuestras manos como un niño". En 1889, la austríaca Berta von Suttner, sufragista por la paz, escribió “ ¡Dejad las armas!", libro que animó al industrial Alfredo Nobel a instaurar el Premio Nobel de la Paz, ella fue la primera mujer en recibirlo en 1905.

4. Véase Enciclopedia Internacional de las Ciencias Sociales, pág. 542. Tomo 7, op. cit. 
La Liga por los Derechos de las Mujeres francesas, publicaba en su periódico, antes de la primera guerra mundial que "La paz mundial, la armonía social y el bienestar de la humanidad solamente existirán cuando las mujeres consigan el voto y puedan ayudar a los hombres a hacer las leyes". En 1910, el Congreso Internacional de Mujeres Socialistas hizo de la lucha contra la guerra un objetivo fundamental, y lo presentó como propuesta de programa a todos los congresos socialistas; Clara Zetkin y Rosa Luxemburgo, como socialistas internacionalistas pacifistas, se enfrentaron al Partido Socialista alemán que apoyaba la guerra.

Existe una interesante documentación de la lucha pacifista de las mujeres después de terminada la primera guerra mundial y aparecen reseñadas en la historiografía sobre las mujeres que se produjo en las dos últimas décadas del siglo $\mathrm{XX}$. Uno de los hitos más importantes es el escrito "Tres Guineas" de Virginia Woolf. Allí se proponía a las mujeres que anónimamente se dedicaran a subvertir y transformar la sociedad controlada por el hombre, la guerra y el capitalismo, rechazando la identidad nacional a favor de la solidaridad con las demás mujeres, formulaba un verdadero programa de lucha para hacer frente a la amenaza de guerra que se cernía sobre Europa. Por esta misma época, Helena Swanwick publicó también en 1935 su libro "Las raíces de la guerra", afirmaba que las mujeres odian la guerra "porque la guerra las golpea más duramente y tiene muy poco que ofrecerles a cambio". Este movimiento mundial se fortaleció en el tiempo previo a la segunda guerra, pero fue duramente afectado cuando las feministas judías, comunistas, socialistas y pacifistas fueron perseguidas, condenadas a muerte, al exilio y a la cárcel con la llegada del fascismo al poder.

La segunda guerra mundial empezó el 3 de septiembre de 1939, las mujeres se opusieron a ella y en un congreso de mujeres celebrado ese mismo año se concluyó que "los hombres son responsables de la guerra ya que todas las oportunidades de esfuerzo conjunto han sido desperdiciadas". La ruptura provocada por esta atroz guerra, llevó al 
suicidio en 1939 a la Swanwick y también lo hicieron, poco después en 1940, Virginia y Leonardo Woolf5.

Después de la segunda guerra mundial, durante la guerra fría que puso sobre el planeta la amenaza nuclear, se han desarrollado interesantes expresiones del movimiento pacifista, entre los cuales podemos registrar el ecofeminismo en pro de la defensa planetaria y de los recursos naturales así como la lucha contra todas las formas de militarismo. En marzo de 1980, en la primera Conferencia que trató este tema, reunida en Amherst se dijo que, "somos un movimiento que se identifica con las mujeres y creemos que estamos llamadas a cumplir una tarea especial en estos tiempos amenazados. Pensamos que la devastación de la Tierra y de los seres que la pueblan, por obra de las huestes empresariales, y la amenaza de aniquilación nuclear, por obra de las huestes militares, son preocupaciones feministas. Son manifestación de la misma mentalidad machista que pretendía negarnos el derecho a nuestro cuerpo y a nuestra sexualidad y que se apoya en múltiples sistemas de dominación y poder estatal para imponerse ${ }^{\prime \prime 6}$.

\section{ApROXIMACIONES AL CONCEPTO DE PAZ}

El concepto de paz es un concepto sujeto a controversias, tanto para propósitos analíticos como políticos. En la época contemporánea se complejiza aún más, a partir de las reflexiones feministas que vinculan la paz al espacio público y privado y de los aportes del movimiento ambientalista que la ligan a la armonía y el respeto a todas las formas de vida. La pregunta acerca de qué debería incluirse en dicho concepto continúa siendo parte intrínseca de la investigación acerca

5. Véanse Historia de las Mujeres, Una historia propia, de Bonnie Anderson y Judith P. Zinsser, Editorial Crítica 1992, Vol 2. pág. 453, y Jean Duby y Michelle Perrot en Historia de las Mujeres Tomo V, Edit Taurus Santillana, 1993.

6. Véase en Maria Mies y Vandama Shiva Ecofeminismo: Teoría, crítica y perspec- 
de la paz, tocaría entonces preguntarse si se trata de un concepto Euro centrado o Masculinamente centrado.

El concepto tradicional de paz está referido a la ausencia de guerra conseguida a partir del triunfo de uno de los bandos sobre el otro y que instaura e impone un orden por la legitimidad que le otorga la victoria. Construir una definición de paz es una labor difícil, debido a que a la paz le pasa lo mismo que a las conductas positivas de la humanidad, de las cuales se han ocupado escasamente las ciencias sociales, en cambio encontramos múltiples trabajos sobre la guerra. Por esta razón, muchos de los escritos que se encuentran sobre la paz, se refieren por lo general a utopías y al futuro, o bien especulativos y subjetivos en vez de empíricos y analíticos. La Enciclopedia Internacional de Ciencias Sociales, afirma que la multiplicidad de enfoques al respecto está dando cuenta de la radical confusión teórica, que también es reflejo de la complejidad del tema. Así, la formulación de la paz puede clasificarse no sólo por su contenido, sino por quien la formula y en que contexto.

Se distinguen "dos conceptos de paz: la paz negativa, definida como la ausencia de violencia organizada entre grupos humanos y la paz positiva, definida como un modelo de cooperación e integración entre los grupos humanos." No hay que confundir la ausencia de violencia con la ausencia de conflictos, la violencia puede estallar sin conflictos y los conflictos se pueden resolver sin violencia ${ }^{7}$. Se plantea la diferencia entre paz negativa, que es entendida como la ausencia de violencia personal, física y directa, y la paz positiva, definida como la ausencia de violencia indirecta o violencia estructural. Juan Pablo Lederach plantea que la paz positiva es un concepto complicado y lo define "como la combinación de varias ausencias y varias presencias" $^{\prime \prime}$. En éste sentido, el Instituto Interamericano de

7. Lederach, Juan Pablo. (1998). “Construyendo la paz. Reconciliación sostenible en sociedades divididas". Bakeaz: Bilbao.

8. Véase Resolución de Conflictos en Módulos de Educación en Educación Cívica y Derechos Humanos, ED-UCA, IIDH, Embajada de Dinamarca, San Salvador, 1996. 
Derechos Humanos y la Universidad Centro Americana, elaboraron una interesante síntesis. Afirman que se puede leer la paz negativa como la no-guerra, que tiene consecuencias como la necesidad de contar con aparatos militares que garanticen el orden, disuadan al enemigo, y aseguren la defensa del territorio. Entonces la paz es algo que solo puede establecerse mediante la preparación y fortalecimiento de los ejércitos, sólo consiste en evitar conflictos armados en el propio territorio. Esta posición se resume en el dicho "Si quieres la paz prepárate para la guerra". Por el contrario, la paz positiva, equivale a la armonía social, justicia e igualdad y eliminación de la violencia estructural. Esta última entendida como formas de violencia y opresión generadas por las estructuras que organizan la sociedad, que producen desigualdad e inequidad en las relaciones entre las personas, grupos y sociedades, de manera que impide a los seres humanos satisfacer sus necesidades fundamentales espirituales y materiales. Por ello, la paz no es sólo lo contrario a la guerra, sino la ausencia de violencia directa y estructural, la armonía consigo mismo, con los demás seres humanos y con la naturaleza9.

Brock-Utne, combina en su pensamiento la perspectiva del feminismo radical con el feminismo socialista, la paz es un estado en el que existen la paz negativa y la positiva, haciendo notar que los diferentes conceptos de violencia son lógicamente independientes, plantea que analíticamente puede haber un tipo de paz sin la existencia de la otra $^{10}$. Desde la perspectiva ética, el filósofo italo colombiano, Angelo Papaccini afirma que entre la paz y los derechos humanos existe un circulo virtuoso, que hace indispensable la una para que los otros sean posible y, que la vigencia de los derechos humanos son indispensables para que la paz sea plena y duradera.

9. Brock-Utne, B.(1989) en "Feminist Perspectives on Peace and Peace Education". Pergamon Press: New York.

10. Accad Evelyn "Sexualidad y Guerra", Indigo ediciones, París, 1998. pág 125 y Ss. 


\section{ORÍGENES DE LA GUERRA, DESDE UNA PERSPECTIVA FEMINISTA}

En el análisis de las realidades contemporáneas de los fenómenos sociales, es fundamental el aporte que se hace desde la categoría de género. Para el tema que nos ocupa, se trata de aplicar al análisis de la guerra, aportes del pensamiento feminista, de manera que la abordemos desde las raíces más intimas de la cultura, es decir, desde las identidades masculina y femenina.

La feminista libanesa Evelyne Accad analizó las condiciones de la militarización, de la guerra y de la paz, pensando en el despliegue de la sexualidad a través de ellas. Afirma que "la guerra siempre ha fascinado a los hombres". A un nivel muy profundo, la guerra ha sido una manera de existir, según Adam Farrar, ella es la expresión del "deseo masculino"11. Este tema ha sido abordado por diversos especialistas desde Freud hasta Lacan, desde la perspectiva de articulación entre sexualidad y guerra, opresión, poder y agresividad, por otros autores como Georges Bataille, Wilhem Reich, Michel Foucault, Henry Laborit y René Girar.

Más contemporáneamente, la relación entre género masculino y guerra, ha sido tratado por feministas y algunos masculinistas como Keith Thompson, Robert Bly, Cooper Thompson, Thomas Moore, Warren Farrel y Aaron Kipnis ${ }^{12}$. En el campo de la investigación social sobre la guerra, cada vez es más claro que la categoría de género es un elemento determinante en el análisis de los conflictos armados y en la construcción de estrategias y propuestas de paz perdurables. La desconstrucción que hace esta corriente masculinista con respecto a la socialización masculina patriarcal, brinda luces para comprender la trascendencia del aporte de la categoría de género en el análisis de las causas de la guerra y la violencia.

11. Cooke Miriam "Wo-man retellind the war myth" Princeton University Press, New Jersey, 1993, pág. 177.

12. Ser hombre. Edición Keith Thompson, Editorial Kairós, Biblioteca Nueva Conciencia 1993, Barcelona España. 
Cooper Thompson plantea que la violencia es el medio por el que se mantienen las dos fuerzas críticas y más socializadoras en la vida de los muchachos, la homofobia o el rechazo a los hombres afeminados, a quienes se aplica el estereotipo de lo femenino, y que circula con miedo a ser considerado como tal, y la misoginia, que es el rechazo a las mujeres. En síntesis, el rechazo a las cualidades femeninas en el hombre y las femeninas en la mujer es un mensaje abierto: las hembras y todo lo que representan son despreciables. Los marines de Estados Unidos tienen una filosofía que combina la homofobia y la misoginia: "cuando quieras crear un grupo de asesinos varones, matas a la mujer en ellos". Al respecto, el autor plantea la necesidad de una nueva concepción de masculinidad, tarea que califica de ambiciosa pero esencial para la salud y la seguridad de hombres y mujeres, "la supervivencia de nuestra sociedad puede radicar en el hecho de que seamos capaces de enseñar a los hombres a proteger la vida ${ }^{\prime \prime 13}$.

Además de la reflexión de género con respecto a los orígenes de las guerras, otras corrientes del pensamiento feminista, contrastan el dominio de los hombres sobre la tecnología de guerra y su papel activo en las confrontaciones violentas con el rol histórico de las mujeres para lograr la paz. Este parecer se sustenta en ejemplos aportados por la historia, que vienen desde Lisistrata en la antigua Grecia hasta las organizaciones contemporáneas de mujeres contra las armas nucleares (Greenham Common en el Reino Unido, Mujeres de Negro en Israel), pasando por la primera organización de mujeres por la paz surgida en la Primera guerra mundial (Liga Internacional de Mujeres por la Paz y la Libertad) y por las mujeres japonesas que construyeron un campo de paz enseguida de una base militar. Toda esta secuencia confirma la vocación de las mujeres por la paz, el amor por la naturaleza y la vida, así como y el carácter inherentemente agresivo masculino y conciliador femenino.

Otras feministas plantean que los orígenes del conflicto armado, más que en los hombres mismos, se encuentran en las estructuras patriar-

13. Ibid. 
cales cuyos intereses están particularmente representados en la nación. Por lo tanto, la guerra sólo podrá eliminarse con la supresión del patriarcado y sólo habrá paz y sostenimiento de la misma cuando se acaben las estructuras sociales patriarcales y se transformen las relaciones de subordinación y opresión de las mujeres. Un factor asociado tanto al origen como a las consecuencias de la guerra en las identidades, la expresa Bridget Byrne al considerar que "la militarización de las sociedades lleva a cambiar las definiciones de masculinidad y feminidad y a cambiar las responsabilidades de hombres y mujeres. Los conflictos se centran en luchas por poder y recursos", que a su vez tienen una distribución propia a través de las identidades masculina o femenina y que además generan una economía política del conflicto y los procesos de militarización que van resignificando y generando nuevos roles ${ }^{14}$.

En este sentido, es importante saber que las guerras contemporáneas, calificadas como "totales", a diferencia de las clásicas no se desarrollan en un "teatro" delimitado, que conocemos antes del siglo XX, en que los guerreros en el "campo de batalla" se enfrentaban cuerpo a cuerpo. Este hecho tiene diversas implicaciones en la afectación de la población civil no combatiente, en los imaginarios sociales y roles de género. De un lado, la transformación de las imágenes estereotipadas del hombre en el campo de batalla y las mujeres protegidas en sus casas, ahora ellas son las principales víctimas de la guerra, directamente en la guerra o como efecto de la destrucción de sus referentes de vida y tejido social del que formaban parte. De otro lado, las mujeres no solo son víctimas sino son actores directos, a través de la vinculación directa a las filas de uno $\mathrm{u}$ otro bando o a través del esfuerzo por apoyar $\mathfrak{u}$ oponerse a la violencia tratando de sobrevivir en medio de la contienda. Este hecho es registrado por Radhika Coomaraswamy, Relatora Especial sobre la violencia contra la mujer, en su informe de 1998 afirma que cada vez más mujeres ingresan a las filas combatientes, por primera vez en la historia se ha acusado a

14. Byrne, Bridget. (1996). "Gender, conflict and development", Bridge briefings on development \& gender: Holanda. 
mujeres de crímenes de guerra. Tal es el caso del genocidio de Rwanda en el que participaron activamente y algunas perpetraron actos de violencia sexual contra otras mujeres.

La escritora Miriam Cooke afirma que las guerras post modernas revelan la negociabilidad de la guerra y del género como una de sus características definidas. Negociabilidad que se desarrolla a nivel del lenguaje y hace borrosos los límites entre el hecho y la ficción, entre el activismo y los escritos, entre la experiencia y su registro. Por ello, invita a nombrar la presencia y el compromiso de las mujeres en el frente de guerra, con el objeto de corregir distorsiones que han sido necesarias para construir el mito de la guerra como una empresa de hombres. Propone como desafío a los estudios de género reducir el espacio vacío entre realidad y mito $^{15}$.

Otro elemento que permitiría complementar este panorama de transformaciones en la feminidad y la masculinidad en el escenario de guerra, son las implicaciones que la transgresión de códigos tradicionalmente asignados a la feminidad (con respecto al cuidado de la vida propia y otros aspectos de la identidad femenina), tienen para las mujeres de la guerra, la emulación en los patrones de la masculinidad guerrera asumidos por las mujeres en combate, etc. Por ejemplo en Colombia se calcula que el 30\% de los integrantes de las FARC (Frente Armado Revolucionario de Colombia) son mujeres jóvenes, caso similar se presentó en la guerra de El Salvador.

Acá habría que retomar elementos aportados por la reflexión acerca de la sicología de la guerra. Para la sociedad civil de mujeres, es fundamental conocerlos, ya que ayudan a avizorar el futuro y a entender el presente del proceso colombiano. $\mathrm{Al}$ respecto, Lawrence Le Shan, plantea que "Cuando estamos en guerra, nuestra percepción de la realidad - de lo que somos, de lo que ocurre en el mundo que nos rodea - es distinta a la que comúnmente tenemos en tiempos de paz. Cuando ocurre este desplazamiento, la

15. Cooke, Miriam. (1993). Op. Cit. pág. 177. 
guerra se hace mucho más difícil de prevenir o de detener. El comprender cómo y por qué ocurre este cambio nos permitirá reconocer los signos que indican que una sociedad se está preparando para la guerra y apreciar qué debemos hacer para detener ese movimiento" ${ }^{\prime \prime 16}$.

La Accad, afirma al respecto que, "la muerte heroica alimenta el imaginario de los combatientes y el de los civiles que sueñan con combatir, reforzando la idea de que la muerte es un juego. El exorcismo de la guerra, el intento de deshacerse de ese lado malo, solo son juegos de esa estrategia general ${ }^{\prime \prime 17}$.

\subsection{Precisiones SObRe las CaRACterísticas de la Guerra Postmoderna}

Se llaman guerras postmodernas aquellas que se desarrollan dentro del período posterior a la segunda guerra mundial, en la llamada guerra fría y dentro de este período en la fase post colonial; es decir después de los procesos de liberación de las colonias de los países del llamado primer mundo en Africa, Asia y América Latina, a finales de los sesenta y principios de los setenta. Es importante traer a colación el hecho de que es precisamente en este período cuando se logra la aprobación en la Asamblea General de la ONU, de los Pactos de los Derechos Humanos, cuya consideración quedó aplazada desde 1948 y su entrada en vigencia sólo viene a ocurrir a finales de la década del 70. Podría afirmarse que la descolonización del mundo y la solución de las guerras y procesos de liberación nacional, fueron el contexto de tensiones de poder que, en el marco de la Guerra Fría, aplazaron el compromiso mundial con los Derechos Humanos y la Paz. Fue solamente en la década del 90, a propósito de la Conferencia Mundial de Derechos Humanos celebrada en Viena, cuando se logra que los países industrializados firmen los ins-

16. Lawrence LeShan "La psicología de la Guerra. Un estudio de su mística y locura." Editorial Andrés Bello, Ejemplar fotocopiado. Sin fecha.

17. Op. Cit. 
trumentos de protección de estos derechos, contenidos en los diferentes pactos y convenciones.

Para Miriam Cooke, las guerras postmodernas "son los productos, así como los consumidores de la revolución tecnológica, proveen espacios discursivos múltiples en los cuales los individuos pueden encontrar, retener e interpretar los actos. En estas guerras las mujeres, que siempre han sido parte de las guerras, pueden articularse más fácilmente y registrar su participación". Una característica fundamental atribuida en las guerras postmodernas a los combatientes es el empoderamiento individual como paradoja moral, "nuevos individuos se empoderan y su empoderamiento y centralización descentra a los otros. ¿Quiénes son estas nuevas personas? Es difícil de responder pero entre ellos se encuentran grupos terroristas, guerrilleros, grupos de liberación nacional, militares. Sin embargo, pueden suceder mutilaciones dentro de uno $\mathrm{u}$ otro grupo. Lo que es fundamental entender de la guerra postmoderna es la fluidez de este modelo, los individuos que han subido pueden igualmente bajar. El combatiente postmoderno puede ser en cierto punto eliminado. Ahora, esta desaparición, puede ser parte de un nuevo proceso de reagrupación. Como un virus, los combatientes han aprendido a mutar para no desaparecer. ¿Cómo puede el estado eliminar a la guerrilla cuando un día es un terrorista y al otro un fiel soldado del ejército? La movilidad individual y el empoderamiento crean la anarquía pero también el orden, no como paradojas sino como varias presencias simultáneas y potenciales" ${ }^{\prime \prime 18}$.

Los combatientes postmodernos están encontrando un espacio para cometer o simplemente hablar de cometer actos violentos. De acuerdo con Juan Corradi, la violencia de hoy en día es diferente, no necesariamente porque es más brutal, sino porque es continua, total e indiferenciada. La violencia es "una narrativa de la destrucción que alimenta la cultura del miedo". La centralidad de la violencia en sí misma no implica simplemente que su práctica debe

18. Cook M. Op. cit. 
continuar indefinidamente. Las victorias y puntos particulares de la historia permanecen abiertos a infinitas negociaciones. En el caso del Vietnam, tanto un lado como el otro celebran su victoria. El problema no es que haya o no acciones más conclusivas, sino que su representación esté más difundida por los medios. Lo importante se relativizó y la información crea el imaginario de victoria o derrota.

La misma autora sostiene que "Por otra parte, las guerras se han homogeneizado dado el hecho de que la guerra se presenta cada vez más como negociable. Las reglas que una vez distinguieron cómo las guerras empezaban y terminaban, cómo la paz era distinta de la noguerra, cómo se participaba, quién era el enemigo, cómo los roles de hombres y mujeres cambiaban completamente cuando se estaba en tiempos de paz y en tiempos de guerra, se han roto sistemáticamente. Los medios son instrumentos que proyectan la nueva realidad de la guerra: revelan la inestabilidad de los mitos de la guerra y los héroes. Mientras que las guerras anteriormente codificaban una estructura binaria en el mundo, designando tareas de género específicas y áreas de género específicas en las cuales las tareas debían llevarse a cabo, ahora las guerras hacen todo lo contrario, cuestionan los modelos binarios que antes inspiraron: guerra/paz, bueno/malo, frente/hogar, combatiente/no-combatiente, victoria/derrota. El desafío a estos modelos binarios revela que tanto el género como la guerra son estructuras negociables dentro de las cuales los significados son construidos y desconstruidos. Las guerras postmodernas participan en enfatizar y cambiar un sistema de significados que había estado allí hasta la aparición de la revolución nuclear"119.

19. Ibid. 


\section{CONDICIÓN DE LAS MUJERES EN LAS GUERRAS CONTEMPORÁNEAS}

En las dos últimas décadas, se ha acentuado la preocupación mundial por los derechos humanos, como condición de posibilidad para garantizar un planeta en paz y debidamente conservado, integrado por naciones respetuosas de la dignidad humana y la democracia. En este sentido, las Naciones Unidas y los sistemas continentales (Comunidad Europea, Comunidad Africana, Organización de Estados Americanos) vienen adelantando políticas en tal dirección, así como para eliminar las diferentes formas de discriminación étnica, racial y religiosa, en especial, contra las mujeres, niños y jóvenes. Esta lucha se encuentra asociada al lema de igualdad y desarrollo, como requisitos para garantizar una paz sostenible. Este proceso circula en dos direcciones: la paz es posible si se elimina la discriminación, y para reforzar y garantizar los derechos de los grupos discriminados, es necesaria la paz, ya que en tiempos de guerra son ellos los más vulnerables.

Los programas y cumbres mundiales de las Naciones Unidas referente a los derechos de las mujeres, se han ocupado de manera especial de la condición femenina en tiempos de guerra. Al respecto, la Cuarta Conferencia Mundial sobre la Mujer, celebrada en Beijing en septiembre de 1995, expresó que "El mantenimiento de la paz y la seguridad a nivel mundial, regional y local, junto con la prevención de la política de agresión y de depuración étnica y la solución de los conflictos armados, tienen importancia decisiva para la protección de los derechos humanos de las mujeres y niñas, así como para la eliminación de todas las formas de violencia contra ellas y de su utilización como arma de guerra" ${ }^{20}$.

20. Véase Informe Cuarta Conferencia Mundial sobre la Mujer, Naciones Unidas A/Conf.177/20. 
La Conferencia Mundial de Derechos Humanos, celebrada en 1993, creó una Relatoría Especial que se ocupa de hacer el seguimiento y elaborar informes relativos a la violencia contra la mujer como atentado contra los derechos humanos. En 1998, la Relatora Especial, Radhika Coomaraswamy presentó el informe sobre "La Violencia contra la Mujer en tiempos de Conflictos Armados", este documento, junto con observaciones sobre la condición femenina en el marco de la guerra, nos permiten sistematizar la manera cómo el conflicto armado afecta a la población femenina. Veamos algunos de los aspectos más relevantes:

- La violencia contra las mujeres entre los ejércitos conquistadores, constituye una práctica aceptada por tácita tradición, el culto de las instituciones militares a lo masculino es, por definición, antifemenino. Se crea así un ambiente hostil a las mujeres.

- La violencia sexual contra las mujeres tiene varios propósitos simbólicos, afectar el "honor" del enemigo, humillarlo, desmoralizarlo y mostrar como victoria sobre el otro bando que no ha sabido proteger a sus mujeres. Al mismo tiempo, esta practica sirve para exacerbar el odio al enemigo e incrementar su imagen demoníaca, también se usa para aterrorizar poblaciones e inducir a los civiles a abandonar sus tierras, huir de sus hogares y aldeas.

- La violencia sexual contra las mujeres, además de las violaciones sistemáticas o incidentales, se expresa en hechos como la prostitución forzada y la esclavitud sexual de las mujeres del enemigo. La fecundación forzada es utilizada como arma para humillar aún más al enemigo, obligando a la víctima de la violación a engendrar un hijo del victimario. Los matrimonios forzados y la intimidación del que son víctimas las mujeres, son otras formas de agresión sexual. Estas son prácticas institucionalizadas en muchas guerras, que además se justifican como mecanismo para evitar la violación de civiles inocentes.

- La mujer es forzada a una relación sexual con un combatiente o soldado a cambio de alimentos (para ella misma y su familia), alojamiento, ropa o protección y seguridad. 
- El aborto forzado y otras formas de castigo frente al embarazo, se aplican a las mujeres de las propias filas.

- Trabajos domésticos forzados expuestos a la violencia sexual.

- En el caso de éxodos masivos o desplazamientos forzados, las mujeres y las niñas están expuestas y son objeto de violaciones por parte del bando contrario o del bando interesado en el territorio que ocupan, de los bandidos en los caminos y de sus propios compañeros de desplazamiento.

- Las mujeres desplazadas están particularmente expuestas en su salud sexual y libertad reproductiva, se registran abortos infectados, embarazos indeseados, infecciones, enfermedades de transmisión sexual, VIH Sida, traumas sicológicos, depresiones, suicidios, pesadillas, insomnios y miedo crónico. El incremento de gestaciones y partos son en la mayoría de casos, producto de los traumas de la guerra y el desplazamiento forzado, de la carencia de asistencia en salud psicoafectiva, sexual y reproductiva.

Consecuencias económicas y sociales que afectan material y psicológicamente a las mujeres:

- Asumen la jefatura de hogar, debido al reclutamiento forzado o la huida del compañero o esposo.

- La cultura de la violencia que predomina en tiempos de guerra se desplaza a la vida familiar y comunitaria.

- Se restringe el acceso a los servicios básicos de alimentación, salud, educación o se hace engorroso y difícil acceder a ellos.

- Los programas de reconciliación y restauración de países afectados por la guerra tienen que visibilizar y considerar los daños socio afectivos ocasionados a las mujeres y niñas, en su condición de tales. 


\subsection{EXPERIENCIA DE LAS MUJERES CENTROAMERICANAS}

El movimiento feminista ha logrado estructurar y escribir una serie de reflexiones sobre la experiencia de mujeres, tanto en el marco del conflicto armado como en el proceso de negociación y de ejecución de los acuerdos de paz. Es una lectura feminista de la distribución y manejo del poder, al interior de los grupos armados (de los que ellas hicieron parte) y en el proceso de negociación, en una sociedad caracterizada por un acendrado machismo.

Las mujeres por la dignidad y la vida (Las Dignas), es una organización feminista salvadoreña, que ha aportado a la escritura de esa historia inédita. En un escrito (sin fecha) de la revista "Las Mujeres ante, con, contra, desde, sin, tras el poder político", ellas hacen una serie de reflexiones con respecto a Los Acuerdos de Paz y la Transición Democrática suscritos entre el FMLN y el gobierno salvadoreño en 1992. Acuerdos que pusieron fin a una guerra civil de 12 años y abrieron las posibilidades para la transición de un régimen autoritario a uno democrático. Valoran el que estos acuerdos hayan iniciado la fundación democrática, "los Acuerdos de paz nunca pretendieron resolver todos los problemas de la sociedad salvadoreña. Así la injusta distribución de la riqueza en el país, el problema estructural de la pobreza, el deterioro ecológico y las desigualdades existentes entre hombres y mujeres, entre otros, no fueron contemplados en los acuerdos". Hacen una detallada reflexión sobre los problemas y resultados de los acuerdos "si bien es cierto que los Acuerdos de Paz no fueron resultado de una negociación entre los actores políticos en su conjunto, sino entre las partes político militares enfrentadas en la guerra, que durante el proceso de negociaciones la sociedad civil se limitó a imponer al gobierno y al FMLN el imperativo de la urgencia de la paz y la democracia; no menos cierto es que a lo largo de estos años de transición democrática, en muy escasas ocasiones los movimientos sociales han demostrado disposición de apropiarse de los acuerdos y capacidad para presionar a las partes para que respondan por los compromisos." 
Haciendo un recuento del proceso con respecto a las mujeres y afirman que:

- Los Acuerdos están escritos totalmente en masculino y no hay referencia alguna a las mujeres, las políticas fueron diseñadas en neutro y aplicadas en masculino. Ello a pesar de la presencia de mujeres en las comisiones negociadoras y de representar el $53 \%$ de la población, el 30\% de combatientes del FMLN y más del $60 \%$ de la población civil que apoyó a las guerrillas.

- Los acuerdos obviaron las relaciones de poder y subordinación entre hombres y mujeres, elemento importante para entender el autoritarismo de la sociedad salvadoreña, así como las particularidades de la reinserción civil y productiva de las mujeres excombatientes. Se obvia el enclaustramiento doméstico de las mujeres, la irresponsabilidad paterna, la sobrecarga de trabajo femenino, el trabajo agrícola de las campesinas, las discriminaciones en el trabajo remunerado y la educación, los obstáculos a la participación política femenina, la violencia de género institucionalizada, la conquista de derechos humanos elementales de las mujeres (la libertad de circulación, ser dueñas de su cuerpo, su sexualidad y capacidad reproductiva).

- Las mujeres que trabajaron la tierra durante la guerra fueron excluidas, se tituló a los hombres.

- La capacitación laboral en el proceso de reinserción se orientaba a oficios domésticos, tradicionalmente femeninos. Para acceder a determinados programas de reinserción se requerían ciertos rangos militares adquiridos durante la guerra, dado que las mujeres (mayoritariamente ex cocineras, operadoras de radio y personal sanitario) no accedieron a los puestos de mando militar o político militar en la misma proporción que los hombres, sus condiciones de reinserción a la vida civil, han sido notoriamente peores que el de los hombres.

Las Mujeres por la Dignidad y la Vida (Las Dignas) de El Salvador realizaron un evento regional en diciembre de 1995, publicando sus 
conclusiones en "Montañascon Recuerdos de Mujer. Una mirada femi nista a la participación de las mujeres en los conflictos armados en Centroamérica y Chiapas". En este evento, "desnudamos las premisas de los proyectos revolucionarios a los que dimos la vida, hablamos de los temas prohibidos en el código revolucionario, de los malestares y bienestares personales que nos arrojó el compromiso total con esa causa, y las herencias que nos dejó, con las que cargamos para bien y para mal en los intentos de construir fuerza feminista en nuestros respectivos países". Unas participaron con sus testimonios y comentarios, otras con reflexiones producto de la experiencia como dirigentes revolucionarias o como investigadoras feministas.

Es un interesante trabajo de desconstrucción y resignificación de las experiencias vitales de las mujeres en los procesos revolucionarios, desde una perspectiva feminista. Presenta una valiosa secuencia de problemas y preguntas sobre el proceso revolucionario, los imaginarios circulantes en el mundo de la montaña y en el país, las identidades masculinas y femeninas en el escenario de la confrontación, la subjetividad en los proyectos revolucionarios, el impacto de la guerra en la sexualidad y la maternidad de las mujeres salvadoreñas, las tensiones entre feminismo y revolución, la identidad étnica y las mujeres en el proceso revolucionario guatemalteco.

Todo el evento giró en torno a cuatro ejes temáticos: la manera en que los proyectos revolucionarios incluyeron o no la perspectiva de género, las formas en que los movimientos de mujeres expresan el legado de esos proyectos, las concepciones y vivencias de la sexualidad y la violencia en tiempos de guerra, y las concepciones y prácticas maternales en estos contextos. A manera de síntesis, presentamos algunas de las conclusiones del evento.

\subsection{Situación de las Mujeres}

\section{EN EL PROCESO DE PAZ COLOMBIANO}

Registramos para la reflexión algunos elementos de la difícil coyuntura colombiana, ubicada en el marco de un proceso tortuoso y prolongado que nos espera para lograr la paz. 
En primer término, es necesario hacer hincapié en los importantes logros conseguidos:

- La propuesta de negociación política del conflicto armado, que tanto ha animado el movimiento ciudadano de paz, no solo es una necesidad sino que ha sido posible ponerla en movimiento. Ello, a partir de la generación de un clima de confianza y aproximación entre las FARC-EP (Ejército Popular) y el gobierno (despeje de una zona de distensión, acuerdo acerca de unos temas de agenda y metodología para abordarla), y el inicio del proceso de conversaciones en una Mesa de Dialogo y negociación, integrado paritariamente, y vinculado mínimamente con el movimiento de paz y la población civil.

- Se ha avanzado en un proceso de conversaciones y de creación de un clima de confianza (propuesta metodológica con el ELN - Ejército de Liberación Nacional), en la delimitación de un área de encuentro y convivencia para la realización de la Convención Nacional con la sociedad civil, en la concertación y el empeño actual para sortear las dificultades, tensiones y contradicciones, propias a procesos de esta naturaleza.

- Se generó un clima de expectativa y seguimiento de este proceso, por parte del movimiento social y ciudadano de paz y de sectores de la opinión pública nacional e internacional.

- Otra fortaleza de la coyuntura lo constituye el esfuerzo del movimiento social y ciudadano por la paz, que desde la cotidianidad trabaja ardua y creativamente por la paz con justicia y equidad social. Para hacerse oír y respetar por los actores del conflicto armado, para reafirmar su autonomía, para no delegar su propia representación y para ser incluido como tercer elemento estructur ral del escenario de la mesa de conversaciones y de negociación del conflicto armado.

Sin embargo, este proceso tiene dificultades y carencias que es necesario precisar, en la perspectiva de contribuir a su solución y de animar el proceso planteando alternativas: 
- Es un proceso caracterizado por un manejo estatal y de la insurgencia, poco inclusivo y con carencias para concertar con el movimiento ciudadano por la paz y la población civil afectada por el conflicto. Se mueve en los cánones tradicionales de la negociación entre cúpulas de la confrontación estado-insurgencia.

- Es un proceso que tiene serias deficiencias en la estrategia comunicativa y pedagógica para crear puentes y una base social y política que anime eficazmente el proceso.

- Es una estrategia que se mueve en los imaginarios pre modernos, que no incorpora ni metodológica ni conceptualmente el tema de la diferencia y la diversidad. Esto se hace evidente con la ausencia tanto de los grupos históricamente discriminados en razón del género, la etnia y la edad, como de los aportes propios de la lucha de estos sectores por la dignidad y derechos humanos. Tanto en la Comisión Temática (C.T.) como en la Mesa de Diálogo y Negociación (FARC EP) las mujeres estuvieron ausentes. Ello hasta que el Consejo Nacional de Paz y las FARC designaron a la C. T representantes mujeres, hecho que refleja el grado de importancia y conciencia que en materia de género tienen las partes.

- La grave degradación del conflicto armado colombiano y las diversas formas de barbarie que lo caracterizan, evidencia la necesidad de introducir elementos urgentes. Esto es, abordar la emergencia humanitaria que se vive en casi todo el territorio del país, urgencia de concertar el cese al fuego multilateral y, las condiciones de sostenimiento material de los ejércitos involucrados en las conversaciones para el cese de agresiones contra la población civil (desapariciones, secuestros, desplazamiento forzado, extorsiones, asaltos, saqueo, destrucción de bienes civiles, etc.).

- Otra gran dificultad es la apuesta de la comunidad internacional para la solución del conflicto colombiano, permeada más por el problema del tráfico que por el consumo de estupefacientes de los países industrializados. Apuesta que se mueve entre las tensiones de la propuesta que busca la agudización de la guerra (poniendo en segundo orden la intervención social, liderada por el gobierno 
de los EEUU) y la propuesta que busca una intervención agresiva en el área social (minimizando las estrategias militares, liderada por los países de la comunidad europea, Japón y Canadá), pero que todavía no están suficientemente claros y decididos al respecto.

- Otra dificultad fundamental es la exacerbación de las tensiones sociales y regionales provocada por el incremento de la miseria y la desigualdad, producto de la aplicación del modelo neoliberal forzado por las agencias financieras internacionales.

Ahora bien, en la perspectiva de lograr una paz sostenible, es importante ubicar las implicaciones mínimas con respecto a las mujeres y la perspectiva de género. Partimos de la tesis que los orígenes de la injusticia e inequidad social, y del conflicto armado, más que en los hombres mismos, se encuentran en las estructuras patriarcales. Sólo habrá paz y sostenimiento de la misma, cuando se acaben las estructuras sociales patriarcales, se transformen las relaciones de subordinación y opresión de las mujeres y se resignifiquen las masculinidades y feminidades. Todo ello hará posible una sociedad justa, equitativa, respetuosa de la diferencia, con capacidad para resolver pacífica y creativamente sus conflictos, en armonía con la naturaleza.

Respecto a las implicaciones en el futuro próximo, en los diálogos y negociación política del conflicto armado y social, y en la concertación de la sociedad que necesitamos y soñamos, el movimiento de mujeres ha trabajado por:

Visibilizar la condición de las mujeres, en su diversidad étnica, social y de edad.

En el marco de la guerra, como población civil afectada por el conflicto armado, con énfasis en la afectación humanitaria del que son víctimas. Las consecuencias económicas y sociales del conflicto armado afectan material y psicológicamente a las mujeres. Asimismo, la cultura de violencia que predomina en tiempos de guerra se desplaza a la vida familiar y comunitaria. 
En los escenarios de toma de decisiones con respecto a la paz. Visibilizar la ausencia de las mujeres, tanto al interior del movimiento ciudadano por la paz, como en el estado y los demás actores del conflicto armado. Carencia de una participación equitativa de las mujeres, tanto de la sociedad civil como de las mujeres de la guerra. En este sentido se exige la participación equitativa, aplicando la filosofía y los parámetros de la Ley de cuotas que fija en un mínimo aceptable del $30 \%$.

Otra estrategia con respecto a la visibilización de la condición de las mujeres es la introducción de la perspectiva de género en todos estos escenarios. En esta dirección, el Movimiento Social de Mujeres solicitó a la Comisión Temática del proceso de conversaciones y negociación con las FARC, la realización de una Audiencia Pública especial sobre Mujer y Economía. Se presentaron dos ponencias centrales, para consideración de la Mesa de Diálogos y Negociación, sobre mujer y empleo, las que articularon las experiencias del movimiento social de mujeres, del feminismo y de las académicas. En primer lugar se logró visibilizar para el país, los actores, el gobierno y las propias mujeres, que somos una fuerza social importante, con tesis propias, con capacidad organizativa. Se introdujo una dialéctica simbólica en las Audiencias Públicas, vinculando otras formas de comunicación estética al proceso. Esta audiencia ha sido calificada por diversos evaluadores como la mejor organizada y colocada como ejemplo a seguir en este difícil proceso de movilización ciudadana por la paz. Las mujeres avanzaron en su empoderamiento para continuar esta labor en todos los escenarios de negociación y búsqueda de la paz.

También se han cursado comunicaciones a la Comisión facilitadora de la sociedad civil con el ELN y al COCE (Comando Central) para animar la inclusión del movimiento de mujeres en este escenario, así como para la introducción de la perspectiva de género al análisis de la realidad del país y a la búsqueda de alternativas sostenibles. 
El empoderamiento de las mujeres en el proceso de paz

Desarrollar estrategias comunicativas de carácter informativo y pedagógico dirigidas al movimiento de mujeres, a las mujeres no organizadas, a los escenarios de diálogo y negociación para incorporar la perspectiva de género y de etnía, como transversal en el proceso de negociación política y de construcción de la paz. Trabajar por posicionar la capacidad comunicativa de las mujeres en la construcción de puentes entre los actores del conflicto. Desarrollar propuestas para lograr que las mujeres de la guerra tengan acceso a los avances logrados mundialmente por el movimiento de mujeres, para que comprendan la importancia de incorporar la perspectiva de género y lograr la equitativa participación de las mujeres en los lugares de toma de decisiones.

Documentar la memoria histórica de las mujeres afectadas por el con flicto en el marco del proceso de justicia y resarcimiento de los daños morales y materiales ocasionados por crímenes de la humanidad en el marco del conflicto social y armado que afecta al país.

Desarrollar estrategias de protección para las mujeres perseguidas por la lucha por la paz y las mujeres afectadas por el conflicto armado, con el apoyo del movimiento internacional de mujeres y la comunidad de países. 
DinOra Aguiñada DERAS

\section{UNA MIRADA FEMINISTA SOBRE \\ LA PARTICIPACIÓN DE LAS MUJERES EN LA guERra. El CASO DE El SALVADOR.}

UN REGARD FÉMINISTE

SUR LA PARTICIPATION DES FEMMES DANS LA GUERRE

Cette intervention aborde la reconstruction de l'identité féminine des excombattantes, des guerilleras, des "retournées» et des réfugiées. Cette reconstruction se réfere aux ruptures des normes traditionnelles survenues pendant la guerre dans le domaine de la sexualité, la maternité et le deuil.

\section{LA REALIDAD NACIONAL \\ DESPUÉS DEL CONFLICTO ARMADO}

El rescate de las repercusiones que la guerra provocó en la identidad y subjetividad de las mujeres, no puede desligarse del momento de desastre nacional que se vive en El Salvador. El dolor, el miedo y la tristeza, a causa de las muertes y desapariciones de seres queridos en el reciente terremoto, remueven y descubren los dolores guardados, uniéndose a la desesperanza dejada por la guerra.

Al mismo tiempo, las condiciones de desigualdad, injusticia, marginalidad económica, social y política que generó la reciente guerra, 
permanecen prácticamente intactas. Los niveles de pobreza se incrementan a causa de la imposición de medidas económicas (privatización de servicios, acelerada dolarización) en condiciones macro económicas totalmente desfavorables, poniendo a prueba de manera constante la fragilidad de la democracia.

Los acuerdos al que se llegaron para dar fin a los 12 años de guerra, en su mayoría no se cumplen, el país mantiene un clima de violencia y autoritarismo. Ello se percibe más claramente en las reformas del sistema jurídico, se modifica sustancialmente las leyes como procedimientos pero se imposibilita su ejecución. Así, prevalece una práctica política jerárquica y dominante. Es cierto que se han experimentado cambios en el ejercicio político institucional de sectores antes enfrentados, pero no existe un cambio sustancial en las prácticas cotidianas de hacer política.

A causa del conflicto, miles de víctimas se enfrentan, una vez más, a una situación extrema que repercute en la convivencia personal y social del país. Los programas de apoyo y reparación para familiares víctimas del conflicto armado fueron sólo un espejismo que terminaron siendo una burla para la dignidad de las personas. Estas, en su mayoría mujeres, quedaron en segunda fila de los programas de reinserción social, los que fueron diseñados y aplicados con una lógica masculina. Actualmente, se repite la impunidad y autoritarismo en la entrega de víveres, medicamentos y enseres para la sobrevivencia de los damnificados del terremoto, la empresa privada y la fuerza armada acaparan el control de las donaciones y privilegian a sus seguidores.

La Asociación de Mujeres por la Dignidad y la Vida, nace precisamente en esta década de pos conflicto. El abanico de nuestras experiencias ha sido construida, de un lado, en tanto mujeres que participamos en la asociación y de otro lado, en tanto facilitadoras de espacios y procesos con mujeres de zonas urbanas y rurales, que participaron o fueron afectadas (directa o indirectamente) por el conflicto armado. Como organización feminista y como parte de esta 
historia, reflexiona y hace lecturas de aspectos que los informes oficiales no toman en cuenta, elabora propuestas para hacer sustancial la democracia con equidad genérica. Estudia temas como la maternidad, sexualidad, subjetividad y discriminación de género en los programas de reparación e inserción, aspectos que no preocuparon a los creadores y ejecutores de los programas y políticas de la pos guerra. Asimismo, realiza investigaciones que plasman la situación actual y las consecuencias para las mujeres. En este marco, queremos compartir las experiencias de los esfuerzos de recuperación de la memoria colectiva que contribuyan a establecer nuevas relaciones sociales entre las mujeres y hombres, haciendo más cercana una pedagogía de paz y equidad.

En esta exposición, abordaremos de manera general los propósitos del conflicto armado y la participación de las mujeres. Trataremos específicamente la situación de las mujeres guerrilleras, colaboradoras del FMLN ${ }^{1}$, refugiadas y retornadas. Asimismo, analizaremos la sexualidad, la maternidad y los procesos de duelo en tanto aspectos significativos de la identidad y subjetividad femenina que fueron removidos y que afecta la convivencia y el ejercicio de la ciudadanía de las mujeres.

\section{LOS PROPÓSITOS DEL CONFLICTO}

Procurar mejores niveles de vida, construir una sociedad justa y humana, y el cese a la represión política, fueron los propósitos del conflicto.

La imposibilidad de establecer procesos electorales limpios y el cierre de todos los espacios legales para la crítica y la lucha política, provocaron la radicalización de las demandas y los métodos de lucha de los sectores sociales. Se crearon estructuras armadas que planteaban construir un partido político que combinara la lucha política, militar y la

1. Frente Farabundo Martí para la Liberación Nacional. 
del movimiento social. En este último, se encontraban diferentes organizaciones de mujeres que, en su condición de madres pobres, reivindicaban luchas especificas.

Los programas de las organizaciones político militares no incluyeron las demandas de las mujeres y la presencia femenina en la vida política del FMLN fueron escasas. No obstante, durante la guerra surgen diferentes organizaciones de mujeres, vinculadas a las expresiones políticas del FMLN. Al finalizar la guerra, dichas organizaciones tratan de entender y aclarar su participación en la lucha política y social, a reflexionar sobre las desigualdades genéricas, sus causas y expresiones en la sociedad salvadoreña. Se dieron acercamientos al feminismo, lo que generó procesos de autonomía respecto a organismos partidarios.

La negociación y los acuerdos de paz, definidos por las cúpulas político militares enfrentadas durante la guerra, ocasionaron desilusion y confusión. No se escuchó la voluntad de los diferentes sectores sociales y mucho menos de las mujeres cuyas demandas fueron excluidas de dichos acuerdos. La población femenina que colaboró con el FMLN no tuvo acceso a la tierra repartida, pues incluyeron únicamente a los "jefes" de familia. Las mujeres que participaron en la guerrilla urbana al no lograr desmovilizarse, no calificaron para obtener los beneficios de la desmovilización, perdiendo así la posibilidad de acceso a beneficios como becas y créditos.

Hacer una lectura critica y revisar los Acuerdos de Paz, a pocos días del pacto, era un verdadero desafío. Estuvimos conscientes de haber participado en muchos acontecimientos de la realidad nacional pero estabamos ausentes en el pacto de caballeros que firmaron el gobierno y el FMLN. 


\section{III.LA PARTICIPACIÓN DE LAS MUJERES EN EL CONFLICTO ARMADO}

Durante la guerra las mujeres se involucraron en varios escenarios políticos. Mujeres guerrilleras, mujeres de las zonas controladas por del FMLN, mujeres refugiadas, mujeres comandos y mujeres para la representación internacional. Dependiendo del momento histórico y la relación con la estrategia política, cada espacio contó con diferentes características y valoraciones. Puntualizaremos tres de ellos.

\section{Las mujeres guerrilleras}

Respecto a la cantidad de hombres, representaban una cantidad desproporcional, la presencia femenina no llegó a superar el 30\% de la población del campamento. En el campamento existía una clara división del trabajo, los hombres estaban principalmente en estructuras militares y las mujeres en tareas de apoyo (cocineras, radistas, médicas, sanitarias, en finanzas y trabajo político de expansión). Pese a ser minoría, las mujeres destacadas asumieron mandos militares, pero el precio físico y emocional que tuvieron que pagar para demostrar que eran capaces de asumir un puesto destinado tradicionalmente a los hombres, fue muy grande. A la base de dichas políticas estuvieron los estereotipos de los roles genéricos.

\section{Las mujeres colaboradoras de las zonas controladas por el FMLN}

Según informes de la Comandancia, el 23\% de los municipios del país se encontraba bajo el control de la guerrilla. Las mujeres colaboradoras se establecieron en los departamentos de Morazán y Chalatenango. Estas zonas, conformadas por mujeres, ancianos y niños, constituían un espacio para oxigenarse y reabastecerse. Las mujeres sostenían la vida de la comunidad (alimentos, educación, salud), además de cumplir con los mandatos "de los muchachos". Su colaboración consistía en la preparación de comida y la compra y traslado de alimentos, medicinas y ropa para la subsistencia de los guerrilleros. La figura masculina se constituye en una imagen de protección más que un apoyo real. 


\section{Las mujeres refugiadas y retornadas}

Se establecieron en varios lugares fuera del país, acá nos referiremos a los refugios de Colomoncagua y Mesa Grande. Estos refugios se encontraban cercados, aislados y despoblados, con una población femenina sustancialmente mayor. Bajo estas condiciones, persistió la división genérica del trabajo, con tareas tradicionalmente masculinas y femeninas. Las mujeres se dedicaban a actividades productivas (crianza de animales, talleres de costura y bordado) y se incorporaron a tareas de vigilancia nocturna para garantizar la seguridad interna de los refugios (cuidado de productos, orden en conflictos familiares, control de bebidas alcohólicas). También estuvieron a cargo de la educación (maestras) y la salud (promotoras de salud) de los refugios, desarrollando actividades de salud preventiva y curativa (higiene básica, limpieza de letrinas, control de la fertilidad). Trabajar en los refugios generó bienestar en las mujeres, pues se sentían útiles y productivas. Los hombres se incorporaron a los talleres de zapatería, sastrería, hojalatería y carpintería. Fueron los niños y ancianos de los refugios quienes se beneficiaron con el resultado del trabajo.

\section{EL DOLOR INVISIBLE DE LA GUERRA: EFECTOS EN LA VIDA DE LAS MUJERES}

\section{A. Rupturas EN lOS MANDATOS SObRE LA SEXUALIDAD}

La sexualidad es uno de los ejes centrales de la subordinación genérica. El control del cuerpo y la sexualidad de las mujeres es uno de los elementos, muchas veces imperceptible, más opresivos y humillantes. La sexualidad en las mujeres es aceptada si se produce en el marco del matrimonio monogámico, heterosexual y destinado a la reproducción humana. Toda sexualidad fuera de éstos marcos es considerada pecado y por lo tanto prohibida. A continuación exponemos las vivencias y rupturas de las mujeres en cada uno de los espacios políticos en que participaron. Es importante destacar que los 
cambios y efectos están marcados por los niveles económicos, educa tivos y la zona (urbana o rural) de procedencia de las mujeres.

\section{Las mujeres guerrilleras}

Para las mujeres combatientes el imaginario y práctica de la sexualidad estuvo ligado al pecado, a la reproducción, caracterizada por una "fuerte represión sexual, ignorantes del funcionamiento de su cuer$\mathrm{po}^{\prime \prime}{ }^{2}$

Durante la guerra se modificó la visión de la pareja. Se aceptaron cambios frecuentes de parejas (tanto a hombres como a mujeres) y se podían mantener fuera del matrimonio. De hecho prevalecieron las parejas legitimadas por el mando. Los estereotipos de familia también se modificaron a partir del momento en que se autorizaron relaciones poligámicas e interrupciones de embarazos. Las relaciones sexuales se permitían siempre que se cumpliera con las normas de silencio, restricción en la demostración de afecto, rapidez en el contacto sexual y sexualidad centrada en el coito. Se distribuyeron anticonceptivos de manera masiva. Contradictoriamente, las mujeres que tenían relaciones promiscuas fueron sancionadas.

Las valoraciones en relación al placer sexual, estuvo mediatizado por el afecto.

Los cambios vividos en el ejercicio de la sexualidad durante la guerra aún no han sido integrados de manera positiva. No se rescata el placer y beneficio obtenido en ese tiempo sino los malestares que generó el haber roto con esos mandatos sociales. Generalmente existen sentimientos de culpa y vergüenza.

\section{Las mujeres colaboradoras de las zonas controladas por el FMLN}

En ellas prevaleció el silencio respecto a su sexualidad, pues ésta no amenazó la vida de los campamentos, se desarrolló de manera 
tradicional. Las mujeres hablan poco y concretamente en relación al tema. Las ideas que sostienen reflejan mitos y prejuicios sobre la sexualidad, por ejemplo el que las mujeres tienen que conservar su virginidad.

\section{Las mujeres refugiadas y repobladoras}

A causa de la falta de hombres, la comunidad se encontraba como insegura, razón por la que no constituía escenario propicio para el ejercicio de la sexualidad. Las mujeres repobladoras se enfrentaban a la ausencia total de hombres, su vida sexual cambió, dándose la expresión más abierta de los afectos, sobretodo en mujeres jóvenes. El trabajo doméstico vuelve a ser la actividad central para la mayoría de mujeres y tarea exclusiva para un grupo reducido. Por esta razón, la participación de las mujeres en los espacios de aprendizaje y organización comunitaria (repoblaciones) disminuyó drásticamente. Sin embargo, la solidaridad y la posibilidad de aprender actividades que nunca habían desarrollado, por considerarse masculinas, son algunas de las valoraciones más frecuentes que las mujeres manifiestan de su vida en los refugios. Ello no disminuía el vacío de libertad, que era lo que más les agobiaba y motivaba para retornar. Así, la posibilidad de circular con libertad y las añoranzas familiares eran las motivaciones fundamentales y comunes para retornar.

En conclusión, es importante señalar que no obstante a las dificultades y penas, la incorporación de las mujeres a la lucha armada rompió en la práctica con las normas tradicionales de comportamiento sexual que se exigen a las mujeres. A pesar de estos cambios, las reflexiones no tenían un contenido liberador ni referentes progresistas. Dichas experiencias, afligen ahora a las mujeres con fuerte dosis de negatividad y culpa.

\section{B. RUPTURAS EN LOS MANDATOS SOCIALES SOBRE LA MATERNIDAD}

La maternidad es un punto central de la subordinación femenina. En efecto, el cuidado afectivo y emocional de los otros, específicamente de la familia, se convierte en un mandato de la feminidad 
tradicional. Esta imagen presume que todas las tareas relacionadas con el cuidado tienen que ser asumidas exclusivamente por la mujeres.

\section{Las mujeres guerrilleras}

El embarazo implicaba la expulsión del ejército, se les recomendaba posponerlos y evitar las relaciones sexuales. Reforzando la idea de que la concepción era responsabilidad únicamente de ellas, se les presionaba a usar métodos anticonceptivos. Se practicó la interrupción del embarazo de manera clandestina y selectiva, cargada de un gran sentimiento de culpa y, nuevamente, centrando la responsabilidad exclusivamente sobre las mujeres. El deseo de tener hijos estuvo mediatizado por la posibilidad de garantizar el cuidado de éstos. Algunas mujeres se aseguraron que sus familiares cuidaran a sus hijos, para otras representó la posibilidad de descansar, algunas optaron por desertar. De este modo, las mujeres que dejaron a sus hijos, en ese momento no lo vivieron como un abandono sino como la única alternativa para mantener su compromiso político, posteriormente, vivieron con mucha culpa y arrepentimiento. Conductas que reafirmaron la irresponsabilidad paterna de los hombres. Finalizada la guerra, las madres biológicas, las sustitutas y los niños, han vivido situaciones dramáticas. En efecto, con el fin de recuperar a sus hijos y establecer relaciones tradicionales entre madres e hijos, las madres biológicas no tomaron en cuenta los vínculos afectivos establecidos con las madres sustitutas.

\section{Las mujeres colaboradoras}

Para garantizar los relevos de la revolución y el cuidado de los hijos de las guerrilleras, a las mujeres colaboradoras se les alentaba a tener muchos hijos. El papel de madre se extendió a un plano más social, contribuyendo a reforzar el rol tradicional femenino. Ellas rechazaron el uso de los métodos anticonceptivos y, aún más, las interrupciones de los embarazos. 


\section{Las mujeres refugiadas y repobladoras}

Para ellas la maternidad continúa siendo un rasgo elemental de la vida de la mujeres, la que las define como mujeres y la que justifica el ejercicio de su sexualidad. Aunque la disminución del número de hijos de las mujeres jóvenes es evidente, les cuesta aceptar abiertamente el uso de métodos anticonceptivos $\mathrm{y}$, para evitar la crítica y el rechazo de la comunidad, su uso es clandestino.

El encuentro de la figura de madres con la de montañas nutrientes y mantenedoras de una guerrilla, dejaron saldos mínimos e insignificantes reconocimientos. La maternidad dejó una cuenta menos favorecedora para las mujeres, fuerte déficit en el ejercicio de la maternidad y con la soledad y la búsqueda solitaria de la restitución de círculos afectivos y emocionales con sus hijos.

\section{Rupturas En los PROcesos De Duelo}

Durante la guerra, la mayoría de las mujeres se enfrentó a pérdidas significativas (materiales, afectivas, psicológicas), las que generaron sentimientos dolorosos. Igualmente, se enfrentaron a un sinnúmero de situaciones que impedían la expresión de sus sentimientos y la elaboración del duelo.

El duelo posibilita entender, aceptar, e integrar a la vida las pérdidas ocurridas, requiere de un proceso, de tiempo, de expresión de sentimientos, de dudas, de inquietudes. Si este proceso se interrumpe, quedan suspendidos, congelados los dolores, afectando así la convivencia social. Las mujeres generalmente no enterraron a sus seres queridos, no realizaron los rituales tradicionales (velatorio, misas) para socializar el dolor con familiares y amistades. Muchas veces ocultaron la muerte de sus seres queridos para garantizar la sobrevivencia personal. Las condiciones de vulnerabilidad y de constante amenaza de muerte les impidió realizar el duelo.

Otro elemento que contribuyó a postergar el duelo fue la sublimación de la misma muerte, creyendo que la causa que motivaba a 
luchar procuraba un bienestar colectivo. Ello imposibilitó llorar a los muertos, negando el dolor y el daño que generaba. La impotencia frente a la impunidad, refuerza y bloquea considerablemente este dolor.

El fin del conflicto armado no respondió las expectativas de lucha que sostuvieron durante tantos años las mujeres, la negociación no tomó en cuenta las expectativas de una vida diferente, que posibilite vivir de manera digna y en convivencia democrática. Una vez más, ello afectó considerablemente el imaginario colectivo.

En este marco, para nosotras cobra un significado particular nuestra participación en la construcción del monumento a las víctimas civiles de las violaciones de los derechos humanos.

\section{RETOS DEL MOVIMIENTO DE MUJERES}

Trabajar la salud mental de las mujeres, ha significado comprender la dimensión política del daño emocional que la reciente guerra causó a las relaciones sociales y políticas como a toda la sociedad en su conjunto. Consideramos que es una tarea pendiente que requiere de voluntad política, que únicamente sanando estas heridas será posible construir un mundo diferente, en donde el dolor humano nos impulse a transformarlo.

Los daños a las estructuras psicológicas de las personas y a la subjetividad de todo el tejido social, nos impulsa a la tarea de recuperar la memoria colectiva y de reconstruir nuestra historia desde una perspectiva renovada, desde una identidad que fortalezca la cultura de paz y que cuestione las exclusiones en razón del sexo y, finalmente, desde una cultura política que reconozca las responsabilidades individuales e institucionales en la tarea de equidad y justicia en todos sus dimensiones. 
La democracia de género es una de las más deficitarias de la historia, por ello debe convertirse en prioridad. En la agenda pública de El Salvador, se encuentra pendiente el diseño y la implementación de políticas y programas de reparación socio económica y de reconstrucción que tengan en cuenta de manera prioritaria a las mujeres.

\section{BIBLIOGRAFÍA}

Garaizabal, C.; y Vázquez, N. (1994). El Dolor invisible. Una experiencia de grupos de auto-apoyo con mujeres salvadoreñas. Madrid: Talasa Ediciones, S.L.

Vázquez, N,; Ibañez, C,; Murguialday, C. (1996) Mujeres-Montaña. Vivencias de guerrilleras y colaboradoras del FMLN. Madrid: horas y HORAS.

Norma, V. Las Mujeres Refugiadas y Retornadas (2000). Publicidad Ramos.

Montañas con recuerdo de mujer, Una mirada feminista a la participación de las mujeres en los conflictos armados en Centroamérica y Chiapas (1996). Imágenes sin Frontera.

Reconstrucción de las identidades, memoria histórica y educación no sexista. Experiencias de las Mujeres por la Dignidad y la Vida. Las Dignas. Junio 2000.

Las dignas en la pos guerra. Folleto Noviembre 1999. 
Goretti NDACAYISABA

\section{IMPACT D'UN CONFLIT SUR LES RELATIONS HOMMES-FEMMES : CAS DU BURUNDI}

Le Burundi a une histoire récente jalonnée de crises politiques et de conflits violents. Les conflits armés affectent profondément les relations humaines. Les femmes, enfants et vieillards, ne faisant pas partie des effectifs des combattants, sont continuellement en route pour chercher des espaces de tranquillité. Dans cet exode, les rapports traditionnels entre hommes et femmes se voient transformés. C'est notamment par la filière des ONG que les femmes - dont la plupart doivent assurer la survie de leur famille sans la présence d'un homme vaillant - sont à même d'ins taurer des structures de soutien.

Afin de vous donner un bref aperçu de l'impact du conflit sur les relations hommes-femmes au Burundi, ma présentation va s'articuler autour des points suivants:

- Contexte général

- Nature et sources du conflit

- Perceptions et effets du conflit sur les rapports de genre

- Rôles et implications des hommes et des femmes dans les conflits et dans la construction de la paix. 


\section{CONTEXTE GÉNÉRAL}

Ces dernières années, le monde a connu des conflits dont la nature a profondément changé. Près de $95 \%$ des conflits armés se produisent non plus entre Etats mais à l'intérieur d'un même pays (guerre civile). Parmi ces pays, il y a le Burundi qui vit, depuis bientôt huit ans, une guerre civile qui n'en finit pas.

Le Burundi est un pays de l'Afrique centrale situé dans la région des Grands Lacs aujourd'hui devenue l'objet de violences cycliques et ininterrompues. Seules les armes à feu et les armes traditionnelles ont la parole.

Le Burundi a connu au cours des différentes périodes (1959-19611965-1969-1972-1988-1991-1993) une histoire jalonnée par des crises politiques et sociales s'exprimant par des violences de toute sorte: l'exclusion, l'exil, les génocides répétitifs, les coups d'Etat. Tous ces phénomènes ont engendré et perpétué des violences interethniques récurrentes marquées par des tueries fratricides généralisées entraînant la mort de milliers de gens et la déchirure du tissu social.

Malgré que le virus des antagonismes ethniques fût déjà inoculé dans la société burundaise depuis l'époque coloniale, le Burundi avait survécu aux sirènes du divisionnisme régional et tribal. Les trois principales ethnies vivant au Burundi (Hutu, Tutsi et Twa) avaient réussi à réguler de manière positive leurs différends et cohabitaient pacifiquement (en témoignent de nombreux mariages mixtes).

Ce n'est qu'en octobre 1993, avec l'assassinat du président Ndadaye, démocratiquement élu, que tout s'effondre. Au son de la cloche, partout dans le pays on assiste à des massacres de milliers de populations innocentes tutsi, qui seront suivis par des actes de vengeance et de répression à l'endroit des innocents Hutu. On compte par plusieurs centaines de milliers des victimes emportées par cette folie meurtrière. On assiste aux déplacements massifs des survivants en désarroi à la 
recherche d'un minimum de sécurité aussi bien à l'intérieur qu'à l'extérieur du pays (déplacés internes: 359’095 ; réfugiés: 421'256).

Dès lors, le Burundi sombre dans une crise politique et sociale sans précédent qui at dégénéré en frustrations individuelles et collectives: actes de vandalisme, division selon les groupes d'appartenance, impunité et confirmation de l'injustice sociale.

Le peuple burundais attend avec impatience les changements véritables qu'apportera la mise en application des accords signés à Arusha le 28 août 2000, date historique pour la majorité de la population.

\section{NATURE ET SOURCES DU CONFLIT}

Les conflits armés affectent fortement les relations humaines et provoquent des sentiments et comportements violents. Quand ils sont encore à l'état latent (gestation), ils peuvent déjà produire des tensions importantes. Quand ils émergent en surface (donc ouverts), ils peuvent s'exprimer de manière violente.

$\mathrm{Au}$ cours de l'évolution de tout conflit, on peut détecter des moments particuliers, "des seuils critiques » pour lesquels diverses solutions sont possibles. Ces solutions peuvent avoir une issue positive, ou bien entraîner une démarche négative pouvant induire un échec profond.

En faisant l'analyse de diverses situations de conflit, on pourrait tenter de comprendre pourquoi, comment et d'où la plupart des conflits naissent :

- du refus d'accepter la divergence de perception ou d'interprétation des faits historiques. Ces perceptions sont engendrées par un certain contexte, s'expriment sous forme de sentiments et se manifestent sous forme de comportement; 
- de l'insatisfaction des besoins élémentaires tels que la sécurité, la dignité, l'alimentation, etc. ;

- des préjugés qui ont été maintenus et renforcés par les systèmes éducatifs et politiques, et qui contribuent à diviser les groupes ethniques. Certains proverbes kirundi par exemple le confirment: "Le Burundais te cache qu'il te hait et tu lui caches que tu le sais»;

- des croyances populaires négatives, de l'intolérance des perceptions des uns et des autres néfaste aux bonnes relations entre populations;

- d'un pouvoir centralisé et illimité qui exclut une grande partie de la population en se servant de concepts à caractère régional, tribal, religieux, traditionnel, ethnique... ;

- de fortes implications d'autres pays; pour le cas du Burundi, la sous-région influence énormément l'aboutissement du processus de paix et la cessation des hostilités en particulier;

- d'un manque de communication avec autrui;

- de la globalisation;

- de la lutte pour le pouvoir et du partage inégal du pouvoir;

- des structures politiques (système électoral).

Cependant, tous les conflits ne se manifestent pas toujours de façon destructrice; ils peuvent être positifs. Pour le cas du Burundi, le processus de négociation à Arusha a forcé la classe politique à dévoiler certains faits historiques qui faisaient l'objet de discorde. Le fait qu'il y a eu consensus sur certains événements et dates historiques a diminué les tensions et permis de franchir une étape positive. 


\section{III.PERCEPTIONS ET EFFETS DU CONFLIT SUR LES RAPPORTS DE GENRE}

Les hommes et les femmes perçoivent le conflit de manière différente du fait qu'ils ont des besoins et des intérêts différents. En période de conflits armés, la situation des femmes et des enfants est particulièrement délicate. Faisant très rarement partie des effectifs des combattants, les femmes, les enfants et les vieillards sont les plus en mouvement, à la recherche des espaces de tranquillité. Au cours de cet exode, les populations sans armes, apeurées, affamées et fatiguées sont confrontées à de nombreux problèmes touchant notamment l'intégrité physique et l'exploitation sexuelle... C'est pourquoi cette catégorie de population mérite une attention particulière.

La guerre détruit l'ensemble de la société, tant les hommes que les femmes. Mais les conflits armés, l'instabilité politique, les tensions civiles infligent des souffrances aux femmes sous forme de tueries, de torture, de viol et agressions sexuelles, d'enlèvement... Le viol a été utilisé par les rebelles au Burundi comme une arme de guerre. Les femmes et les petites filles endurent cette souffrance qui se répercute sur toute leur vie: la prolifération des maladies sexuellement transmissibles et le VIH/sida, les grossesses non désirées et précoces, les déformations physiques, la marginalisation sociale, les traumatismes psychologiques, etc.

Comme tous les rapports structurels, les rapports entre les hommes, et les femmes ont été gravement endommagés par la guerre et crée une situation de tension permanente dans le pays.

Mon analyse des rapports genre va se concentrer beaucoup plus sur l'entité familiale, parce que les perspectives de construction de la paix commencent dans le ménage pour s'étendre ensuite à tout le pays.

Bon nombre de couples mixtes se sont dissolus et les enfants se sont retrouvés déstabilisés, ne pouvant choisir entre les deux parents. Les conséquences qui s'ensuivent sont nombreuses: enfants de la rue, 
prostitution, propagation des maladies sexuellement transmissibles (MST) et du VIH/sida, traumatismes, etc.

Aujourd'hui, l'homme n'est plus le seul garant de la survie familiale du fait que les femmes sont devenues des chefs de famille suite au décès, à la fuite ou à la disparition pure et simple du mari. La femme fait face aux nouvelles et doubles responsabilités qui l'amènent à s'organiser pour subvenir aux besoins de la famille (de manière à rendre honneur à son foyer).

On remarque que pour pallier les problèmes de pauvreté, beaucoup de femmes se sont réunies dans des systèmes associatifs qui leur permettent de développer de petites activités mais aussi de se soutenir dans les expériences difficiles.

Les initiatives associatives sont nombreuses. Je citerai le cas du CAFOB (Collectif des associations et ONG féminines du Burundi), qui regroupe plus de 45 associations de femmes et dont l'objectif a deux points d'entrée stratégiques:

- d'abord, amorcer le dialogue et la solidarité entre les femmes des groupes ethniques et politiques différents afin d'avoir la même vision du conflit burundais ainsi que les mêmes approches de construction de la paix ;

- ensuite, soutenir cette dynamique de solidarité et de cohésion sociale entre les femmes par des activités génératrices de revenus.

A l'heure actuelle, la capitale compte plus de 800 organisations et groupements de femmes qui militent pour la paix et assurent l'autonomie économique. Ces réseaux s'étendent également sur d'autres parties du pays.

Cette adaptation des femmes au conflit influe sur les rapports entre les hommes et les femmes. Le dialogue change parce que la femme réclame plus de reconnaissance, d'autonomie, de prise de décision. Les hommes de son entourage sont quant à eux sensibilisés aux compétences «hors ménage» de la femme. Cependant, malgré cette sen- 
sibilisation, l'homme burundais reste déstabilisé par le conflit qu'il utilise parfois comme prétexte pour fuir les responsabilités familiales.

Les femmes dont les époux sont décédés ou absents se heurtent à de nombreux problèmes de subsistance face aux nouvelles et doubles responsabilités de chef de famille. Elles doivent apprendre à gérer, à décider, à se défendre publiquement.

Dans certains cas, on a vu des enfants de moins de 15 ans quitter l'école primaire pour devenir chef de famille. Le taux d'enfants non accompagnés a atteint les limites. Bon nombre d'entre eux n'ont pas de logis; ils sont dans la rue toute l'année et apprennent à piller pour subvenir à leurs besoins. Ils sont exposés aux maladies, à la drogue, à la douleur. Le taux de scolarisation au Burundi a considérablement chuté. Les enfants de moins de 5 ans meurent chaque jour de la malnutrition, de la malaria, des maladies parasitaires et virales étant donné qu'ils n'ont pas d'accès facile à l'aide humanitaire distribuée par les ONG.

Au niveau politique, les hommes s'enferment dans leurs positions et ne tiennent pas compte des intérêts des populations. Il y a un grand fossé entre gouvernants et gouvernés et le leadership local est affaibli. La population en général est manipulée par l'opinion politique; les jeunes sont particulièrement désabusés par les politiciens qui les enrôlent de force dans les milices, ils deviennent des objets de propagande. Ils apprennent à tuer, à piller et à violer avec le silence complice des adultes qui n'ont plus de contrôle sur leurs propres enfants. 


\section{IMPLICATION DES HOMMES ET DES FEMMES DANS LES PROCESSUS DES CONFLITS ET DE LA CONSTRUCTION DE LA PAIX}

Les hommes paraissent toujours en agresseurs et les femmes en victimes passives. On pourrait se demander comment les belligérants peuvent réussir s'ils n'ont pas l'appui des populations civiles.

$\mathrm{Au}$ Burundi, bien qu'en nombre moins important, nous savons que les femmes et les filles combattent aux côtés des hommes rebelles. Ce sont elles qui leur préparent à manger, les soignent quand ils sont blessés, leur offrent toute l'attention sexuelle et psychologique. Elles jouent le rôle d'informateur en infiltrant tous les milieux politiques et professionnels.

Cependant, pouvons-nous affirmer que ces hommes et ces femmes combattants ont les mêmes motivations? On voit que dans le processus de négociation, ce sont les hommes qui occupent les places importantes. Quelle est alors la vraie place de la femme dans les guerres et dans la construction sociale de la paix? Les femmes sont uniquement des intermédiaires et propagandistes. Les hommes foncent dans les guerres pour leur propre satisfaction et se servent des femmes pour y arriver. En effet, la femme est dans une situation de dilemme et n'a pas le courage de dénoncer les hommes, car le rebelle est soit le mari, le frère, le fils, etc.

Dans la plupart des cas, les femmes revendiquent la paix après avoir tout perdu. Aujourd'hui, elles se rendent compte qu'elles ont subi les mêmes conséquences quelle que soit leur ethnie: hutu, tutsi ou twa. Certaines organisations de femmes sont conscientes que la résolution du conflit burundais ne pourra pas être l'affaire des hommes uniquement, mais qu'elles doivent tout faire pour d'abord l'analyser, comprendre tous les enjeux et contribuer de manière significative à la recherche d'une paix durable. Pour que cette lutte pour la paix soit une réalité, les femmes doivent être représentées dans toutes les 
sphères où se prennent les décisions, c'est-à-dire là où on décide pour la paix ou contre la guerre.

En temps de crise, les femmes ont contribué à la réhabilitation de l'économie nationale et à la redynamisation de tous les secteurs de production. Cependant, malgré tous les efforts fournis, l'Etat ne leur accorde pas encore la place voulue dans les accords de paix qui ont été signés le 28 août 2000 à Arusha, ni dans le processus de la mise en application de ces accords. Elles doivent elles-mêmes se frayer un chemin pour participer à tout ce processus.

\section{CONCLUSION}

Nous venons de montrer les difficultés de dialogue entre les hommes et les femmes. Ces difficultés ont été accentuées par la guerre certes, mais leur soubassement reste traditionnel et culturel.

Le problème du manque de dialogue est crucial au Burundi. La position sociale des femmes ne leur permet pas de jouer pleinement un rôle influent dans la prévention et la gestion des conflits. C'est encore une autre lutte que la femme doit mener par le renforcement du dialogue afin de clarifier son agenda pour la promotion de l'équité entre les genres.

Grâce au processus d'Arusha, une lueur d'espoir s'allume. Quelle que soit l'issue de la crise burundaise, la femme aura quelque part gagné sur le plan de son identité, de son indépendance, car elle aura fait preuve de sa capacité comme chef de ménage et contribué aux perspectives de la paix. 
Alla Kuvatova

\section{GENDER ISSUES IN TAJIKISTAN : CONSEQUENCES AND IMPACT OF THE CiVIL WAR}

\section{CONSÉQUENCES ET IMPACT DE LA GUERRE CIVILE: PROBLĖMES DE GENRE AU TADJIKISTAN}

L'impact de la guerre civile au Tadjikistan a été énorme et ses consé quences continueront à être ressenties pendant un laps de temps considé rable. Le fossé entre la position sociale des hommes et des femmes śest creusé durant cette période (1992-1997) dans toutes les sphères - éco nomique, politique, culturelle, familiale. Les rôles sociaux différenciés par genre dans la société tadjik sont en train de changer, mais le schéma traditionnel a encore la vie dure. Les phénomènes sociaux négatifs sont en augmentation: criminalité, violence, polygamie. Le rôle des femmes au sein des ONG est un élément transformateur de la société tajik.

The Republic of Tajikistan - one of the new independent States of Central Asia (since 1991) - is currently engaged in a process of social, economic and political transition. This transition is very specific for several reasons. One of its peculiarities comes from the fact that during the Soviet times Tajikistan was one of the most backward republics in terms of social and economic development. Moreover, still in the course of its earliest independent years, the country is dealing with the consequences of the civil war that 
destroyed the social, economic and political systems of its society. Indeed, the collapse of the Soviet Union and the civil war have brought the country to the edge of catastrophe. After signing the General Agreement on the Establishment of Peace and National Accord in 1997 the country entered the peace-building process.

The impact of the civil war on Tajikistan was enormous and its consequences will continue to be felt for a very long time. Among them:

- Human losses are 60,000 deaths (1\% of the national population) ; 25,000 widows and 55,000 orphans.

- Material losses are estimated at a total amount of $\$ 7$ billion, which is almost 18 years' GDP at current level.

- Demographic changes: nearly 1 million persons - one out of every six Tajiks - were displaced by the war. More than 250,000 persons fled the country entirely, and 700,000 were internally displaced.

- Social relations disintegrated, mostly for religious and political reasons.

- Political processes of struggle between the new government and the opposition, followed by a process of reconciliation, reconstruction, and peace-building.

- Moral and psychological traumas (the growth of criminality and violence) (Tajikistan Human Development Report 1996 : 12-16).

This situation has a strong impact on gender relations in the Tajik society. The gender gap widened in all spheres of life - economic, political, cultural, family. With the introduction of gender studies, Tajikistan is progressively understanding and formulating gendersensitive development policies implemented by local researchers and professionals ${ }^{1}$. At the same time several international experts are also investigating these issues ${ }^{2}$.

1. Kuvatova \& Khegai 1997 : 67-74; Khegai 1997; Modern Woman... 1998; Babajanov 1998; Olimova 1998; Gender and Culture... 1999; School of 
Talking about gender issues in Tajikistan presupposes that we overcome the existing stereotype of the so-called "women's question". The social problems in Tajikistan concern both women and men, and their respective roles and responsibilities have to be understood before they are addressed. The prevailing social problems are not only women's problems, but also male concerns. In this respect gender relations crosscut all social and political institutions, culture, and way of thinking.

In Tajikistan, where $73 \%$ of the population live in rural areas, the main barrier to equal opportunities are the traditional stereotypes about female and male roles. Gender as social categories of women and men are differently constructed in the city than in the villages. Urban women had good results in fighting gender inequalities. In the city there are more opportunities for women to get secondary and professional education, to get a paid job (employment), to participate in the decision-making process, to access health services, etc.

The Gender Related Development Index (GDI) for Tajikistan is 0,524 (National Status Report on Gender in Tajikistan 1999 : 106). Main statistical data show the disadvantages of women compared to men, in the fields of income, employment, leadership positions, high management positions in enterprises and university education. Unemployment rates among women are high. Especially in the rural areas where women only do household chores and take care for the members of family. Some are involved in unpaid labour at home. This traditional image of their unpaid non-productive labour at the household reproduces the steady stereotype of man as the breadwinner and woman as a dependent person. The absence of economic assessment of many forms of women's occupations explains their low social status. According to the data of a survey

Leadership for Women 1999; Avakova 1999; Women's and Gender Studies... 2000 ; National Status Report... 2000.

2. Shahrbanou Tadjbakhsh 1996; Birkenes 1996; Shahrbanou Tadjbakhsh 1998; Violence against Women 2000; Collete Harris 2000. 
conducted in 1998 the work of $33,3 \%$ of women of working age in our country is not rewarded economically. (Gender Statistics of the Republic of Tajikistan 1999 : 222-223).

During the armed conflict in Tajikistan (1992-1994) many women lost male relatives, i.e. protectors and breadwinners. Others saw their husbands become refugees and labour migrants. These women were forced to take up the burden of keeping their households going. Women started searching additional sources of income since their husbands were either in armed groups or refugees, or had no opportunity to move about freely because of the ongoing armed conflict. Trading in the market became a major occupation for many women as a form of survival, regardless of their educational and professional level. Women began to do jobs that were traditionally classified as male in Tajikistan, such as growing cereals and vegetables on private plots and gardens. In many regions where men left for Russia or other countries in search of an income, new responsibilities fell on women's shoulders. In general they handled this situation rather well.

Consequences of the civil war in Tajikistan together with the breakup of the traditional social organisation, and the increase of socioeconomic difficulties during the post-conflict period created fertile grounds for the growth of criminality and violence in the community. Violence occurs in all spheres of women's life, from private to social, i.e. there is always a risk of being a victim of violence. Wife beating is a serious problem in both urban and rural areas. Many cases go unreported and many of those cases reported are not investigated. The problem of "domestic" and "psychological" violence has become salient in Tajikistan.

Social phenomena such as poverty, prostitution, drug addiction are affecting many women. In 1997 the share of female criminality grew from $12,5 \%$ to $14,5 \%$ (Tajikistan. Human Development Report 1998 : 99). Women basically used to commit rapine, theft and seldom murders, but in recent years, they have committed grave crimes: gangsterism, robberies, murders, and often in connec- 
tion with narcotics trafficking. In 1993, 29 women were arrested on drug-related crimes, in 1994 - 47, in 1995 - 58, in 1996 - 66, in 1997 - 63 women (Gender Statistics of the Republic of Tajikistan 1999 : 214-216).

The stereotype that a woman should be under the protection of a man and the revival of Islam in the region has brought polygamy as a new phenomenon in Tajikistan. Today's reality shows that polygamy has become an everyday fact, due to the low economic status of women (absence of permanent work, low income). Many women cannot make their own living and are facing an uncertain future, and an absence of security. In the 1991-1998 period the number of officially registered marriages decreased 2.7 times. But this does not prove an actual decrease or an increase in extra-marital unions. Many marriages are sanctioned through a religious ceremony called "nikoh" with the agreement of the parents of the bride. This means that second or third wives have no legal rights as to joint property, inheritance or their part in case of divorce or death of husband. The full economic dependence and absence of legal rights deprive them of the opportunity to make choices concerning their social and economic activities.

Social and political life is slowly being reformed and a program of transition to the market economy is being elaborated. Women have played an increasingly important role in these processes, especially during the last five years. The number of women's organizations has grown from 3 in 1995 to 54 in 1998 (Gender Statistics of the Republic of Tajikistan $1999: 14$ ) and now there are more than 70 women's NGOs (Ministry of Justice 2000) working in all regions of Tajikistan. Women NGOs have proven to be the most active private organizations, as a result of the challenges women had to face during the transition period after the fall of the Soviet Union.

The female NGOs defined their missions in the following directions:

- promote the formation of the civil society through the comprehension of the role of a woman in the democratic reorganization; 
- enliven women's movement to ensure stable peace;

- give equal possibilities for village women in all spheres of life, protect their interests and rights;

- give women and girls law education;

- organize various kinds of training with the purpose of increasing the activity of women in all spheres of socio-political and economic life;

- support and develop female business;

- increase the role of women in science, culture, (applied) arts and use their creative potential;

- study the problems of violence against women and rehabilitation of victims of violence;

- guarantee reproductive rights and reproductive education of the population.

Through their work they pursue an operational and a long-term goal. The first direction is restoring destroyed dwellings for the returning refugees and rendering assistance to children-orphans as well as support and help to families whose breadwinners died during the military conflict. The second direction is upholding the civil and political rights, the civil and legal education, training of women leaders, etc.

About half of the women's NGOs work hard to construct the civil society. These NGOs have set their priorities in reaction to the straightjacket of the traditional gender roles, which are reflected in all main structures of social life. As the rights of women extend, many of those women's problems that were considered private (such as cruelty, assault on the part of the husband) become concerns for the whole society. Gender injustice is particularly strong in rural areas. This fact is aggravated by poor communication, lack of access to information and education, by low mobility for rural women, poverty and other factors. 
As the number of organizations has risen, qualitative changes have occurred. In the early 90 s, NGOs primarily worked within a vertical hierarchy, from the donor to the organization to the target group. Now NGOs work more horizontally with local counterparts in conferences, seminars and joint projects. In the past two years, women's NGOs have started forming coalitions to lobby for their interests, especially to improve the representation of women in appointed and elected government positions.

As a result of this campaign, in December 1999 the country's president issued a decree entitled "On Increasing the Role of Women in the Society". The decree charged the government with appointing qualified women to leadership positions in the ministries, state committees, agencies, judicial bodies, and educational institutions. Shortly after the president issued this decree, the number of women in both national and local governments increased remarkably. Eight women were elected to the new lower chamber of the Parliament, Majlisi Namoyandagon, at the 2000 elections (compared to five women in the old Majlisi Oli). These women represent 13 percent of the total number of seats in the lower chamber (compared to 3 percent in the old Majlisi Oli). A National Program on the Main Directions of State Policy on Equal Rights and Equal Opportunities for Men and Women (2000) was developed in a mutual effort from scientists, professionals and representatives from women's NGOs and its implementation is discussed now at different levels of Tajik society.

NGOs and community groups have become an alternative for women interested in becoming more active in public affairs. Unlike membership in a political party, NGO activism is seen as apolitical. Yet it can help get people involved in politics, and it can promote their interests in the upper echelons of power where policies are defined. Unlike political parties, which usually stand in opposition to one another, NGOs can collaborate with several political parties at once. 
During the 2000 parliamentary election campaign, many NGOs, including women's groups, helped organize roundtables, training seminars, civil forums and debates, giving candidates equal opportunities to promote their election platforms to the voters. Women, as compared to men, were generally more motivated to achieve agreement on diverging points rather than to achieve personal leadership.

All these facts testify that non-governmental organizations and social movements can help counter centralization and the expansion of state power and facilitate civil control. They can also help ensure the participation of people in the political process, creating informal channels along with formal democratic institutions.

The experience of Tajikistan with regard to the resolution of armed conflict and peace-building at different levels of society is important and useful and will be analyzed by local scientists and professionals. Furthermore it can be considered as a successful model for other countries having to resolve conflicts and complications in a postconflict period. 


\section{REFERENCES}

AvaKova N., 1999, Self-immolation of Tajik Women: An Attempt at Describing and Considering, Budapest, Central European University, June.

BABAJANOv R., 1998, National Report on Gender Policy, Dushanbe.

BIRKENES Robert M., 1996, Household and Market (Bazar) Research in Tajikistan. Save the Children US, January.

COllete HARrIS, 2000, Control and Subversion (Gender, Islam and Socialism in Tajikistan), Amsterdam.

Gender and Culture: Educational Manual for the Students of Humanitarian Departments, 1999, Dushanbe, "Asia-Plus" Information Agency.

Gender Statistics of the Republic of Tajikistan, 1999, 1999, Dushanbe.

KHEGAI M., 1997, Gender Research of Social and Economical Status of Women in the Kishlachny Sovet Karasu of Kofarnihkon District of RT, Report of Bureau "Women in Development", August.

Kuvatova A. \& Khegai M., 1997, Woman in Transition Period, Izvestiya of Tajik Academy of Sciences, $\mathrm{n}^{\circ} 1$, pp. 67-74.

Ministry OF Justice, Republic of Tajikistan, 2000.

Modern Woman in the Family, at Work and in Politics: Gender Aspect, 1998, Brochure, Dushanbe.

National Status Report on Gender in Tajikistan. 1999, 2000, Dushanbe.

Olimova S., 1998, Report on Women's Status in Tajikistan, Republic of Tajikistan, Information and Analitical Center "Shark", Dushanbe.

School of Political Leadership FOR Women, 1999, Manual for Trainers, Dushanbe, Business Initiatives Center.

SHAHRBANOU TADJBAKHSH., 1996, The Analysis of the Survey on Economic Status of Women in Tajikistan, Dushanbe.

-, 1998, "Between Lenin and Allah: Women and Ideology in Tajikistan", in Bodman Herbert L. \& Tohidi Nayeren (eds.), Women in Muslim Society: Diversity within Unity, Lynne Rienner Publishers, Inc.

Tajikistan Human Development Report, 1996.

Tajikistan Human Development Report, 1998. 
ANNEMIEK RICHTERS

\section{Gender Violence, Health and Healing in SituATIONS OF ETHNO-NATIONAL CONFLICTS: THE CASES OF THE Former YugOSLAVIA AND TAJIKISTAN}

Cette intervention parle des expériences que l'auteure a vécues en exYougoslavie et au Tadjikistan en travaillant sur la question de la violen ce du genre. La violence du genre est étudiée dans toute sa complexité interpersonnelle, socioculturelle, économique et politique. La complexité du phénomène demande des réponses thérapeutiques et préventives qui tiennent compte du spectre entier de ces facteurs. La mise sur pied des approches et des projets de santé pour le traitement des traumatismes cau sés par un conflit nécessite une vision holistique. La promotion de la santé dans ces cas ne peut se faire sans les aborder comme une question de droits fondamentaux des femmes.

My contribution to the colloquium will focus on the presentation of a gender perspective on the violence specifically conducted against women in all phases of a conflict. Specific issues to be addressed will be the function and meaning of the various forms of this kind of violence, its consequences for women and for society, and ways to prevent it and care for its victims. The article consists of two parts: the first discusses general issues, while the second elaborates on these issues in the context of the conflicts in the Former Yugoslavia and Tajikistan. Both countries went through a conflict at about the same 
time. While the conflict of the Former Yugoslavia stood in the spotlight, the one in Tajikistan remained ignored from the outside world.

These two countries were chosen because I have had an experience in both. This made me read more about developments in the two countries than I would have done otherwise. During the war in the Former Yugoslavia I worked 9 months (1994) for Doctors without Borders in Sarajevo in order to develop and co-ordinate a community mental health program. Back home, in the Netherlands, I was involved as a consultant for different psychosocial projects in the Former Yugoslavia. In 1999-2000 I worked as a consultant for the World Health Organization (Regional Office Europe) and the Swiss Development Co-operation in a study on violence against women in post-war Tajikistan. I was particularly interested in the gender conflicts in both countries. For this study I build on the knowledge about gender violence that I gained from a literature review conducted in 1993 about violence against women in the South (Richters, 1994). In 1993 literature on violence against women related to conflict situations was scarce. In the following 7 years, however, literature on that theme increased tremendously. Yet, as my article will show, much empirical and analytical work remains to be done. Within the scope of one article I cannot discuss the issue of gender violence in the context of two conflicts in detail. My purpose is merely to raise some issues hoping that others will take them up in their own studies in countries around the world where conflicts rage or have raged recently. I will stress the complexity of issues related to gender violence in conflict situations, but as a physician and anthropologist I am interested in health and healing approached from a cultural comparative perspective and I will highlight issues of health and healing in particular situations. 


\section{Gender Violence: Forms, Definitions, Causes, CONSEQuences AND ResPonses}

\section{Gender Violence in Peace and War}

Gender violence is an almost universal phenomenon. Only a few societies seem to be exempt from it (Levinson, 1989; Counts et al., 1992). It takes many different forms. Some of those forms, like male violence against an intimate female partner, can be found in almost any society ${ }^{1}$, while other forms, like female circumcision and dowry murder, are culturally specific. Gender violence occurs in every war, but only in particular wars is one particular form of gender violence, sexual violence in the form of rape, part of the war strategy and can be called "war rape".

A problem in addressing gender violence cross-culturally is that as yet there is no uncontested definition of gender violence. Violence is a broad concept, lending itself to various definitions and theories, significations and categorizations. On the whole violence is seen as an act carried out by one person with the intent, or perceived intent, of causing pain and injury to another. In addition to physical injury, however, violence in a fuller sense includes sexual and psychological abuse. The latter is generally experienced by women as the most painful. It is therefore important that a definition of gender violence is not restricted to physical violence. Women in developing countries have stressed that economic violence should be added as a fourth form (Hof \& Richters, 1999). Examples of economically disempowering acts include preventing someone from working, not providing

1. In every country where reliable, large-scale studies have been conducted, results indicate that between $10 \%$ and $50 \%$ of women report that they have been physically abused by an intimate partner in their lifetime. Population-based studies report that between 12 and $25 \%$ of women have experienced attempted or completed forced sex by an intimate partner or ex-partner at some time in their lives (WHO Fact Sheet, n.d.). Data must be compared with caution, as research methods used to compile data vary across studies. 
support when money is available, and forcing a woman out of the house where she lives.

When the act of violence is directed against a woman because of her sex, or affects women disproportionally, one generally speaks of gender violence. At times gender violence may be consciously used to perpetuate male power and control; at other times that intent may be missing, but the effects are nonetheless harm or suffering in a way that reinforces female subordination. Accordingly gender violence then comprises any act of force or coercion directed at an individual woman or girl that jeopardizes her life, body, psychological integrity, or freedom and that perpetuates female subordination (Heise, 1994).

A more comprehensive definition of gender violence would move beyond discrete acts to include forms of ongoing, institutionalized sexism, such as discrimination against girl children in food and medical care, lack of access to "safe" contraception and abortion, and laws and social policy that perpetuate subordination without necessarily leading to physical, sexual, or psychological harm or suffering. The appeal of such an all-embracing definition is that it would permit many violations of women's rights to be addressed under the rubric of violence. But a drawback is that it is so all-embracing that one loses focus (Heise, idem).

In 1993 the United Nations General Assembly adopted at its 48 th Session the Declaration on the Elimination of Violence against Women. This Declaration was the result of worldwide women's activism against gender violence. It was drawn up in order to stress that violence against women occurring across the world should finally be acknowledged and addressed as an issue of human rights. The UN definition offers a list of abuses that represents a compromise between a desire to be inclusive and the need to keep the definition specific.

In the Declaration, violence is defined to include "any act of genderbased violence that results in, or is likely to result in, physical, sexual or psychological harm or suffering to women, including threats of 
such acts, coercion or arbitrary deprivation of liberty, whether occurring in public or private life". Article 2 of the Declaration states that "violence against women shall be understood to encompass, but not be limited to the following: a) physical, sexual and psychological violence occurring in the family, including battering, sexual abuse of female children in the household, dowry-related violence, marital rape, female genital mutilation and other traditional practices harmful to women, non-spousal violence and violence related to exploitation; b) Physical, sexual and psychological violence occurring in the community, including rape, sexual abuse, sexual harassment and intimidation at work, in educational institutions and elsewhere; trafficking of women and forced prostitution, c) Physical, sexual and psychological violence perpetrated or condoned by the State, wherever it occurs".

In this article my main focus will be on a) various types of domestic violence and $b$ ) rape as part of the organized violence of war (war rape). The limited definition of gender violence - violence as a discrete act directed at one person - does apply to domestic violence. While discussing this form of violence I will emphatically conceptualize it as an act embedded in the socio-economic, political, and ideological context of power relations between men and women, as violence which reflects power imbalances inherent to patriarchal society. War rape asks for a different definition in cases where it is executed in the context of organized violence (in the guise of state violence, ethnic conflict or civil war). Organized violence can be defined as the inflicting of significant and avoidable pain and suffering on others by an organized group according to a declared or implied strategy and/or system of ideas and attitudes (Richters, 1994). The definition of "rape" adopted by the International Criminal Tribunals for Rwanda and Yugoslavia is "a physical invasion of a sexual nature, committed on a person under circumstances which are coercive" (quoted from Haydn, $2000: 27)^{2}$. War rape, however, is not simply

2. Sexual violence as a war strategy may include more than rape defined as physical vaginal penetration. The definition given by the Tribunals of sexual violence is "any act of a sexual nature which is committed on a person under 
an action of one individual person on the body of another, but a social action. In situations of ethno-national conflicts rapes are committed because both the perpetrators and their victims see themselves as components of larger social entities, and rape would have a serious impact on the relations of those entities (and thus of their members) to each other (Haydn, $2000: 28$ ). Thus rape is not used in the first instance to regulate power relations between the sexes and perpetuate female subordination, but rather to regulate power relations between two competing groups ${ }^{3}$. Thus, in the ethno-nationalist conflicts of the Former Yugoslavia and Tajikistan, women's bodies are used as a prominent battleground on which the conflicts have been waged.

\section{The Causation of Gender Violence}

The various forms of gender violence need to be understood in the particular contexts in which they occur if one wants to work towards the prevention of gender violence and the treatment of its victims. There are many factors to distinguish in the social environment that may be conducive to gender violence. Increasingly, researchers use an "ecological framework" to understand the interplay of personal, situational and socio-cultural factors that combine to cause abuse. Heise (1998) used the model as a framework to understand partner violence. Based on a wide range of studies she identified the factors that increase the likelihood that a man will abuse his partner4.

circumstances which are coercive ... not limited to physical invasion of the human body, and may include acts which do not involve penetration or even physical contact". Examples are compulsory nudity, electroshock to the nipples and vagina, the squeezing or binding of the breasts, suspension of the breasts, being threatened with the above.

3. See for a criticism of feminist analyses of rape in war, analyses that disregard the ethnic dimension: Rejali (1996). The relation between sexual violence and war is complex and has been conceptualized in different ways. Skjelbaek (2001) presents three different conceptualizations based on her literature review (1999) of 140 scholar texts published mainly during the 1990s.

4. See also Heise et al. 1999 in which the content of Heise's model is reproduced in adapted form. 
- At the individual level the relevant factors with regard to the perpetrator include being abused as a child or witnessing marital violence in the home, having an absent or rejecting father, extreme use of alcohol or other substances, ownership of weapons and loss of status.

- At the level of the family and relationships, cross-cultural studies have cited male control of wealth and decision-making within the family and marital conflict as strong predictors of abuse.

- At community level women's isolation and lack of social support, poverty and low socio-economic status, together with male peer groups that condone or legitimize men's violence, predict higher rates of violence.

- At societal level studies around the world have found that violence against women is most common where gender roles are rigidly defined and enforced and where the concept of masculinity is linked to toughness, male honor, or dominance. Other cultural norms associated with abuse include tolerance of physical punishment of women and children, acceptance of violence as a means to settle interpersonal disputes, and the perception that men have "ownership" over women.

The more risk factors are present and the stronger the interaction between the various risk factors, the higher the likelihood of violence and the more complex the necessary interventions to prevent violence. What the specific risk factors are and how they interact may vary with the situation and society. When I discuss gender violence in Tajikistan I will show that in this country we can distinguish a few culturally specific risk factors not listed above. Furthermore I will indicate when I discuss gender violence in the Former Yugoslavia that we should be aware that the presence and prevalence of certain risk factors and the nature of their possible interactions may change over time, for instance in the pre-conflict, conflict and post-conflict phase.

Conversely, it can be illuminating to focus on factors which are predictive of little or no gender violence. Possible protective factors 
within the immediate social context for partner violence may include community characteristics such as women's involvement in groups or their mutual support, possibility of land ownership and resources mobilization, or possibility of maintaining custody of their children upon separation. In cross-cultural studies, whether the society under study is matrilineal or patrilineal is a criteria singled out as relevant. A number of studies have shown that in matrilineal societies relationships between husbands and wives are not as tense and adversarial as in patrilineal ones.

It has often been postulated that the systemic daily violence inflicted upon women and children in the family in times of so-called peace is a predictive factor for gender violence in the context of the organized violence of war. Whether a close relationship between both forms of gender violence does exist or not is a question that has not been answered yet. Nor do we know much about the precise nature of the possible connection between the two. Answers to these questions should be sought first of all by studying both forms of violence in specific socio-cultural and historical circumstances. Only recent has some attention finally been paid to the linkage of domestic violence and war rape in the context of the ethno-nationalist conflict of the Former Yugoslavia (see below), following the last decade's exclusive focus on war rape in that part of the world.

Mass rape in the war fought in Bosnia gave a sudden impetus to the appearance of a body of literature discussing the function and meaning of rape in war (Richters, 1998). In that literature mass rape is often presented as a universal occurrence in war. Haydn (2000), however, defends the thesis that indeed mass rape is common in ethnic or nationalist conflicts, but it is not a universal occurrence. Using South Asian and Bosnian data, he argues that mass rape is likely when such conflicts take place during the partition of a territory or a population, when the state itself is liminal, both its territory and control over it uncertain. These factors can thus be conceptualized as risk factors for mass rape during the conflict. In the cases presented by Haydn, perpetrators and victims of mass violence often speak the 
same dialects of the same languages and frequently were neighbors, at least acquaintances, before their communities were disrupted. Violence is then used to ensure that there will be no future coexistence, and rape seems to be a powerful weapon, even more powerful than murder, to bring about that end. Rapists rape in order to make the victims not want to return. The message of rape is particularly effective when the adversaries are groups for whom the honor of the group is determined by the honor of its women and by the masculinity of its men. This cultural norm can thus be conceived as a further risk factor. Studies of cases where rape is intentionally avoided are rare. There is some evidence, however, that rape is avoided in conflicts in which the state is not itself threatened, and thus groups feel that they will continue to coexist.

\section{Gender Violence as a Comprehensive Issue REQUIRING A COMPREHENSIVE RESPONSE}

Gender violence is a complex issue, being an issue of human rights, health and development (Richters, 1994). It is an issue of human rights in so far as violence is a threat to women's life, liberty or security. The Declaration on the Elimination of Violence against Women refers to all the former human rights instruments that should in principle be sufficient for the elimination of violence against women. However, this form of violence never got any detailed attention. One of the important steps forward is that domestic violence, which has always been considered a private affair, is placed by the Declaration within the context of international human rights laws and practices; this makes governments responsible for the elimination of this kind of violence. Another matter is the frequent lack of political will to implement the Declaration. A recent victory of the women's movement is that the Yugoslavia Tribunal in the Hague has convicted (23 February 2001) three war criminals because of their involvement in the rape of women in 1992 in Foca (Bosnia-Herzegovina). This verdict is historic. For the first time in history sexual violence was included in the reasons for a verdict as a crime against humanity. Instead of feeling guilty and ashamed, 
being ostracized from their community and deprived from their dignity, women who have experienced this terrible crime as well as their families and communities can now perceive war rape as a crime against humanity and demand that justice be done. The courts are obviously only one of the possible arenas for this to occur.

Justice is a crucial element in healing from some of the wounds resulting from gender violence. Considering the many consequences of gender violence, however, justice is generally not sufficient. The health consequences can be many. They can be non-fatal in the form of physical injuries, ranging from minor cuts and bruises to chronic disability, or mental trauma. They may also be fatal, resulting from either intentional homicide or injuries sustained or from AIDS. In the case of mental trauma, women may commit suicide as a last resort to escape violence. The physical consequences include: death, serious injuries (bruises, fracture, chronic disabilities), injuries during pregnancy (low birth weight, low maternal weight gain, infections, anemia), unwanted and early pregnancy (with adverse health outcomes for mother and child; illegal abortions with fatal outcomes), vulnerability to disease (severe mental problems, sexually transmitted diseases, urinary tract infections). Gynecological consequences of childhood sexual abuse are: inflammation of the ovaries or uterus, urethritis, vaginal infections, discharge, menstrual pain, irregularities of the menstrual cycle or pelvic pain. Some of the major psycho-somatic consequences include chronic headaches and chronic backaches, gastro-intestinal problems, loss of appetite, sleep problems, fatigue. And finally, major psychological long-term consequences include: anxiety and panic attacks, feelings of shame and guilt, depression, abuse of medication, alcohol and drugs, suicidality, post-traumatic stress disorder, eating disorders (see e.g. WHO, 1996).

Seeing the long list of health consequences, it will come as no surprise that those women burdened with the physical and psychological scars of violence cannot fully devote their labor or creative ideas to development. Violence drains women's energies, and may undermine all their efforts to further their own, and their community's 
development. Development policies should thus support women's efforts worldwide to end gender violence and help create the conditions of development and justice for all humanity, including women. One of those conditions is good health services in which the various health consequences of gender violence are identified as such and given the appropriate treatment. One of the consequences of war, however, is that appropriate health services together with other key institutions (like the justice system) instrumental to the reconstruction of society are lacking.

In conclusion, the issues related to gender violence are complex, multifaceted and structural. Health, justice and development with regards to gender violence are interlinked. In order to address them effectively, multidisciplinary, multisectoral and multilevel interventions are needed. No single intervention will cure the problem. By the same token, Anderson (1999 : 19) argues, "any intervention can affect the system. So choose one you know about, you feel passionate about, and can do something about."

\section{Gender Violence and Posttraumatic Stress Disorder ON INDIVIDUAL PSYCHOLOGICAL AND SOCIO-CULTURAL LEVEL}

An Indian woman says about the battering she experienced: "In fact the body mends soon enough. Only the scars remain... But the wounds inflicted upon the soul take much longer to heal. And each time I re-live these moments, they start bleeding all over again. The broken spirit has taken the longest to mend; damage to the personality is the most difficult to overcome" (quoted in Richters, 1994). It is common practice nowadays among mental health specialists to diagnose the psychological problems the Indian woman refers to as "posttraumatic stress disorder" (PTSD). This diagnosis acknowledges that many mental problems suffered by women are the consequences of abuse and not something inherently wrong with the woman in question (Richters, 2001).

The characteristic symptoms of PTSD involve 1) re-experiencing the traumatic event, 2) numb responsiveness to or reduced involvement 
with the external world, and 3) hyper alertness or exaggerated startle response. Not only for psychotherapists but for all health workers as well it is important to be knowledgeable about these symptoms. During a vaginal examination by a gynecologist, for instance, a woman may be re-experiencing the sexual violence she experienced as a child. Her reaction should be understood as such. The second and third symptom can be a risk factor for violence. Numbing may, for instance, make the woman be indifferent to her husband's violence who then continues without any resistance from the woman. And a startle response may, for instance, result in violence conducted by an abused woman against her children or in violence by a man who relives a war trauma.

Survivors of concentration camps, labor camps, chronic sexual assault and the like develop symptoms which are more complex and diffuse, and last longer than the ones described under the label of PTSD. They develop drastic personality changes, particularly relational and identity problems. Herman (1992) uses the term "complex PTSD" for these changes. One of the symptoms of complex PTSD is that one's basic assumptions are shattered by the chronic traumas women have experienced. These assumptions may include the idea that the world is benevolent, the idea that the world is meaningful, the idea that other people are trustworthy, the idea that I am worth, the idea that I am in control of my life, and the idea that I am invulnerable (it will not happen to me).

War in the Former Yugoslavia in particular started debates in the literature about the validity of the use of PTSD to diagnose people's state of mind in conflict and post-conflict areas around the world. The discourse in the West about violence, loss and trauma is focused on long-term effects of what happens inside the body and psyche. Western psychological concepts and methodologies are products of a globalizing culture and may risk an unwitting perpetuation of the colonial status of the non-Western mind (see e.g. Summerfield, 2000). In other cultures, for instance torture (including rape), may be perceived not so much as an assault on the "individual self", but 
more as destruction of family and group relations and disruption of the moral order. Relational, socio-cultural wounds have then priority over individual wounds, or are at least of equal importance. In such cases we can speak of psycho-socio-cultural trauma, a trauma which next to healing on an individual level asks for the healing of the posttraumatic stress in the fabrics of culture and society, for instance by rituals in which the whole community takes part.

Even though in the past I focused on the importance of a non-individualistic approach to traumatic stress disorder (Richters, 1994 \& Richters, 2001), I do value a person-centered approach, particularly in health care for women who have suffered from gender violence. The emphasis on, for instance, the effects of war rape on individual women may, however, not be appropriate in every context. Haydn (2000 : 35) refers to a Bosnian Muslim woman who said during an international conference on Bosnia held in early 1993 that she felt that the international emphasis on rape was inappropriate, because all Bosnian women were victims: they lost their homes, their sons, their husbands, their jobs, their lives, and whether they had been sexually assaulted or not was not really the most important problem. In the Netherlands social workers who work with female refugees from Bosnia told me that they often hear this same "complaint". In other words, what these women suffer from is "multiple trauma" or "massive trauma", rape being just one element of that trauma.

Robben and Suarez-Orozco (2000 : 23-24) argue that Western psychology and psychiatry have placed such an emphasis on the manifestation of trauma in individual psychopathologies that the term "massive trauma" is little more than a quantitative concept to date. The question to be answered is whether massive or collective trauma is more than the sum total of the individual suffering. Populations subjected to massive trauma are affected as groups even though each person works in a particular way through the effects. This raises a subsequent question. How do individual and socio-cultural healing relate to each other? To date there is some evidence that women who recover best from gender violence are those who give meaning to 
their experiences which surmount the boundaries of personal tragedy. This meaning is often found in a collective struggle against the violence suffered (Herman, 1992). These struggles are now taking place in the post-conflict societies of Tajikistan and the Former Yugoslavia. They are discussed in the next part of this article that focuses on various aspects of gender violence in the changing sociocultural contexts of those countries.

\section{GeNDER Violence AND WOMEN'S RESPONSES IN T RAJECTORIES OF SOCIET AL CHANGE IN THE FORMER YUGOSLAVIA AND IN TAJIKIST AN}

\section{A COMPARISON BETWEen the Former YugoslaVia AND TAJIKIST AN}

The term "transition" is commonly used to describe the processes experienced by socialist countries of East Central Europe and the USSR following the collapse of the Communist Regimes after 1989. The use of this term however, Cockburn (2000) argues, suggests too similar a past. The Former Yugoslavia differed in many important ways from other countries governed by Communist parties in the second half of the twentieth century and certainly from Tajikistan. The characteristics of Tajikistan are, for instance, more "East" within the East-West dialogue than the characteristics of the Former Yugoslavia. Furthermore, in contrast to the Former Yugoslavia, Tajikistan shares with many countries in the South historical experiences of post-colonization and characteristics of "underdevelopment" which do not apply to large parts of the Former Yugoslavia.

The term "transition" also suggests a predetermined destination, but who knows whether the Western powers' vision for the region (Western-style democracies, neo-liberal free market states) will come to be? So instead, when considering the continuities and discontinuities in the pre-war, war-time and post-war moments of the 
Former Yugoslavia's and Tajikistan's experience, it might be better to accept Cockburn's proposal and use terms like change, transit, pathway, trajectory, choice. They leave more possibilities open. Besides the women and men of both countries are undergoing change not of one kind but of several kinds simultaneously.

Next to substantial differences between Tajikistan and the Former Yugoslavia, there are a number of similarities, particularly with regard to the gender regimes in both countries, the honor-andshame complex being a significant element of those regimes, as I will show below.

Both Tajikistan and the Former Yugoslavia went through a period of conflict. Tajikistan became independent from the Former Soviet Union in 1991 and subsequently experienced a civil (ethnic) war in 1992-1993. Between 1991 and 1995 the Socialist Federative Republic of Yugoslavia collapsed and between 1992 and 1995 an ethnic war raged in Bosnia, one of the six former Republics. In both countries the war resulted in a great number of refugees and internally displaced people. In Bosnia as well as in Tajikistan, a peace treaty was signed (respectively in 1995 and 1997) but is there really peace? Even today infrastructures are barely functioning in many parts of in Tajikistan and Bosnia and the impoverished population experiences extreme physical and psychological hardship. Killings are continuing, together with civil unrest, harassment and corruption. In both countries rape of women was part of the war strategy and in both countries various kinds of gender violence, in particular domestic violence, seemed to have increased significantly after the war. Also in both countries new kinds of non-profit, non-governmental organizations are burgeoning, many of which are women's organizations. The latter, however, do not make a women's movement, certainly not a movement strong enough to effectively challenge the gender regimes which promote and facilitate gender violence (Cockburn, 2000; Harris, 2001). 


\section{The Role of Gender in Both Conflicts}

Recently two Ph.D. theses were completed in the Netherlands, each focusing in their own way on a number of gender aspects of the different phases of the conflicts in respectively the Former Yugoslavia (Zarkov, 1999) and Tajikistan (Harris, 2000). Without knowing about each other's work, both authors discuss in detail the gender regimes in the two countries that function(ed) as risk factors for various forms of gender violence. Summarizing some of the points made by both authors, I can do little justice to the detailed descriptions and analyses of the two books.

Dubravka Zarkov describes how in the Former Yugoslavia traditional notions of femininity went hand in hand with the new, modern, socialist female images. Despite the obvious and widely publicized progress in many spheres of women's lives, realities were much more problematic. In this respect the Former Yugoslavia's past resembles Tajikistan's. In the Former Yugoslavia, in the 1970s a process of depolitization of women took place. In the mid 1980s however, as nationalist forces became increasingly effective, groups of women in particular parts of the country seemed to be returning to the political life. Their sudden presence was both highly symbolic and utterly physical. During the 1987 fall season Serb and Montenegrin women from Kosovo (one of the six Republics) demonstrated against the accusation by a prominent Albanian politician from Kosovo (Hoxha) that they would be ready to prostitute. The reason was that the Albanian men were, at the time, charged by the Serbian press and politicians of raping Serb and Montenegrin women. Hoxha was reported as saying that the problem of these inter-ethnic rapes could be solved by bringing in women to work as prostitutes. That would, presumably satisfy the Albanian men and reduce the incidence of rape. The fury this statement caused was further aggravated by the alleged suggestion that Serb and Montenegrin women, unlike Albanian women, would be ready to prostitute. The resulting demonstrations were a significant watershed in the production of ethnicity in the Former Yugoslavia. Since then gender and sexuality 
became the core issues around which nationalist forces consolidated and battled". After some time a "media war" started as a nationalist practice of producing ethnicity through media images. Parallel to the "media war" a different war started: an "ethnic war" which produced ethnic groups through violence. In both the "media war" and the "ethnic war" gender and sexuality became central to the production of ethnicity. However, Zarkov argues, stating that these two wars engaged in the same productive process does not entail that they did so in the same way. The "media war" achieved its objective through textual and visual representation, the "ethnic war" through physical violence. The texts in the press per se did not produce sexual violence against women in the "ethnic war", but rather the norms of gender and sexuality through which specific types of violence against women were rendered justifiable or even acceptable. Ethnicity is not only produced, however, by the "media war" and the violence of the "ethnic war" but, Zarkov demonstrates, also through women's personal narratives as well as feminist texts.

In the context of these two wars Zarkov addresses the relationship between the symbolic, metaphoric and the material, lived female body. She selected three categories of the female body as specific sites of production of ethnicity, the maternal body, the victimized body and the armed body. These categories are equally significant for all fields of production of ethnicity that Zarkov defines: the two wars, women's experiences and feminism.

5. Mladjenovic (1999:85) claims (contra Rejali, see note 3) that "the enemy of first resort is Woman; ethnicity comes in a distant second". She writes about the "post-TV news violence syndrome". Mladjenovic explains that the daily war propaganda television broadcasts in Belgrade had the unintended effect that men who watched the programs would become agitated and angry, and start hitting their wives or children as a proxy for the "enemy" that was far away and not as easy to reach. For many women, according to Mladjenovic, it was the first time they had been struck by their husbands, and they would call the SOS Hotline for Women and Children Victims of Violence (founded in Belgrade in 1990) asking, "What happened to him?" 
The outcome of the war is that ethnicity did emerge as an important feature. Large parts of Bosnia are now "ethnically clean". Sarajevo used to be a modern city where ethnicity played hardly any role and tolerance between the various religions existed, but it is not any more. National identities and conservative gender relations have been established. In parts of Bosnia, the influence of Islam has become stronger and has made women turn to the veil again, and traditional gender norms have become a stronger element in people's identities.

Colette Harris states that in Tajikistan throughout the Soviet era gender norms and relations, the practices of Islam, and the form of Soviet socialism were in a state of flux (also Tadjabakshsh, 1998). Changes in any of these inevitably impinged on others. At moments of strength the Soviet regime tried hard to suppress religion and to encourage changes to local gender norms. But these changes took place first of all at the top political levels and it is far from clear what their real effect was at the grass-roots level, particularly in the rural areas where the vast majority of the Tajiks lived. The main significance of the intersection of Islam and socialism with Tajik gender norms was, according to Harris, that it was the central battleground between the Soviet regime and the local population. This battle is still going on today, albeit on slightly different ground. It is now being fought between the secular state represented by the post-communist government of Rakhmonow on the one hand, and the more radical factions of the Islamic opposition on the other.

Summarizing Tajik history of the twentieth century as far as gender relations are concerned, Harris argues that both the Soviet regime and the Tajik people found gender norms to be the most important facet of cultural identity to be attacked, or conversely, preserved. The Bolsheviks endeavored to penetrate Tajik culture and modernize it, chiefly by forcing its women out of seclusion. As this was viewed by men as an attack on their masculine identity there was strong resistance. In fact the Tajik people were able to subvert the might of the Soviet State by their refusal to make significant changes to their gen- 
der norms. What comes out of a long history is that women (still) suffer, in particular from the constraints their family and community force them to live under. Despite all the changes over the last hundred years, the dominant set of gender norms perpetuating the subordination of women remains apparently unchanged. Harris argues at length that this subordination is neither monolithic, nor unresisted. However, resistance has not led to significant changes in the dominant gender regime yet.

Right now the situation is such that despite a Soviet-based legislation stating the equality of rights and treatment between men and women, women in the new Tajik state have lost many of the achievements of the Soviet Union in terms of gender equity. Women are particularly discriminated with regard to income generation, access to education and health services. Especially in rural areas, women are more and more bound to "traditional" domestic roles with increased difficulties to access public positions. The various societal developments have also resulted in an exacerbation of the various forms and scope of gender violence. Most of the now recognized forms of gender violence were probably there before the war. However, we do not know much about them because of a lack of documentation. Many people told me that gender violence in Tajikistan has definitely escalated after the war. In this respect Tajikistan differs from post-war countries, where domestic violence was not more of a problem as a result of the war. The war merely made women "denaturalize" and delegitimate the problem. Like in other post-war countries, however, what was once "normal" and acceptable in Tajikistan because of prevailing norms and values is now increasingly seen as something abnormal and illegitimate, as clearly a gross violation of human rights, and as something to fight against. 


\section{Gender Violence OVER Time}

The case of the Former Yugoslavia shows that one must understand the constructions of gender violence in peacetime in order to understand the meanings of wartime sexual tortures (Olujic, 1998). Wartime gender violence highlights preexisting socio-cultural dynamics. War rapes in the Former Yugoslavia would not have been such an effective weapon of torture and terror if it were not for concepts of honor, shame and sexuality that were attached to women's bodies in peacetime. War rapes became such an effective weapon in the Former Yugoslavia precisely because the ideology of honor/shame was shared by C roats, Muslims, and Serbs.

In peacetime control of women by men and protection of their sexuality were means of justifying the domination of women by men. Men placed high value on women's chastity, monogamy and fertility. Because a woman's body is a microcosm of her lineage, and the body's weak points are its orifices (openings), the rapist symbolically dishonored the entire lineage of the raped woman with sexual violence. Through the penetration of a woman's corporeal body the social body of her family was permanently and irretrievably damaged.

In wartime, violation of female honor was a weapon used by the men of one ethnic group against those of another. Men suffered from the shame of their failure to protect their property that includes women, family, bloodlines, and soil. Women suffered from having to endure the private stigma of shame. By acting as a group and by systematically imposing their methods through acts and words of brutality, rapists were a social body that acted against another body. In short, one purpose of ethnically organized rape was to destroy another ethnic group. War rapes in Bosnia symbolized an assault on the Muslim social body. The rapes of individual women were also microcosms of the larger invasion of territory (cf. also Zarkov, 1999; Haydn, 2000). After the war, sexual violence of women became almost a non-issue in the Former Yugoslavia. Mainly women's NGOs keep paying 
attention to it. As far as I know studies of the prevalence of the various forms of gender violence in the postwar situation and the complex of risk factors involved are scarce. One such study is conducted by the local NGO Medica Zenica (1999) which shows that gender violence is a deep rooted and widespread problem in the Bosnian town of Zenica.

What precisely happened in terms of gender violence during the conflict in Tajikistan has not been studied systematically (yet). We do know, however, that women became the "honor" victims of war crimes between communities (Tadjbakhsh, 1994). I was regularly told that in certain villages in various parts of Tajikistan, virtually every woman was beaten and raped. Harris (2000 : 193) writes that what happened was "raping with bottles and other objects, some of them large and/or sharp enough to cause very serious physical damage indeed; shooting in the pelvis or the abdominal area, burning them alive; taking them captive and subjecting them to humiliation and violence over long periods".

Some figures concerning women's experiences with gender violence are available thanks to a nation-wide study done by the local NGO Open Asia with support from the international organizations WHO, SDC and UNDP. During womanhood (age $15+$ ), approximately $50 \%$ of women experienced physical, psychological and/or sexual violence by a family member; $47 \%$ of women experienced sexual abuse by their husband. Most of the risk factors listed in the ecological model for partner violence (see above) appear to apply to Tajikistan. There are also risk factors, however, which are specific to the Tajik situation. For instance, traditional and polygamous marriage instead of civil marriage, low level of education/information, refugee status, living in a rural area, living in a region that suffered a great deal from the civil war, and traditional Islamic religious surroundings. To what extent all these risk factors also play a role in the Former Yugoslavia we may only guess since there are no studies available to confirm or refute this. 
In Tajikistan the problem of the universality versus cultural relativity regarding individual women's rights comes clearly to the fore. What is considered to be acceptable and unacceptable forms and amounts of aggression can differ from one (sub)culture to the other. Psychological violence which, I am told, is considered to be acceptable in Tajikistan is for instance: isolation and restriction of freedom of behavior by husband or in-laws; restriction on freedom of dress by husband and in-laws; need to ask permission to husband and inlaws to go out and do things; husband refusing to collaborate in house-work and upbringing of children. Another issue is that Tajikistan knows forms of domestic violence that are not universal. It is for instance common that a woman is forced by her parents to marry and is abused by her mother-in law or her brother. What the specific risk factors are for these kinds of violence would need further elaboration, together with what the risk factors are for the various types of violence in the community, like: abduction of girls, rape by a stranger, use of women for drug traffic, women being forced into prostitution, etc. All these issues seem also relevant in the various contexts of the Former Yugoslavia.

The serious social crises Tajikistan went through during the last decade are clearly reflected in an increase of gender violence. Women assign the increase after the war (1992-1993) in particular to deteriorating socio-economic conditions. According to the survey, women attributed economic difficulties (93\%), lack of education $(77 \%)$, commonly held attitudes towards women (56\%) and low status of women in society $(86 \%)$ as major causes of gender violence. Harris (2000) stresses that Tajik society in all aspects of life, particularly gender norms, is very much shaped by the honor-and-shame system. The pressures of maintaining appropriate masculine gender performance highly contribute to gender violence. In this respect Tajikistan seems to be very similar to The Former Yugoslavia. 


\section{Women's Responses to Gender Violence: Women's Rights, EMPOWERMENT AND HEALTH PROMOTION}

As I have showed, gender violence is a complex issue when it comes to its various risk factors, its impact on society and its impact on individual women. Gender violence thus needs comprehensive responses for effective prevention and care for its victims. For instance, treatment of some of the health consequences may require gynecological in combination with psychotherapeutic services. And treatment of posttraumatic stress may require psychological help in combination with the provision of income generating activities ${ }^{6}$. From a public health perspective the prevention of gender violence will be most effective if one focuses on the societal and cultural roots of gender violence in the pre-conflict, conflict and post-conflict situation, like militarism, nationalism, and sexism resulting in abuses of all sorts (cf. Richters, 1998).

History has taught us that forced fast-timetrack, top-down approaches of development (for women) often meet with enormous resistance in the mentalities. Socialism in Tajikistan and the Former Yugoslavia was in essence a human rights movement wanting equality for men and women, but it failed in its implementation. The question is now what other approaches towards the development of a human rights climate might be more effective.

Long term experiences with the failure of top down development approaches have taught us that one thing we need is systematic, interdisciplinary research which can show whether the abstract formulation of external definitions of human rights can chime with indigenous, cultural specific norms that are based on human dignity without being detrimental to women. Social sciences seem to be

6. An interesting finding to mention in this context comes from a study carried out in the summer of 1994 in Bosnia that suggests that women highly distressed by the war derived greater benefit from group therapy than from occupational activities (Schei \& Dahl 1999). 
equipped to focus on the analysis of the meaning of social and cultural conditions and evaluate the possibility of introducing human rights (including women's rights) in such a manner that they are observed de facto and not predominantly acknowledged in a merely normative-rhetorical way. So they may help devise the most appropriate strategies for promoting and protecting human rights. Some sort of decentralization seems necessary to escape the power of the State and the corporation at the local levels. At the same time, however, we need international coordination and cooperation of groups and social movements interested in human rights and democracy. Thus, struggles for democracy and rights at the local level must be coupled with an institutional recognition of the global implications of these struggles at the international level. The question is how development or other agencies can act as some sort of mediator in this process.

The health promotion strategy within public health takes starts with the importance of empowerment. The strategy itself is to facilitate the behavioral, societal and environmental changes necessary for health promotion in communities as a whole. At the heart of this process is empowerment and capacity building at community level. Communities should be empowered to ownership and control of their own endeavors and destinies. Projects around the world have taught us that community empowerment, especially empowerment of women, is the key to successful programs for social change that affect the quality of life and health of poor and powerless families and communities.

A meta-analysis of 40 case studies across the world with regard to bottom-up "empowerment of women for health promotion" found that all grassroots movements began with a strong discontent and motivation for change among victims (Kar et al. 1999). It was not necessary to persuade or motivate them; they needed empowerment opportunities and organized support in their struggle. They received support from their fellow victims, concerned professionals, community and/or religious leaders and organizations close to their struggle. Such 
support promotes psychological empowerment of the innovators and enhances their self-efficiency. External recognition and support enhance institutionalization and wider adoption of landmark local initiatives. Recognition from credible national and international organizations legitimizes a struggle that empowers those involved. It also helps generate resources, stabilize and expand the program and enhance its diffusion.

In the Former Yugoslavia and Tajikistan a number of women's NGOs and informal women's groups have responded in various ways to the different kinds of gender violence I have discussed. Which (complex of) risk factors and root causes and which (complex of) health consequences are addressed may differ between the various groups and organizations. Some of the groups and NGOs I have met or read about seem to have been successful in their own field, albeit within a limited scope (cf. e.g. Richters, 1998).

One of the lessons learned from the operation of women's projects addressing gender violence in the Former Yugoslavia is that most of them could only operate on the scale and intensity they did thanks to financial and moral support from abroad and various kinds of expertise offered by foreign women's organizations. While the manipulation of women's assault by the media for political ends contributed to women's victimization, that same media attention resulted, for the first time in history, in special programs to help survivors of wartime rape cope with their war traumas. The Dutch NGO ADMIRA, for instance, was founded to provide information, advice, support and training for NGOs in the Former Yugoslavia working with multitraumatized women from different ethnic and religious communities (Foeken, 1999). The regular welfare and health care organizations and also many foreign IGOs and NGOs proved to be rather insensitive to women's sexual traumatization, and did not know how to approach it. Therefore ADMIRA chose a multi-track policy: support to institution building and training and advice with regard to work with traumatized women and girls, specifically in relation to sexual abuse. What proved most welcome was knowledge about modern 
forms of psychotherapy and counseling, since in the Former Yugoslavia psychiatric care was very traditional and dogmatic. Nevertheless, understanding of and respect for the professional ability of local colleagues in their own socio-cultural context was very much acknowledged and respectful listening was practiced by the ADMIRA trainers. In the process approaches and working methods were developed which aimed at enabling women (and others) to find their own solutions, rather than telling them what they need and what they should do.

ADMIRA's experience confirms what many other authors have observed. What women in former communist systems need to learn is how to play active roles rather than passively wait for the government to act, as they were trained to do by a system in which everything came from above. They must begin to define emancipation in their own terms, defend their already existing rights, and prevent the manipulation of women's bodies and minds. This is why support to training processes aimed at democratic institution building and conflict resolution became such an important element in the ADMIRA project. Perhaps this is what wounded societies and cultures like the Former Yugoslavia's and in Tajikistan's need most, not only with respect to the healing of the wounds of war but also to prevent further sexual violence and future wars.

Incidental women's projects promoting empowerment at grassroot level like they exist in Tajikistan are an important step towards the realization of women's rights and the eradication of gender violence. But eventually these first steps should lead to mainstreaming gender policies. Only a powerful women's movement may succeed in keeping (in The Former Yugoslavia), c.q. bringing (in Tajikistan) the issue of sexual violence and other kinds of gender violence on the agendas of welfare organizations, media and authorities. Real changes require patience and persistence, the implementation of universal human rights in a culture-sensitive way, individual care and political projects. 
General guidelines for intervention in gender violence should be adapted to particular socio-cultural contexts on the basis of longterm action and participatory research. In this action and research the gender dimensions of the culture and society concerned before, during and after the war should always be taken into account. However, privileging gender as the unifying element of the community of all women should be avoided, since issues pertaining to class, nationality, race, ethnicity, religion, or sexuality usually intersect with those of gender. They all influence the role the various forms of gender violence play in the different phases of conflict and the experiences of women with gender violence ${ }^{7}$.

\section{REFERENCES}

Anderson, A. (1999) "Feminist psychology and global issues: An action agenda", in S. Sharratt \& E. Kaschak, Eds. Assault on the soul: Women in the former Yugoslavia, pp., 7-23. New York: The Haworth Press.

Cockburn, C. (2000) Gender and democracy in the aftermath of war: Women's organization in Bosnia-Herzegovina. Utrecht: Universiteit voor Humanistiek.

Foeken, I. (1999) "Confusing realities and lessons learned in wartime: Supporting women's projects in the former Yugoslavia", in S. Sharratt \& E. Kaschak, Eds. Assault on the soul: Women in the former Yugoslavia, pp. 91-107. New York: The Haworth Press

Harris, C. (2000) Control and subversion: Gender, Islam, and socialism in Tajikistan. Thesis, University of Amsterdam.

Harris, C. (2001)...

Haydn, R.M. (2000) "Rape and rape avoidance in ethno-national conflicts: Sexual violence in liminalized states", American Anthropologist 102(1):27-42.

Heise, L. et al. (1994) "Violence against women: the hidden health burden". World Bank Discussion Paper \# 255. Washington D.C.: The World Bank.

7. In this article I left the vulnerability of men for sexual violence in war out of consideration. See for a discussion of this issue e.g. Zarkov 2001. 
Heise, L. (1998) "Violence against women: An integrated, ecological framework", Violence against women 4(3):262-290.

Heise, L. et al. (1999) Ending violence against women. Population reports, Series L, No. 11. Baltimore: Johns Hopkins University School of Public Health.

Herman, J. (1992) Trauma and recovery: The aftermath of violence - from domestic abuse to political terror. USA: Basic Books.

Hof, C. \& A. Richters (1999), "Exploring intersections between teenage pregnancy and gender violence: Lessons from Zimbabwe", African Journal of Reproductive Health 3(1):51-66.

Kar, S.B. et al. (1999) "Empowerment of women for health promotion: A metaanalysis", Social Science \& Medicine 49: 1431-1460.

Medica Zenica (1999) To live with(out) violence. Final report - Violence against women. Zenica: Infoteka, Medica Zenica.

Mladjenovic, L. (1999) “Beyond war hierarchies: Belgrade feminists' experience working with female survivors of war", in S. Sharratt \& E. Kaschak, Eds. Assault on the soul: Women in the former Yugoslavia, pp. 83-91. New York: The Haworth Press.

Olujic, M.B. (1998) “Embodiment of terror: Gendered violence in peacetime and wartime in Croatia and Bosnia-Herzegovina", Medical anthropology quarterly 12(1):31-50.

Rejali, D. M. (1996) "After feminist analyses of Bosnian violence", Peace review $8(3): 365-371$.

Richters, A. (1994) Women, culture and violence: A development, health and human rights issue. Leiden : VENA.

Richters, A. (1998) "Sexual violence in wartime: Psycho-sociocultural wounds and healing processes - The example of the former Yugoslavia", in P.J. Bracken, \& C. Petty, Eds. Rethinking the trauma of war, pp. 112-128. London: Free Association Books.

Richters, A. (2001) “Trauma as a permanent indictment of injustice: A socio-cultural critique or DSM-III and DSM-IV", in M. Verwey, Ed. (2001) Trauma und Ressourcen - Trauma and empowerment, pp. 53-75. Berlin: Verlag für Wissenschaft und Bildung.

Schei, B. \& S. Dahl (1999) “The burden left my heart: Psycho-social services among refugee women in Zenica and Tuzla, Bosnia-Herzegovina during the war", in S. Sharratt \& E. Kaschak, eds. Assault on the soul: Women in the former Yugoslavia, PP, 139-153. New York: The Haworth Press.

Skjelsbaek, I. (1999) Sexual violence in times of war: An annotated bibliography. Oslo: International peace research institute.

Skjelbaek, I. (2001) "Sexual violence and war: Mapping out a complex relationship", European journal of international relations 7(2):211-237. 
Suarez-Orozco, M.M. \& A.C.G.M. Robben (2000) “Interdisciplinary perspectives on violence and trauma", in idem (Eds.) Cultures under siege: Collective violence and trauma, pp. 1-43. Cambridge: Cambridge University Press.

Summerfield, D. (2000) "Childhood, war, refugeedom and "trauma": three core questions for mental health professionals", Transcultural psychiatry 7(3):417433.

Tadjbakhsh, S. (1994) “Women and war in Tajikistan”, Central Asia Monitor, OnLine Supplement, Issue No. 1. Pp. 1-5.

Tadjbakhsh, S. (1998) "Between Lenin and Allah: Women and ideology in Tajikistan", in H.L. Bodman \& N. Tohidi (Eds.) Women in Muslim societies: Diversity within unity, pp. 163-187. Boulder, Col.: Lynne Rienner Publishers.

Zarkov, D. (1999) From "media war" to "ethnic war". The female body and the production of ethnicity in former Yugoslavia (1986-1994). Thesis, University of Nijmegen.

Zarkov, D. (2001) "The body of the other man: Sexual violence and the construction of masculinity, sexuality and ethnicity in Croation media", in C.O.N. Moser \& F.C. Clark, Eds. Victims, perpetrators or actors? Gender, armed conflict and political violence, pp. 69-83. London: Zed Books.

World Health Organization (1996) Violence against women. Geneva: WHO.

World Health Organization (2000) Violence against women: Report on the 1999 WHO pilot survey in Tajikistan. Copenhagen: WHO, Family and reproductive health unit. 


\section{Micheline Centlivres-Demont}

\section{HOMMES COMBATTANTS, FEMMES DISCRÈTES: ASPECTS DES RÉSIST ANCES SUBALTERNES DANS LE CONFLIT ET L'EXIL AFGHANS}

Contrairement aux traditions de résistance féminine lors des guerres anglo-afghanes $d u$ XIX siècle, l'interminable conflit afghan, qui commence au coup d'Etat d'avril 1978, a suscité peu de prouesses guerrières féminines. Le caractère islamique et traditionaliste de la résistance afgha ne y est peut-être pour quelque chose. Dans ce conflit, lesfemmes afghanes semblent avoir été avant tout des victimes, une condition d'ailleurs utili sée par les partis à des fins de propagande.

Dans les camps de réfugiés au Pakistan, la «gestion» des femmes, en par ticulier des veuves sans soutien de famille, a provoqué un conflit entre les notables afghans et les experts des organisations internationales.

Cependant, on aurait tort de considérer les rapports hommes-femmes dans le conflit afghan comme une simple relation de subordination entre l'autorité des uns et la passivité des autres. La résistance discrète des femmes s'est exercée aussi bien contre l'adversaire commun que contre la situation qui leur est imposée.

Quelques héroïnes guerrières afghanes se fraient un chemin dans les manuels d'histoire afghane à l'époque de Zaher Shah (1933-1973); elles avaient pris part au $\mathrm{XIX}^{\mathrm{e}}$ siècle à la lutte contre les troupes britanniques des Indes, c'est ce que rapportent du moins des historiens afghans. 
A la bataille de Maiwand (27 juillet 1880), au cours de la deuxième guerre anglo-afghane (1878-1880), les Afghans étaient acculés à la défaite, leur porte-drapeau tué. C'est alors qu'une jeune fille, Malalaï, ramassa l'étendard et exhorta les hommes au combat. Les combattants galvanisés par son exemple mirent alors les Britanniques en fuite et remportèrent la victoire. Certains récits disent que Malalaï fut tuée sur le champ de bataille.

Mythe ou personnage historique, Malalaï est pour les Afghans le symbole du courage féminin l'emportant sur les hommes par son héroïsme. Légende ou vérité, elle est l'image d'une meneuse d'hommes; elle incarne la bravoure, le sacrifice. Pour les Britanniques, en revanche, qui affrontèrent les Afghans au XIX ${ }^{e}$ siècle, la femme afghane est objet de terreur, non parce qu'elle porte des armes mais parce qu'elle a la réputation de hanter les champs de bataille à la nuit tombée, d'achever les blessés et d'arracher des trophées sanglants (Centlivres-Demont 1994 : 362).

$\mathrm{Au}$ cours du $\mathrm{XX}^{\mathrm{e}}$ siècle, Malalaï est récupérée par le courant nationaliste et moderniste qui tente de bâtir une identité de femmes pardelà celle d'épouse et de mère, incarnant les luttes de la construction nationale. Ainsi le premier lycée de jeunes filles à Kaboul, créé en 1940 et où l'enseignement était donné en français, porte le nom de Malalaï. L'un des partis communistes afghans donne, il y a un quart de siècle, l'exemple de Malalaï comme celui d'une femme libérée de l'arriération et la compare à Jeanne d'Arc (Tarzi 1999). Plus tard, après le coup d'Etat marxiste de 1978 et l'intervention soviétique, leurs adversaires font de Malalaï le symbole du combat contre l'ennemi étranger et non musulman. Pour certains intellectuels afghans aujourd'hui pourtant, nous serions là en présence d'un cas d' «invention de la tradition", pour reprendre le titre de l'ouvrage de Hobsbawm et Ranger (1983).

De l'histoire afghane en général, les femmes ne sont pas absentes, en particulier les épouses et mères de souverains durrani (XVIII ${ }^{e}$ et $\mathrm{XIX}^{\mathrm{e}}$ siècles) qui favorisèrent la carrière de leurs maris et de leurs fils. 
Cependant, elles n'eurent aucune activité guerrière et exercèrent leur influence dans le quartier des femmes. Les sources historiques afghanes tout comme européennes du XIX ${ }^{e}$ siècle parlent certes d'Afghanes apportant de l'eau aux combattants sur les champs de bataille, mais elles ne sont pas armées.

La société afghane et la société pachtoune sont le théâtre de la domination masculine. Ces sociétés sont pour l'essentiel régies par les valeurs masculines, guerrières, dans un environnement virilisé à l'extrême où les femmes, la plupart analphabètes, ne sont pas en mesure de jouir même des droits que leur confère la tradition religieuse ou tribale; elles subissent une double oppression: physique et morale. Par ailleurs, elles représentent une sorte de témoin caché de l'honneur masculin, pour lequel elles sont aussi, par leur inconduite éventuelle, une menace. «C'est l'opinion de la femme, le regard de la femme, qui décident de comment l'homme doit se comporter selon son propre code de l'honneur», dit l'écrivain et poète afghan, Sayd Bahodine Majrouh (1988 : 31). Les femmes peuvent s'entremettre dans des conflits internes, mais restent en dehors du groupe des hommes de la tribu et de leurs réunions coutumières. Par leur potentialité sexuelle et leur prétendue faiblesse, elles sont une proie éventuelle pour tout ce qui vient de l'extérieur du cercle domestique et familial, donc un des points faibles de l'honneur des époux et des frères. Au combat, elles ne portent pas les armes, mais elles exhortent les hommes au courage, exaltent leur héroïsme. Les femmes sont les gardiennes du foyer et de l'intégrité du lignage, construit selon la filiation masculine. Dans la culture pachtoune, les landay (poèmes de deux vers libres de 9 et 13 pieds, sans rimes obligatoires) sont, pour et par les femmes, un moyen d'expression où «la femme prend l'homme au piège de ses propres valeurs» (Majrouh 1988 : 32). La femme ne peut aimer qu'un guerrier mais seulement un guerrier qui a prouvé sa valeur et ne recule pas devant la mort. «Je ne vais qu'au courage, disent-elles, jamais je n'aimerai un lâche. »

«Puisses-tu périr au champ d'honneur, mon bien-aimé Afin que les filles chantent ta gloire chaque fois qu'elles s'en iront puiser l'eau à la Source» (id.: 33). 
«Aujourd'hui pendant la bataille, mon amant a tourné le dos à l'ennemi.

Je me sens humiliée de l'avoir embrassé hier soir. » (id. : 33)

Cependant, dans la société afghane, dans la vie quotidienne, la femme est dans l'ombre de l'homme. Au cours du XX $X^{e}$ siècle, pour les «progressistes» afghans, elle est symbole d'arriération, et donc son émancipation mise au centre des projets de modernisation voulus par l'élite éclairée de Kaboul. Dans les faits, les femmes accèdent à des «libertés» plus par les progrès législatifs voulus par le souverain et le premier ministre que par leur volonté à elles ou par un mouvement féministe. Objets d'une condition définie par d'autres, beaucoup de femmes afghanes ont intériorisé la condition d'infériorité à elles imposée par leurs maîtres. Comme le remarque Nancy Dupree, les femmes afghanes se sont vu accorder ou refuser leurs droits par des gouvernants masculins, sans qu'elles aient eu la possibilité de se battre pour leur cause (Dupree 1998 : 5). Le flux et le reflux des «progressistes» et des "conservateurs» en matière d'émancipation des femmes jalonnent le $\mathrm{XX}$ e siècle afghan. Sous le roi Amanullah (1919-1929), un premier mouvement d'émancipation se dessine: écoles de jeunes filles, formation d'infirmières, étudiantes envoyées à l'étranger, journaux et associations de femmes; cependant ces mesures ne touchent que des femmes des classes moyennes supérieures de la capitale. Il faut attendre 1959, année où le premier ministre Mohammad Daoud ordonne le dévoilement des femmes lors des cérémonies publiques, et surtout la Constitution de 1964 et les élections de 1965 pour que quelques femmes occupent un siège au Parlement ou obtiennent un portefeuille de ministre. On assiste à une promotion-modernisation forcée sous le régime communiste de 1978 à 1992, suivie d'un retour en arrière avec l'arrivée des moudjahidin à Kaboul, et enfin à un confinement quasi absolu, spécialement à Kaboul, dès 1996, avec les taliban.

Au milieu des années 60, l'Organisation démocratique des femmes afghanes, l'Organisation des jeunes filles scoutes ainsi que d'autres 
associations furent mises sur pied pour développer la conscience sociale et politique des femmes afghanes et introduire des réformes, mais elles émanaient de cercles relativement étroits et élitistes: la bourgeoisie, les cercles de l'aristocratie et les milieux urbains éduqués, d'où venaient d'ailleurs aussi les femmes des différentes tendances du parti communiste afghan (Centlivres-Demont 1994 : 342).

Les milieux traditionalistes s'opposèrent souvent violemment au mouvement relatif d'émancipation des femmes. Leur résistance aux réformes s'est focalisée sur une certaine libéralisation des mœurs plutôt que sur les droits politiques obtenus par les femmes.

Le coup d'Etat marxiste d'avril 1978 suivi de l'intervention soviétique de décembre 1979 vont remettre en question, selon deux conceptions diamétralement opposées, la position des femmes et les rapports entre hommes et femmes dans la guerre, la résistance et l'exil. En octobre 1978, le gouvernement communiste du président Taraki décréta des mesures instaurant l'alphabétisation forcée des femmes et des hommes et l'éducation mixte. D'autres directives réglementèrent plus particulièrement le mariage et le douaire. Ces mesures furent considérées par la population comme contraires aux traditions et aux croyances religieuses; appliquées brutalement, elles touchaient à ce qui pour les Afghans fait partie de la sphère privée liée à l'honneur masculin; elles conduisirent à une résistance des milieux traditionnels et des campagnes, puis à l'opposition armée. Suite à la riposte violente de Kaboul, des centaines de milliers d'Afghanes et d'Afghans quittèrent leur pays pour se réfugier au Pakistan et en Iran.

Cependant, sous le gouvernement communiste de Kaboul (19781992), les mesures d'émancipation des femmes de la capitale s'accélérèrent: cours, apprentissages, emplois gouvernementaux, stages à

1. Deux d'entre elles ont fait une tournée aux USA en mai 2000 (New York Times Magazine, 14 mai 2000), suite à quoi Meena Nanji, une cinéaste afghane établie à Los Angeles est venue au Pakistan tourner un film sur les femmes afghanes au Pakistan (The Digital Talkies Magazine, Inde, vol. 1/6, $1^{\text {er }}$ janvier 
l'étranger, c'est-à-dire en URSS et dans les pays du bloc soviétique. Dans l'armée pourtant, le régime n'intégra pas de femmes dans ses unités de combat même si un certain nombre d'entre elles ont servi dans la milice communiste à Kaboul et dans les campagnes où elles participèrent à des combats défensifs au même titre que les hommes (Dupaigne 2000 : 26). Des magazines publièrent quelques photos de femmes portant une arme dans les rangs de la milice (Afghanistan Today, mars-avril 1986, $\mathrm{n}^{\circ} 2: 28$; Afghanistan Today, janvier-février 1990, $\mathrm{n}^{\circ} 1: 2$ ) ou d'une jeune parachutiste (Afghanistan Today, juillet-août 1988, n $4: 13$ ). Mais il n'y eut pas de recrutement généralisé d'unités féminines armées.

De son côté, la résistance islamique au régime communiste fit encore moins appel à des combattantes - contrairement à ce qu'avait fait l'Iran voisin - et s'est gardée de glorifier des figures héroïques féminines. "Nous n'avons pas de femmes combattantes; Dieu soit loué, nous avons suffisamment d'hommes», s'écrie le moudjahid Shah Bazgar (1987 : 174). Si les femmes participent au djihad, c'est comme épouses, mères et sœurs des moudjahidin; elles cachent à l'occasion des résistants. Sous le chadri, certaines transportent des munitions, du ravitaillement et des tracts parfois jusqu'au centre de Kaboul. Mais comparées à l'image des Iraniennes, par exemple, les Afghanes sont restées à l'arrière-plan de la résistance armée. Leur participation dans le djihad est indirecte, et ce n'est qu'en auxiliaires des combattants, et non en combattant elles-mêmes, qu'elles font l'objet de mentions (Centlivres-Demont 1983; 1994 : 362).

Seuls les hommes peuvent être moudjahidin et par conséquent martyrs, c'est-à-dire tombés en combattant au cours de la guerre sainte et, par leur mort, témoins de la foi. Les femmes, durement touchées par la guerre, sont l'objet de pitié. Les organes de presse des partis de la résistance anticommuniste et leurs états-majors se préoccupaient des veuves chassées de leurs foyers par la guerre et qui avaient difficilement accès à l'aide internationale. Pour les Afghans comme pour l'opinion internationale, il s'agissait avant tout de victimes, témoignant malgré elles de l'inhumanité de l'ennemi, et non d'héroïnes 
nationales ou de témoins de la foi. Ajoutons que les actes d'héroïsme de lycéennes de Kaboul manifestant contre le régime communiste en mars 1980 et ceux de nombreuses villageoises étaient presque passés sous silence par les partis de la résistance, comme peu conformes à l'ethos féminin.

Pour les partis islamistes de la résistance, «l'émancipation des femmes afghanes ne saurait être semblable à l'émancipation des femmes occidentales. La femme afghane a sa propre culture et ses problèmes spécifiques..." (Résistance/Renaissance Afghane, $\mathrm{n}^{\circ} 2$, mars-avril 1988: 5).

Une exception cependant; celle de RAWA (acronyme de Revolutionary Association of the Women of Afghanistan), une association de femmes progressistes fondée en 1977 par Kishwar Kamal, connue sous le nom de Mina et assassinée à Quetta (Pakistan) en 1987. Etablie à Quetta, l'association s'est opposée au régime communiste de Kaboul et a toujours été en conflit avec les sept partis de la résistance établis à Peshawar, et en particulier avec les islamistes, et donc maintenant avec les talibans. RAWA a été et est la seule organisation de femmes à promouvoir la lutte armée pour les femmes; elle a organisé des grèves dans des usines textiles de Kaboul en 1987 (Centlivres-Demont 1994 : 361). Inutile de dire qu'elle était largement minoritaire parmi les partis de la résistance. Aujourd'hui, toujours depuis Quetta, les membres de RAWA luttent pour l'instruction, la promotion des femmes, la reconnaissance de leurs droits. Elles entretiennent un hôpital (le Malalaï Hospital justement) pour femmes et enfants à Quetta, des écoles pour garçons et filles dans les camps de réfugiés au Pakistan et, clandestinement, des cours à domicile pour filles et femmes en Afghanistan. A Islamabad, à l'occasion du Jour des droits de l'homme (12.12.2000), une démonstration de RAWA contre le régime taliban a tourné à l'affrontement avec des Pakistanais qui ont alors incendié des boutiques de commerçants afghans. 
Le cas des réfugiés afghans est unique au $X X^{e}$ siècle: ils ont constitué la plus grande population de même origine réfugiée hors ses frontières: plus de 3,2 millions au Pakistan et plus de 2 millions en Iran dans les années 1980. Malgré le retour de près de la moitié d'entre eux à partir de 1992, il en reste 2,4 millions au Pakistan et en Iran, auxquels sont venus s'ajouter depuis l'été 2000 des dizaines de milliers d'Afghans fuyant la sécheresse, la famine et les combats dans le nord-est du pays.

Durant les années 80, dans les camps au Pakistan, les femmes adultes représentaient environ $28 \%$ des réfugiés (Centlivres et CentlivresDemont, 1988 : 72 ; id. 1999 : 953). Pour le HCR, comme pour les organisations qui plus tard, allaient s'installer en Afghanistan, il y avait là un "groupe vulnérable», des victimes parmi les victimes, alourdi encore par les $48 \%$ d'enfants que comportait la population réfugiée. Il y avait surtout pour les organisations internationales (OI) une cause à défendre, celle de l'égalité et de l'émancipation des femmes, d'où l'importance de "to raise, and be firm on, issues of principle - human rights, gender [...]» (Donini et al. 1996 : 3).

La gestion de l'élément féminin du groupe domestique dans un contexte de camp posait de nombreux problèmes aux chefs de famille. Pour eux en effet, comme pour tant de sociétés «tribales» du Moyen-Orient, les femmes représentent une préoccupation centrale liée à l'ethos masculin, un point sensible par lequel l'honneur peut être mis en danger, un domaine interne sur lequel l'étranger, et même le voisin, n'a aucun droit de regard. "Women make men vulnerable», écrit justement Edwards (1996 : 243, note 23). Le contexte de promiscuité des camps, l'entassement de familles et la présence de célibataires étrangers à la famille, la perspective d'inspections et de vérifications de la part de membres d'OI, la visite de journalistes ou d'experts rendaient la protection de l'espace privé féminin extrêmement difficile. Un domaine sensible donc.

Alors que les hommes afghans s'efforçaient de maintenir l'invisibilité des femmes, les OI et le Haut-commissariat aux réfugiés (HCR) 
cherchaient au contraire, et cherchent toujours, à mobiliser les femmes, à les rendre autonomes, à encourager diverses formes d'apprentissage, à assurer l'accès direct des femmes chefs de famille au même titre que les hommes aux distributions des rations alimentaires et celui des filles à l'instruction dans les écoles des camps. Les OI et les organisations non gouvernementales (ONG) ont mis sur pied dans les années 80 , souvent avec succès, des ateliers de broderie ou des réseaux de brodeuses à domicile, dont les produits créés pour un marché occidental, étaient commercialisés dans les boutiques gérées par ces organisations. Pourtant, dans l'Afghanistan d'avant-guerre, vendre ses broderies (bonnets, tentures...) était pour une femme signe de grande pauvreté, ces objets étant destinés au seul cercle domestique, exception faite pour les tapis tissés et noués. En exil, l'entrée d'un artisanat domestique dans la logique du marché et sa commercialisation furent peut-être un signe de promotion, mais un signe ambigu. De leur côté, les hommes se montraient très méfiants vis-à-vis des projets destinés aux femmes, surtout depuis les tentatives de la République démocratique afghane (1978) pour faire participer les femmes à des cours d'alphabétisation et des manifestations de rues pro-gouvernementales.

Les (hommes) Afghans réagirent fortement contre des mesures qui leur arrachaient, en partie du moins, la responsabilité de la protection et du contrôle des femmes. Dans les camps de réfugiés, du fait de leur inactivité et de leur dépendance économique, beaucoup d'hommes se sentirent humiliés et privés de leur rôle de chefs de famille. Peut-on parler de «revanche» pour les talibans qui restaurent aujourd'hui la primauté masculine dans tout l'espace public?

En 1982, le HCR établit un camp «autonome» de veuves et d'orphelins, près de Peshawar; ce camp fut attaqué par des réfugiés d'un camp voisin, comme contraire aux usages afghans. Des intellectuels du Hezb-e islami, le parti islamiste de Gulbuddin Hekmatyar, rappelèrent que la polygynie et le lévirat, loin d'être des usages dégradants et attardés, permettaient au contraire de résoudre les problèmes nés de la surmortalité masculine en temps de guerre en 
obligeant les parents mâles survivants à prendre en charge les veuves de leurs proches qui trouvaient ainsi une solution à leur veuvage. Cependant, du fait de la dispersion des familles et de l'éloignement du milieu d'origine, beaucoup de veuves se replièrent sur leur propre famille et retournèrent vivre chez leur père ou leur frère. On disait aussi que les veuves de shahidân, martyrs, pouvaient refuser de se remarier, contrairement à l'usage tribal. Quant aux écoles des camps, elles n'accueillirent que des fillettes d'âge prépubère.

Pourtant, le discours des leaders politiques afghans de la résistance sut s'adapter dans une certaine mesure à celui des OI et à leur insistance sur l'égalité des hommes et des femmes. Contrairement à d'autres chefs de parti, Hekmatyar se déclara favorable au suffrage féminin. Le Hezb-e Wahdat, qui regroupe les principaux mouvements chiites hazaras, introduisit plusieurs femmes dans ses organes législatifs (assemblées) au début des années 90.

Un tournant se dessine dès 1994 avec l'arrivée des talibans sur la scène afghane et surtout dès septembre 1996 avec la prise de Kaboul.

Est-il nécessaire de rappeler que les décrets des talibans à l'égard des femmes aboutissent pratiquement à les exclure de la sphère publique, en leur interdisant, dans les villes, de travailler hors de leur domicile, ce qui a mis au chômage des dizaines de milliers d'employées, de représentantes de professions libérales et les collaboratrices des OI, et ce qui a rendu encore plus difficiles les conditions d'existence des veuves, plus de 50000 dans la seule capitale afghane. Jusqu'en 1996, avant l'arrivée des talibans à Kaboul, l'administration de l'Etat comptait $60 \%$ de femmes, occupant la plupart du temps des emplois subalternes. Mais la rigueur actuelle touche aussi bien les hommes que les femmes, puisque ce sont les maris qui sont punis d'une amende, de bastonnade ou de prison en cas d'infraction aux décrets par leurs épouses, preuve que le régime insiste sur la responsabilité masculine dans le contrôle du comportement féminin. Le principe de la séparation totale des sexes s'est étendu dans un premier temps également aux soins hospitaliers avec un système médical tota- 
lement cloisonné. Le régime a depuis, sur ce point, fait quelque peu marche arrière. La société tout entière subit le contrecoup d'un régime qui, tout en ayant diminué l'insécurité des vies et des biens, impose par la force une utopie morale sans apporter de solution à l'appauvrissement général dû aux destructions et au sous-développement.

Dans une grande ville comme Kaboul, il est clair que l'application de ces normes est particulièrement choquante et discriminatoire. Le recours aux mesures répressives, à une conception crispée de la place de l'homme et de la femme dans la société révèle une angoisse profonde, causée par l'impuissance et l'humiliation des hommes au travers des désordres de la guerre.

L'ordre taliban, ancré dans une interprétation très étroite de la loi religieuse, la charia, se réclame d'un projet global et systématique touchant l'ensemble de la société. Les talibans nient que les mesures décrétées le soient à l'encontre des femmes et les privent de leurs droits. Ils affirment au contraire rétablir ces derniers par une stricte application de la charia et imposer le juste rapport entre les hommes et les femmes. Ils affirment enfin œuvrer en faveur de l'honneur des femmes, de leurs droits et de leur dignité (Centlivres 1999).

Quels sont ces droits? Quels sont les fondements de la condition féminine selon Mullah Omar, le commandeur des croyants de l'Emirat islamique d'Afghanistan? Sa doctrine implique tout d'abord une certaine conception de la nature féminine qui fonde la différenciation des tâches et des responsabilités. Selon Mullah Omar: «Dieu Tout-Puissant a conçu l'homme et la femme différemment afin qu'ils remplissent des fonctions distinctes sur cette terre. »

Peut-être en réaction à l'indignation de la communauté internationale, mais aussi pour affirmer la supériorité et la priorité des principes de la loi islamique sur les usages tribaux familiers aux talibans, Mullah Omar a promulgué à l'automne 1998 un décret en sept points, qui condamne des pratiques fondées sur le droit coutumier 
tribal et répandues en Afghanistan. Le premier et le quatrième points réaffirment le droit des femmes à une part de l'héritage (la moitié de celle des hommes); le deuxième condamne l'échange des femmes ou la remise d'une femme pour le règlement d'un conflit, en compensation d'un meurtre par exemple; le troisième rappelle que nul n'a le droit d'obliger une veuve à épouser un parent de l'époux décédé. Les points cinq, six et sept insistent sur l'accord nécessaire des futurs conjoints en vue du mariage, et en particulier sur l'accord de la femme et son consentement. Ce décret est-il appliqué?

Au travers d'un carcan d'interdictions, en l'absence de réseaux d'information et de communication modernes, dans un pays ruiné et vidé de son élite scolarisée, les femmes afghanes n'ont pas baissé les bras. La guerre et l'exil ont rapproché les habitantes des villes de celles des campagnes. Alors qu'avant la guerre, les services sociaux et les emplois féminins ne fonctionnaient que dans les zones urbaines, aujourd'hui ces services subsistent et se développent avec l'aide des ONG dans les campagnes. Ce sont dans les régions rurales que l'on trouve la majorité des quelques médecins restés au pays. Comparé avec les années d'avant-guerre, l'accès des femmes et des filles aux services de santé et à l'éducation est plus élevé dans les zones rurales que dans les zones urbaines. Et ce sont quelques femmes afghanes, venues des villes, qui, sous le chadri et accompagnées de gardiens que leur impose le régime, forment d'autres femmes aux règles d'hygiène. Elles utilisent des moyens simples pour rendre ces femmes responsables, leur apprendre qu'elles appartiennent de plein droit à la société. C'est leur façon de combattre, non dans les rangs des militaires ou des milices, mais sur le plan social, comme militantes du savoir et de la santé. Carol LeDuc, du Swedish Committee for Afghanistan, témoigne de la part que prennent des femmes dans le fonctionnement de la société civile (1999 : 13-15). Des femmes, à Kaboul et en province, font l'école à des enfants à domicile; les talibans ferment les yeux s'il s'agit de fillettes prépubères. A Kandahar (v. Paris Match, 10 janvier 2001), des jeunes femmes, totalement voilées, suivent les cours d'infirmières, sous la haute surveillance des talibans. 
A l'écart des centres urbains, il y a une faible marge de manœuvre, des possibilités pour aller au-delà de ce qui est interdit. Là, les femmes se sentent plus fortes, elles s'adaptent; sans défier l'autorité, elles la contournent. Elles sont ce que le régime en place leur demande d'être: voilées, accompagnées et silencieuses en public. Elles ne protestent pas en parole; mais elles cherchent à agir, dans la discrétion et la dignité suivant en cela les préceptes religieux, dont disent s'inspirer les talibans.

\section{RÉFÉRENCES}

Bazgar, Shah

1987, Afghanistan: La résistance au cour. Paris, Denoël.

Centlivres, Pierre

1999, «Le mouvement taliban et la condition féminine», Afghanistan Info (Neuchâtel), nº 44, mars, pp. 11-13.

Centlivres, Pierre et Micheline Centlivres-Demont

1988, «The Afghan Refugees in Pakistan: A Nation in Exile», Current Sociology, Londres, 36/2, pp. 71-92.

1999, «Etat, islam et tribus face aux organisations internationales. Le cas de l'Afghanistan 1978-1998», Annales (Histoire, Sciences Sociales), n 4, juilletaoût, pp. 945-965.

Centlivres-Demont, Micheline

1988, «Les femmes afghanes aujourd'hui», Afghanistan Info (Neuchâtel), $\mathrm{n}^{\circ} 23$, pp. 17-18.

1994, «Afghan Women in Peace, War, and Exile.» In: Myron Weiner et Ali Banuazizi, ed: The Politics of Social Transformation in Afghanistan, Iran, and Pakistan. Syracuse, Syracuse University Press, pp. 333-365.

Donini, Antonio, Eric Dudley et Ron Oc kwell 1996, Afghanistan. Coordination in a Fragmented State. New York, Department of, United Nations.

Dupaigne, Bernard 2000, «La femme dans l'économie rurale», in La femme afghane à travers l'his toire de l'Afghanistan. (Actes du colloque, Unesco-Paris, 11 décembre 1998), Paris, Ceredaf, pp.19-31. 
Dupree, Nancy Hatch

1998, The Women of Afghanistan. Islamabad.

Edwards, David B.

1996, Heroes of the Age. Moral Fault Lines on the Afghan Frontier. Berkeley, University of California Press.

Hobsbawm, Eric et Terence Ranger, éd.

1983, The Invention of Tradition. Cambridge, University Press.

Kabul Times

1998, [articles parus dans les] $\mathrm{n}^{\text {os }} 25$ et 28 , octobre et novembre.

LeDuc, Carol

1999, «Perspectives on the Status of Women in Afghanistan», Afghanistan Info (Neuchâtel), no 45, septembre, pp. 13-15.

Majrouh, Sayd Bahodine

1988, Le suicide et le chant., Poésie populaire des femmes pashtounes. Traduit du pashtou et adapté par André Velter et l'auteur. s.l., Les cahiers des brisants.

Tarzi, Amin

1999, «Malalaï: la Jeanne d'Arc afghane». Les Nouvelles d'Afghanistan (Paris), $\mathrm{n}^{\circ} 87,4^{\mathrm{e}}$ trimestre, pp. 18-20. 
Clara InÉs MaZo López

\section{UNA MIRADA AL CONFLICTO ARMADO COLOMBIANO DESDE LA PALABRA, LAS ACCIONES, LAS PROPUESTAS Y LOS SÍMBOLOS CONSTRUIDOS POR LAS MUJERES}

"Cómo resistir?... porque a la vida le basta el espacio de una grieta para renacer"

Ernesto Sábato

UN REGARD SUR LE CONFLIT ARMÉ COLOMBIEN À PARTIR DES ACTIONS, DES SYMBOLES ET DES PROPOSITIONS CONSTRUITS PAR DES FEMMES

Le conflit armé interne en Colombie provoque le recul des transforma tions positives que le mouvement social des femmes avait réussi à intro duire. Les rôles et les valeurs de genre sur lesquels se fondent la discrimi nation, l'exclusion et la violence contre les femmes sont en train de se ren forcer. La logique de la guerre renforce la vision de la domination et de l'héroïsme comme attributs masculins, en même temps que la soumission et la discrétion comme attributs féminins. Actuellement, des négociations de paix se déroulent au milieu de la guerre (sans cessez-le-feu). La négo ciation est, elle aussi, un acte patriarcal, où les accords sont signés uni quement entre les hommes. A cet exercice politique, la majorité de la population ne participe pas davantage. Des femmes sont impliquées directement et de plusieurs manières dans le conflit. Mais nous autres, les 
femmes organisées, nous nous opposons à la guerre et à la solution des conflits et des différences par la voie armée, la disparition et la mort. Ce travail présente les actions concrètes de plusieurs groupes de femmes qui tentent de sauver et de faire connaître d'autres logiques possibles, diffé rentes de la logique de guerre, permettant de reconstruire des modes de vie «durables».

\section{La Corporación VAmos Mujer}

La Corporación Vamos Mujer nace en 1979, ligada al fuerte movimiento campesino de la ANUC (Asociación nacional de los usuarios campesinos) y al trabajo pastoral en Medellín. Nuestro propósito es acompañar procesos individuales y grupales en busca de la reconstrucción de la identidad de las mujeres y el fortalecimiento de sus formas organizativas. De esta manera, generar procesos de participación cada vez más conscientes, críticos y propositivos en el ámbito público y privado para contribuir a su posicionamiento social, a la tramitación negociada y pacífica de los conflictos y a la humanización y equidad de las relaciones entre hombres y mujeres en nuestro país.

Trabajamos con mujeres jóvenes, adultas, pobladoras de barrios populares y campesinas. Igualmente con mujeres y hombres jóvenes y desplazados por el conflicto armado. Nuestro trabajo se desarrolla principalmente en el departamento de Antioquía, así como en Medellín, Bello, Nordeste Antioqueño, Oriente Antioqueño, Urabá, Montería, Barrancabermeja, Villavicencio, Bogotá, Chocó. Los programas con los que contamos son "Mujer Rural Desarrollo, Medio Ambiente y Paz", "Programa Mujer y Hábitat Urbano", "Experiencia de Capacitación en Derechos Humanos Con Enfoque de Genero, con Población de Mujeres y Hombres Afectados por la Guerra".

Los siguientes son algunos de los componentes de la intervención. Fortalecimiento organizativo para el posicionamiento social y político de las mujeres. Trabajo de fortalecimiento de la identidad personal, de una posición de dignidad, ética no violenta y de no exclusión. 
Trabajo psicosocial de elaboración del duelo y fortalecimiento de esperanza en las mujeres y sus familias afectadas por el conflicto armado. Educación-formación-capacitación de las mujeres para el acceso a sus derechos. Mejoramiento de las condiciones materiales. Desarrollo de alternativas agroalimentarias, agroecológicas, económicas, sostenibles, rentables; que disminuyan la pobreza de las mujeres y consideren su aporte a la dinámica económica, y que incorporen una relación de respeto y preservación con los recursos naturales y el medio ambiente.

\section{EL ENFOQUE POLÍTICO DEL TRABAJO}

\section{EL FEMINISMO DESDE SUS VISIONES PACIFISTA Y ECOFEMINISTA}

Partimos de que la humanidad, mujeres y hombres, somos sujetos de derecho con la posibilidad de tener una vida digna y sin violencias, en la que se respeten los derechos fundamentales. Desde este enfoque asumimos que el respeto entre mujeres y hombres es el limite que preserva la vida, la integridad y la dignidad del otro $u$ otra y permite construir actos cotidianos y propuestas creativas que se contrapongan a la guerra y a la violencia.

Partimos del reconocimiento de igualdad de mujeres y hombres ante la ley, ambos géneros tenemos las mismas oportunidades en todos los campos de la vida, sin distingos de edad, etnia, sexo, opción sexual. Este enfoque implica que mujeres y hombres nos fortalezcamos en nuestras identidades individuales y colectivas, dando conscientemente una oportunidad mayor a que las mujeres reconstruyan su propia identidad y se posicionen y empoderen en la participación y las negociaciones cotidianas en todos los escenarios de la vida (el grupo familiar, la pareja, la parcela o finca, la vereda o barrio, el municipio, la región, la ciudad, el país, el planeta). Desde el enfoque feminista, la paz de Colombia no es un asunto teórico o ideal sino del orden de lo concreto en el que se tiene que responder por acciones que permitan prioritariamente a las mujeres, y también a sus 
familias, y al conjunto de la población, generar condiciones de desarrollo no violentas, equitativas y sostenibles, tanto materiales como de posicionamiento y participación social.

Como ecofeministas planteamos que las mujeres nos hemos construido un sentido de finalidad y de relación con el mundo, con los otros y otras, diferente al de los hombres. Nos hemos construido ideas de progreso y desarrollo diferentes a partir de nuestros referentes, de nuestras necesidades, intereses y potencialidades. Las mujeres hemos propuesto, soñado y en muchos casos construido, una relación igualitaria/equitativa con el mundo, expresando con esto una relación de respeto y justicia con la naturaleza/entorno y con los sujetos hombres y mujeres que nos rodean. Esto no significa que no seamos también responsables del daño ocasionado. Bajo este enfoque nos atrevemos a decir que las mujeres hemos tenido una relación estrecha con la vida y con el medio ambiente, lo que nos hace preservadoras y vigilantes. El ecofeminismo al interceder por "las otras y otros" y por "lo otro", el medio ambiente y la naturaleza, busca comprender las raíces, interconectadas de toda dominación y los caminos para resistir y cambiar. Desde el ecofeminismo reconocemos que las mujeres y los hombres hemos aprendido a pensar, a actuar y relacionarnos con el mundo con las mismas dualidades. El sistema social no es bueno para ninguno, pero somos mujeres y hombres las y los que constituimos el sistema social y somos ambos los que podemos influir en la estructura profunda de nuestras relaciones con los otros y otras y con el entorno. Somos mujeres y hombres las y los que podemos participar en formas de resistencia y de desobediencia civil no violentas que celebren la gran diversidad planetaria y animen a reflexionar sobre las consecuencias de nuestras acciones en todas las relaciones.

Desde nuestra concepción ética, estética y simbólica introducimos que la fuerza de la vida constituye el núcleo en la propuesta plural que asumimos, porque es necesario de-construir paso a paso "la cultura de la muerte" que ha puesto en uso un imaginario y unas maneras de actuar dominantes y patriarcales, imponiendo unos manejos, unos agenciamientos y unos dispositivos en relación con los otros y las 
otras, con el entorno, con el erotismo, el amor y el deseo, atravesados en lo fundamental por la fascinación del thanatos, el miedo, la amenaza, la dominación, la desaparición y la muerte.

Para nosotras entre todos los derechos, entre la libertad y la igualdad, se sitúa la solidaridad como único puente de conexión entre ellos. "La solidaridad es la prueba del reconocimiento con el otro u otra desde el dolor sentido, no desde la compasión, más bien desde la capacidad de asumir la prueba de la condición humana en el límite. Mientras no seamos poseídos (poseídas) por el misterio de la vida que aviva el contagio, no es posible la solidaridad, ni puede expresarse el ligamen relacional que nos dignifica y que nos humaniza". El encuentro con el otro $u$ otra representa una de las preguntas más actuales desde la ética y los Derechos Humanos.

En una postura ética es fundamental el encuentro con el otro $u$ otra desde la razón, desde el diálogo, desde el lenguaje, desde el o la sujeto de derechos; la relación con el otro $u$ otra es un encuentro entre sujetos distintos y por tanto iguales en derechos y respeto.

\section{EL CONFLICTO ARMADO Y LA VIOLENCIA}

\section{VIOLENCIAS SOCIALES Y VIOLENCIA POLÍTICA}

Según William Ospina en su libro La Franja Amarilla "Colombia es hoy el país con más alto índice de criminalidad en el planeta, tiene la mitad de su población en condiciones de extrema pobreza, de 35'000.000 de habitantes su riqueza está en manos de 5'000.000". En Colombia, por cada 100.000 habitantes la tasa de muertes violentas es de 207 en Medellín, 41 en Bogotá y 89 en Cali. En Medellín, en los últimos seis años se han producido aproximadamente 25.000 muertes, de las cuales el $88 \%$ son hombres jóvenes entre 14 y 25 años. 
Sin embargo, continúa el autor "Colombia es un país donde no existe la protesta y la movilización ciudadana como una manera de expresar el rechazo y la inconformidad", fácil de entender "sabiendo que después de las marchas pacíficas vienen las desapariciones silenciosas y las ejecuciones anónimas". "Colombia es un país donde todos los días ocurren cosas indignantes y el estado no opera para poner freno o para tomar medidas y generar las transformaciones básicas que se requieren". "Lo que vivimos es el desencadenamiento de numerosos problemas represados... Colombia a pospuesto demasiado tiempo la reflexión sobre su destino, la reflexión sobre su proyecto nacional".

Como decía el historiador ingles Eric Hosbawm "la presencia de los hombres armados forma parte del paisaje natural de colombiano".

"Siempre nos dijeron que la violencia de los años 50 fue entre liberales y conservadores, los dos únicos partidos que han existido por lo menos hasta entrados los 70. Eso no fue cierto, fue una violencia entre liberales pobres y conservadores pobres, mientras los adinerados de ambos partidos los azuzaban y financiaban su rencor". Cualquier parecido con es esquema del pasado y el del conflicto armado del presente no es mera coincidencia, es el lastre que arrastramos de la manera de concebir la participación ciudadana, una participación enceguecida por borrar la protesta, la diferencia, y por perseguir el poder político y económico camuflando la mentira y la impunidad.

A causa de la violencia de los años 50, los índices de población urbana y campesina se invirtieron, las ciudades crecieron inconteniblemente". Nuevamente se reproduce el esquema y en el presente, los grandes volúmenes de desplazamientos forzados de campesinos mujeres y hombres engrosa las ciudades. "A la par de que se fue cristalizando una enorme miseria, la pasividad ciudadana, la indiferencia y el miedo, en los últimos 50 años han surgido grandes procesos de iniciativa social pacífica que lucha por los derechos de la comunidad", de los grupos étnicos, de los grupos etareos, de las y los obreros, de las y los maestros, de las mujeres. 
En Colombia siempre hubo en los campos hombres con armas, más no en las ciudades y menos aún mujeres vinculadas a los ejércitos, este es un fenómeno que inicia a finales del 60 y básicamente en los años 70 .

Con este mapa de nuestra realidad histórica intento decir que está en manos de las mujeres y de los hombres sensibles, mantener las iniciativas de resistencia y construcción de la vida, de la propia historia, de la risa, la creatividad, la dignidad, la esperanza, la rebelión pacífica, la confianza, los vínculos sinceros y la solidaridad, que hagan posible la unión para luchar por el bien común, para lograr un desarrollo incluyente de la diversidad de Colombia, que piense a favor de la patria, el planeta y las generaciones futuras.

\section{LAS VIOLENCIAS CONTRA LAS MUJERES}

La violencia masculina sobre las mujeres, no es sino una de las formas de la exteriorización del dominio patriarcal. La dominación de lo masculino y la subordinación de lo femenino es parte del andamiaje de un modelo de relacionamiento constituido e introyectado culturalmente en mujeres y hombres desde el nacimiento. Aunque se viene trabajando desde el movimiento de mujeres y algunos estados comprometidos para transformar dicho modelo, esta labor es aún muy incipiente y lenta.

A pesar de los esfuerzos y las luchas permanentes de las mujeres organizadas del mundo, es claro que no basta con plasmar los acuerdos y compromisos relacionados con las medidas (de prevención, de atención a las víctimas, con la aplicación y el seguimiento al cumplimiento de los derechos humanos de las mujeres) para eliminar las violencias contra las mujeres. Si bien es fundamental hacer memoria, verdad, justicia y reparación, también es fundamental trabajar con mujeres y hombres por la re-socialización, re-educación, desconstrucción- construcción de roles, sentidos, imaginarios, subjetividades, mentalidades, actitudes de género. 
En 1998 en Antioquía el 93\% de la violencia conyugal se ejerció contra mujeres y en Colombia se presentaron diariamente un promedio de 110 casos de lesionadas. El maltrato contra la mujer a nivel intrafamiliar ha aumentado del $74 \%$ en el 98 al 79\% en el 99. En la ciudad de Medellín se cometen 16 violaciones diarias, con el agravante de que sólo se denuncian 4 . Un gran porcentaje de las mujeres víctimas de la violencia conyugal no se perciben a si mismas como maltratadas y consideran que no es pertinente buscar ayuda. Muchas de las que reconocen el maltrato no denuncian por temor o por que conocen la inoperancia de las instituciones que tienen la responsabilidad de recibir estos casos.

"El incremento de las violencias contra las mujeres, tiene como una de sus explicaciones, la crisis económica y el conflicto armado por el que atraviesa el país, el desequilibrio emocional que afecta la imagen, el reconocimiento social, la sexualidad, las relaciones interpersonales de mujeres y hombres; se exacerban los valores tradicionales y conservadores, fundados en una cultura machista, que producen que las mujeres no se alejen demasiado de los modelos convencionales de comportamiento socialmente asignado como femenino, sobre el cual la guerra también se sostiene".

Numerosos estudios dan cuenta de la situación de violencia contra la mujer, referida principalmente a la violencia intrafamiliar, la violencia sexual y/o conyugal (considerada como doméstica, del orden de lo privado), pero que se articula a la violencia social y política. Esta violencia, que tiene severas y alarmantes consecuencias que vulneran los derechos humanos de las mujeres, las niñas y los niños, no es la única violencia soportada por las mujeres. En efecto, la violencia político-militar, recaen en gran medida sobre las mujeres. Lo que hace necesario y urgente abordarla, si pretendemos acercarnos al reconocimiento y compresión de que la negociación política del conflicto político-militar interno, el respeto y vigencia del DIH, y la consolidación de la paz, pasan por la reducción de la inequidad. El cual implica visibilizar las afectaciones que las violencias y conflictos producen en el ejercicio de la democracia, la justicia y la equidad para las mujeres. 
Aunque la violencia político-militar, exceptuando el desplazamiento forzado, afecta mayormente a los hombres, no se pueden desestimar la violación de los derechos humanos de las mujeres y las niñas causadas por la violencia, así como el número de éstas involucradas y afectadas por el conflicto político armado.

\section{EL CONTEXTO POLÍTICO ACTUAL}

Desde mediados de los 80 el conflicto armado interno ha venido extendiéndose en forma vertiginosa por el territorio nacional, uno de los rasgos más sobresaliente es la situación de violencia generalizada. La tasa de homicidios en Colombia es del 78.4 por cada 100.000 habitantes. Del mayor porcentaje de las muertes violentas acaecidas en el año en Medellín, 1.000 son causadas por los actores armados, que en la ciudad, en el departamento y el país, toman manifestaciones de violencia organizada por la acción de grupos insurgentes, paramilitares, milicias urbanas, narcotraficantes, delincuentes comunes organizados.

La falta de acuerdos humanitarios entre los actores armados, ha llevado a cometer las mayores atrocidades, teniendo a la población civil en un estado de pánico generalizado. En consecuencia las, grandes masas de población desplazada interna, sin contar con la población que ha salido del país, ascienden a más de dos millones de personas en los últimos dos años. No se están dando mecanismos legales ni acciones que señalen la voluntad del estado en regular y sancionar las acciones de los actores armados en contra de la población civil y los territorios que les pertenecen.

El actual contexto de agudización y generalización de la guerra en todo el territorio Colombiano prevé, una radicalización de la misma y una tendencia de derechización acelerada de diferentes sectores del país, donde la punta de lanza es el llamado Plan Colombia. Este plan posiciona a Estados Unidos en la región de América Latina, su componente social sólo mitiga los efectos del componente militar, va en 
contra de un espacio civil y coloca a todas las organizaciones sociales y grupos comunitarios en una situación de fragilidad, y fragmentación, que termina oponiéndose a la consolidación de un movimiento social por la paz.

Entre noviembre del 2000 y enero del 2001, los actos atroces y la muerte vuelven a rondar de manera agudizada en Colombia. A finales del 2000 "se necesitó que la sociedad civil, las organizaciones no gubernamentales, la iglesia y la comunidad internacional, han presionado para que el gobierno colombiano se decidiera a prolongar la zona de distensión en San Vicente del Caguán para que el proceso de negociación con las FARC (Frente Armado Revolucionario de Colombia) no muriera". "Los opositores del proceso presionaron para dar fin a la zona y a la negociación. Las ONG'S y la sociedad civil, por su parte, insistieron en que los diálogos no sólo no se deben suspender sino incluso, se deben ampliar al ELN (Ejército de Liberación Nacional.), con lo que se ha acordado otra zona denominada de encuentro en el Sur de Bolivar Magdalena Medio, que no se ha concretado por las presiones de los paramilitares".

En el marco de un contexto tan complejo, a las organizaciones sociales nos surgen algunos interrogantes ¿Qué podemos hacer? ¿Cuál es la postura más estratégica? ¿Qué es lo posible en éste contexto?

El conflicto armado colombiano requiere ser analizado para evitar que sus interpretaciones estimulen la noción de caos y de acciones desarrolladas por individuos locos y desequilibrados. El entender la lógica de los actores armados, no debe confundirse con justificar el ejercicio de la violencia ni las formas degradadas que adopta el conflicto. Si no entendemos las razones de fondo, será muy poco probable que podamos avanzar en los diálogos, las negociaciones, acuerdos y pactos que puedan establecerse.

Igualmente surgen otras interrogantes desde una perspectiva de género ¿La guerra es una estrategia patriarcal? ¿Afecta la guerra de manera diferente a mujeres y hombres? ¿Tenemos las mujeres y 
hombres alternativas específicas contra la guerra? ¿Tenemos alternativas comunes?

Es en este contexto que las mujeres debemos dar a conocer nuestra visión y nuestras propuestas, en la vía de posibilitar una des-acomodación de una única manera de ver las cosas, de ver la realidad, de ver y concebir los problemas de Colombia, sus necesidades y sueños.

\section{LAS NEGOCIACIONES CON LOS ACTORES ARMADOS: AUSENCIA DE LAS MUJERES ORGANIZADAS Y LA SOCIEDAD CIVIL}

La Paz en Colombia se está negociando en medio de la agudización de la guerra, de la violación de los Derechos Humanos y el Derecho Internacional Humanitario, de la degradación del conflicto, del aumento alarmante del desplazamiento forzado de la población, de los ataque a la población civil por parte de los actores armados, de actos de control de la vida de mujeres y hombres.

La población de Colombia es de aproximadamente 42 millones, el $50 \%$ es femenina. Sin embargo, las mujeres no estamos participando en el proceso de negociación. Este año tanto las FARC y el gobierno por fin nombraron a mujeres en la comisión temática. Como vemos, la negociación en Colombia es un claro acto patriarcal en el que sólo se pactan acuerdos entre hombres, las mujeres no estamos participando en este ejercicio de construcción de pactos sobre el futuro del país. En este ejercicio político tampoco esta participando la gran diversidad de población civil que constituye nuestro país.

Si bien existen mujeres involucradas directamente y de diversas maneras en el conflicto armado, las mujeres colombianas organizadas nos oponemos a la guerra y a la tramitación de los conflictos y diferencias por la vía armada y por la vía de la desaparición y la muerte. 
Si bien se ha venido instaurado la lógica guerrera en las mentalidades, las subjetividades, las actitudes y los cuerpos de las personas, igualmente siguen vivos los actos de defensa de la vida y la dignidad, en eso nos unimos y hermanamos las diferentes organizaciones de mujeres'. El movimiento social de mujeres, constituido por, entre otras, las mujeres populares y feministas, está haciendo posible, en condiciones inhumanas, la sobrevivencia del conjunto de la población. Esto es, que se mantengan los vínculos y el tejido social, que se frene la degradación de la naturaleza.

Las mujeres que apostamos por la vida, estamos haciendo de cada espacio, una oportunidad para dar a conocer otras maneras, otras lógicas que no son las guerreristas. Desde los proyectos que llevamos a cabo con otras mujeres, estamos persistentemente intentando transformaciones profundas en las relaciones de equidad entre los géneros y construyendo actos de hermandad y protección entre mujeres para hacer posible la verdad, la justicia y la reparación de los efectos de la violencia y la guerra sobre nosotras y sobre el conjunto de la población. Estamos tejiendo propuestas sostenibles de vida. Por todo lo anteriormente dicho, proponemos la participación del movi miento de mujeres en todos los espacios de negociación y concertación política del conflicto armado.

\section{LA PERSPECTIVA DE GÉNERO \\ EN EL CONFLICTO ARMADO}

El conflicto armado en Colombia, esta generando un retroceso alarmante en los avances del movimiento social de mujeres y está reafirmando roles, valores, subjetividades, mentalidades y actitudes de género que hacen que la discriminación, la exclusión y la violencia contra las mujeres sea cada vez mayor, así como el desencuentro en

1. El movimiento ambiental, el movimiento ecologista, los movimientos indígenas, los movimientos afro-colombianos, la Red Juvenil de Objetores de Conciencia. 
las relaciones de mujeres y hombres. Lo masculino y lo femenino se reafirman en la lógica guerrera del predominio del uno (lo masculino) sobre el otro (lo femenino), del heroísmo del uno (lo masculino) y la invisibilización-desaparición del otro (lo femenino).

Como un dato preciso, señalamos que el 13\% del total de combatientes de todos los sectores armados en Antioquía, para el año 1999, eran mujeres

\section{EL PAPEL DE LAS MUJERES}

En general las mujeres han jugado diferentes roles, analizamos algunos de ellos.

Como Guerreras: Aunque hay un número considerable de mujeres en la guerra y que éste ha ido creciendo, es evidente que su participación no juega un papel definitorio. Ellas están ejerciendo roles tradicionales, generalmente secundarios y excepcionalmente de altos mandos, ejercen funciones de vigilancia, manejo de comunicaciones, inteligencia militar, informante, escondiendo armas y/o guerreros, trabajo doméstico, amantes. Según La Defensoría del Pueblo, hay un incremento de mujeres jóvenes involucradas por los actores en la guerra.

Como prisioneras: Existen 243 mujeres en las cárceles por razones de conflicto armado. Evidentemente en relación con la población carcelaria colombiana son una minoría. En comparación con los hombres prisioneros por esta misma razón, no tienen guardias de sexo femenino, no tienen posibilidad de actividades de recreación, de visitas familiares y menos conyugales, no pueden criar a sus hijos en la prisión, carecen de atención médica, especialmente ginecológica.

Como víctimas de la guerra: Haciendo de padres y madres, encargadas de resolver la salida de la población de los territorios amenazados. Pérdida de identidad, autoestima, referentes familiares y sociales. Obligada a incursionar en espacios públicos para negociar 
y exigir los derechos de la población desplazada y la ayuda humanitaria, poniendo los muertos en uno y otro lado del conflicto y posponiendo su duelo y necesidades ante la fragilidad, vulnerabilidad y dependencia de los(as) otros(as).

Como constructoras de Paz: Invisiblemente y a veces de manera inconsciente, las mujeres mantenemos y garantizamos el tejido social, familiar y comunitario, posibilitamos reconstruir los proyectos de vida de las poblaciones afectadas por la guerra, generamos y fortalecemos la resistencia a la muerte.

Aunque políticamente nuestro papel es aún débil, nuestro aporte a la paz es invisible, y las mujeres que participan en los espacios e instancias de decisiones del país son pocas, este conflicto nos ha permitido la reflexión sobre nuestra realidad como mujeres, identidad de sufrimientos, posibilidades de reconstrucción del país desde las mujeres y el papel importante que estamos jugando en la lucha contra la muerte y por la vida.

\section{LA POBLACIÓN CIVIL AFECT ADA, POR GÉNERO Y ZONA}

La guerra en Colombia tiene particularidades según las regiones, pero sus causas, efectos y secuelas son semejantes a nivel nacional. Además de razones profundamente culturales arraigadas en una tradición patriarcal que privilegia el uso de fuerza sobre la razón, la guerra se enmarca en un contexto de globalización, con un modelo neoliberal excluyente que generaliza la guerra y la pobreza. La implantación del modelo económico neoliberal (injusto, inequitativo y excluyente) y las bonanzas (caucho, madera, petróleo y coca), han dejado cada vez más violencia y desplazamiento forzado. Dentro de este modelo, es relevante la feminización de la pobreza, las mujeres estamos cargando con la responsabilidad de asumir las consecuencias que deja la exclusión en la construcción de familias y comunidades (hambre, desempleo, carencia de servicios básicos, educación, salud, recreación, vivienda, etc). 


\section{Las mujeres}

- Involucrarmiento de los hijos en la guerra e incremento de reclutamiento forzado de mujeres menores de edad, sea por opción o por la fuerza o por precariedad de la situación económica. Las mujeres estamos en contra del servicio militar obligatorio, sea en el ejercito que fuese.

- Se niega el derecho a enterrar los hijos, si se reclama los cadáveres se sufre represalias y venganzas.

- El cuerpo de la mujer es usado como instrumento de guerra y de venganza. Se exacerba las conductas de violación y abuso sexual y la degradación del cuerpo.

- Golpizas públicas contra mujeres alegando "conducta inmoral", acusación tanto de la guerrilla como de los paramilitares. Otras mujeres han tenido que escoger entre ser asesinadas o desplazarse.

- Los actores armados de todos los bandos, empiezan a controlar no sólo el territorio, sino la vida cotidiana, el afecto y hasta el cuerpo de las mujeres, con el agravante de que transmiten valores tradicionales sobre el rol del hombre y la mujer.

- La guerra presiona a las mujeres jóvenes, las lleva a la prostitución como posibilidad de ingresos, así como a los hombres a los grupos armados como alternativa económica.

- Existen cada vez más presiones para que las organizaciones de mujeres participemos en acciones y movilizaciones de los actores armados. No tenemos posibilidades de decidir individualmente, es obligación y se cobran cuentas.

- La coacción de los actores armados ha llegado a tal punto que ellos son los que ponen las reglas hasta de cómo vestirse. Por ejemplo, ponerse minifalda se convierte en riesgo de violación, seducción y objetivo militar.

- La presión psicológica que ejercen los actores armados sobre las mujeres, las rabias acumuladas y la impotencia, genera crisis nerviosas y somatizaciones del cuerpo. 
- Las mujeres se encuentran en una encrucijada, es igualmente problemático apoyar o no apoyar las zonas del despeje para los diálogos, $\mathrm{u}$ otras iniciativas de negociación.

- Se incrementa el miedo a opinar, las mujeres venimos de una tradición de sumisión, primero al padre, luego al esposo, ahora a los actores armados.

- Las mujeres cargan con todas las problemáticas que se derivan de la guerra. Igualmente, las instituciones y organizaciones que trabajamos con mujeres, estamos asumiendo una responsabilidad que debería ser asumida por el Estado.

- El genocidio y la aculturación de los pueblos indígenas, conlleva a que sus mujeres sean reducidas a la mendicidad en las ciudades.

- Se ha incrementado la adhesión de mujeres a la religiosidad alienante en la búsqueda de salidas a esta situación desesperante.

- Han aumentado considerablemente las muertes selectivas de mujeres atribuidas a su relación con actores armados, bandas, y otros. En particular de mujeres jóvenes.

- Incremento de la impunidad y la violación del derecho al debido proceso y a las garantías judiciales, esto repercute en las mujeres quienes son las responsables de las denuncias de las muertes y desapariciones de seres queridos.

- A las mujeres organizadas se nos asocia permanentemente con los grupos armados.

- Los actores están presionando el cierre de proyectos y programas dirigidos por mujeres, que organizan a la mujer desplazada, amas de casa, jóvenes, etc.

- A las mujeres organizadas se nos niega el derecho de desarrollar procesos, en los marcos de civilidad y autonomía respecto a los actores armados. Este es el caso de la "Organización Femenina Popular del Magdalena Medio", en donde uno de los actores armados pretende mediante la coerción y la presión, obligar a las mujeres a participar en eventos, reuniones, marchas, comunicados. 


\section{EL DESPLAZAMIENTO FORZADO}

En Colombia el $74.54 \%$ de los desplazados son mujeres y niñas y niños. Los desplazamientos, son ocasionados por las disputas de poder político y económico entre los actores armados (guerrillas, autodefensas y ejército). Se enmarca fundamentalmente en la lucha por el control territorial por razones estratégicas o por las riquezas naturales, de gran interés para los capitales nacionales e internacionales.

La violencia, las amenazas y el miedo son las causas del desplazamiento. Las personas huyen de sus tierras en medio de la angustia y la zozobra con la esperanza de salvar sus vidas y la de sus familias. Estas circunstancias implican un agudo impacto negativo en la vida mental y familiar.

- Con el desplazamiento se destruyen vínculos afectivos, económicos, culturales, políticos y se incrementa el hambre y el desempleo por llegar a sitios que no permiten vivir dignamente.

- La situación de desplazamiento es antecedida de hechos violentos: Testigo de masacres, muerte de algún ser querido, reclutamiento forzado de hijos, víctima de violación sexual pública, hostigamiento por ser mujer y uso de su cuerpo como arma de guerra.

- Las condiciones de vida de las mujeres se vuelven aún más indignas, precarización del empleo femenino, trabajos mal remunerados (servicio doméstico, sector informal).

- Señalamiento de la población desplazada como "peligrosa", generándose desconfianza hacía ella.

- Alto índice de mujeres desplazadas indocumentadas y analfabetas. Quienes buscan nuevos horizontes en las capacitaciones y en las organizaciones.

- Aunque de alguna manera las mujeres desplazadas adquieren liderazgo y se empoderan, con la sobrecarga de trabajo, soledad y desprotección, se incrementan los índices de violencia intrafamiliar y 
de enfermedad emocional y física. Toda carga económica, psicoafectiva, emocional, de seguridad y doméstica, recae en las mujeres, problemáticas que obstaculizan su desarrollo social y humano, tanto de las que llegan como de las que las reciben.

- Notorio incremento de los índices de viudez, situación que fuerza a la niñez y a la juventud a asumir roles que no corresponden a su edad. Se está gestando generaciones sin futuro, obligando a las jóvenes a enfrentar su rol de madres y embarazarse prematuramente. Adultas y jóvenes son enfrentadas a vivir la maternidad en soledad, por el asesinato de su compañero o porque éstos no asumen la paternidad.

- Destrucción y debilitamiento de las redes de solidaridad y apoyo.

Hemos constatado cómo la guerra y los conflictos han sido impuesto a las mujeres. Ahora, somos nosotras las que soportamos las pérdidas de nuestros referentes afectivos (esposos, amantes, hijos, hermanos) y culturales (territorio, grupo étnico, lazos de vecindario, organizaciones, tierras, fincas, casas), todo lo construido por años.

El desplazamiento forzado, la desaparición forzada, la muerte y la pérdida, nos dan una idea no sólo del sacrificio humano que conlleva el conflicto político armado, sino también del sufrimiento y trastorno de las costumbres y responsabilidades de las mujeres. Las mujeres no sólo han tenido que asumir obligadamente, la ausencia (muerte, desaparición forzada) de padres, hermanos, esposos, compañeros e hijos, sino, soportar otras vejaciones, como la violación y el ultraje de sus cuerpos. Todo ello significa "cargar con la vida", "cargar con la pobreza", "cargar con la emergencia" a los lugares de acogida, a ciudades y pueblos desconocidos.

Frente a estas problemáticas el Estado tiene pocas políticas de atención y ninguna aplicación de las existentes. 


\section{LA REPARACIÓN Y ELABORACIÓN DE DUELOS}

Las pérdidas que viven mujeres y hombres requieren de un tratamiento especial. Las pérdidas afectivas no sólo producen dolor, sino las pérdidas de referentes materiales y simbólicos desde donde se construye el arraigo y la identidad cultural. Vivenciarlas constituye un elemento que favorece el quiebre (ruptura) de las identidades subjetivas (mujer-hombre) y de las identidades colectivas (culturales), todas fundamentales para el desarrollo de los vínculos sociales y la reconstrucción del tejido social.

La pérdida de sentidos que dan identidad es vivida de manera radicalmente diferente por las mujeres y los hombres. Para ellos, la pérdida de la tierra, la finca y el trabajo es lo más traumático, para las mujeres, la casa y los afectos les deja sin esos referentes culturales que dan sentido su existencia. Si bien mujeres y hombres pierden todo y viven el dolor y el miedo, cada uno lo elabora desde su historia personal y género. Los hombres manifiestan no poder llorar ni poder hablar del miedo, no lo aprendieron y hacerlo los califica de flojos y frágiles. Las mujeres en cambio lo nombran, en muchos casos no con la palabra sino con el cuerpo, a través de las enfermedades que somatizan.

Ha sido prioritario construir una alternativa de intervención y acompañamiento que ofrezca, a través de la palabra y elementos simbólicos y creativos, un efecto sanador que facilite el proceso de vivir "El luto", el dolor, los miedos. Que facilite el proceso de reconstruir en cada individuo, mujer y hombre, un sujeto de derecho y una posibilidad de re-construir una vida digna.

\section{EL QUIEBRE DE IDENTIDADES INDIVIDUALES}

La población que ha vivido en medio del conflicto armado, expresa un quiebre-escisión de identidad, como producto del desarraigo forzoso, enfrentando la pérdida de referentes sociales y territoriales. Arrancados de su entorno, las mujeres y los hombres son sometidos 
a cambios forzados de roles, debido a la nueva condición social que enfrentan y las dificultades para la reintegración a una vida productiva. La guerra no permite ni pretende crear condiciones y proceso para posibilitar los cambios. La experiencia en la intervención con la población desplazada nos muestra, aún con las diversidades inherentes a cada individuo y comunidad, que las mujeres y los hombres expresan un quiebre de su identidad personal a partir de la ruptura con el entorno social y cultural original que se da de una manera específica en cómo cada género se adapta al nuevo entorno.

Los hombres, enfrentan dificultades para involucrarse en la dinámica social y económica de la ciudad, la oferta de trabajo cercana a lo que saben hacer es escasa, para ellos la relación con el trabajo ha estado mediada por su labor como comerciante o trabajador del campo que cultivan la tierra, actividades que han representado para ellos el manejo de dinero, ser proveedores y reconocimiento social. En medio del desarraigo vemos algunos de los hombres dirigir su interés hacia los trabajos comunitarios, los espacios de participación y toma de decisiones que con el tiempo pueden llegar a ser generadores de recursos económicos que les benefician y les permiten mantenerse, como proveedores, rol que comparten con las mujeres. Otros por el contrario se sienten "marginados", "arrinconados", sin autoridad y reconocimiento ante los otros y otras, y con escasas posibilidades de producir en un medio ajeno.

Para ellas, el desplazamiento ha significado, de un lado, un gran dolor por la pérdida de su afectos y una gran sobrecarga ya que a su rol tradicional como ama de casa y reproductora se le suma el de proveedora. De otro lado, la dinámica de la ciudad les "ofrece" algunas oportunidades económicas, oferta que sigue siendo bastante limitada y mal remunerada. En esta línea vale precisar que las mujeres acceden a trabajos domésticos remunerados que, al ser un trabajo pagado, adquiere cierto reconocimiento social y se convierte en una fuente de satisfacción. En estas circunstancia cabe interrogar si realmente para las mujeres este incremento en sus labores como amas de casa, madres y ahora proveedoras y líderes comunitarias es, desde el punto de vista de la valoración, una ganancia en la posición y en 
la condición o, se continúa generando una sobrecarga y delegando en ellas la responsabilidad de ser soporte de la estructura social y económica representada en la familia y la sociedad en tiempos de guerra.

A pesar de este análisis, las mujeres en su mayoría afirman no querer regresar, porque regresar no es volver a sus territorios, sino volver a las viejas costumbres donde ellas no tenían ningún valor para los otros. Ellas afirman que después de estar en estos nuevos territorios "ya no son las mismas", se han capacitado, se han organizado, "han abierto los ojos". Piensan que una vez que estén en sus comunidades, los hombres retornarán a sus territorios físicos y simbólicos y esto les regresaría el poder perdido en las ciudades, volverían a los roles y de manera más afirmada y violenta. En los escasos retornos de población que han sido posibles, se ha constatado un recrudecimiento de las formas de violencia intrafamiliar, los hombres asumen que han recuperado el territorio del poder perdido y ellas han quedado desarticuladas entre ellas (ya no están juntas).

En este sentido, se hace más urgente la necesidad de fortalecer el trabajo bajo la perspectiva de género, que permita construir bases firmes a los cambios en las relaciones entre hombres y mujeres. En la realidad del desplazamiento, se produce no una transformación sino un quiebre de las identidades de género, un cambio forzado, en el que los roles, se presenta como una estrategia de sobrevivencia debido a las condiciones limitadas ofrecidas por el medio para la satisfacción de sus necesidades, por la ruptura con sus referentes y por una dinámica social que las y los expone a "re-aprender" relaciones sociales y no como una variación en las mentalidades, subjetividades, actitudes, posiciones sociales, ni como una transformación social. 


\section{RECONSTRUCCIÓN DEL TEJIDO SOCIAL, VÍNCULOS E IDENTIDADES CULTURALES}

En el desplazamiento mujeres y hombres enfrentan uno de los efectos más lesionadores para la dignidad humana: el desarraigo. Este es el efecto de ser arrancados violentamente de la tierra en donde han construido redes sociales, económicas y culturales, que crean condiciones particulares que les dan identidad, raíces y les diferencia de otras comunidades. En el desplazamiento se produce una ruptura violenta en estos sistemas de relaciones cuyo efecto es un quiebre con los referentes que proporcionan identidad colectiva.

El desplazamiento se le niega las oportunidades de duelo o luto de tener una vida digna, de ser reconocidos como sujetos de derecho, de optar libremente y de construir posibilidades, de mejorar sus condiciones de vida en un territorio donde sus raíces culturales e identidad construida les da sentido de pertenencia.

En la re-construcción del tejido social, una de las expresiones que hemos observado entre los pobladores de asentamientos, es el cambio en la vida comunitaria para este grupo humano, las condiciones en las relaciones han variado, no sólo en la expresión de su espacio físico sino en la relación con éste y con quienes igualmente lo habitan, crecen las desconfianzas, los silencios y los miedos. El espacio físico se hace fundamental a la hora de la re-construcción del tejido social porque es en éste donde se viven y construyen las relaciones sociales, los vínculos y referentes para la identidad.

Los desplazados no se encuentran totalmente despojados, ellos y ellas son portadores de su identidad cultural, raíces que se mantienen ya sea porque el medio les ofrece mínimas posibilidades de recrearlos allí o porque, si bien el desarraigo produce rupturas, éste no logra la pérdida total de la memoria cultural. 


\section{LA NEGOCIACIÓN}

La Negociación, como una manera de tramitar los conflictos familiares, sociales y políticos, a través de otras posibilidades diferentes a la violencia, requiere de un proceso que involucra no sólo a la comunidad con quien se trabaja sino a la sociedad y al estado como entorno.

Surgen los interrogantes ¿Negociación de qué? (de qué derecho, de qué dignidad) ¿Con quién? Si la población desplazada no existe para el otro y no existe la voluntad política del Estado para enfrentar el problema del desplazamiento? ¿Negociar con los actores armados el regreso a su trabajo, a su territorio? Cuando estos territorio están en disputa entre poderes ¿Cómo negociar un asentamiento o una reubicación en condiciones de dignidad? Cuando para lograrlo se requiere el reconocimiento mutuo de la existencia, de la problemática y voluntad política.

\section{LAS NiÑAS Y LOS NiÑOS DESPLAZADOS}

Al igual que los adultos tienen el sentimiento de la pérdida, de dolor que suelen manifestarse de diversas maneras. Si no se interviene adecuada y oportunamente, serán niñas y niños sin una alternativa distinta para transformar su visión del mundo, visión que ha sido atravesada por la violencia, pudiendo reconocer en ésta un mecanismo legítimo para resolver sus conflictos y dificultades.

Uno de los principales elementos que ha surgido durante los talleres es la agresividad. Ésta se manifiesta a través del juego y la palabra dirigida a los otros. La actitud agresiva la expresan tanto con sus pares (otros niños y niñas) como con los adultos, pero de manera distinta. Por ejemplo, no reconocen a sus pares como iguales, el otro no inspira propiamente solidaridad, ternura o compasión, por el contrario, provoca su destrucción. Con los adultos la actitud agresiva se manifiesta a través del no reconocimiento de la autoridad. El adulto no representa para ellas y ellos una figura que encarne la ley, sobre todo cuando en la relación no media el afecto. 
Acerca de la identidad, en las niñas el referente de identidad está situado principalmente en los otros, donde la presencia del afecto es un determinante importante. En los niños, el referente de identificación que aparece se relaciona con modelos agresivos y violentos, en ocasiones legitimados por la ley ("quiero estar en las fuerzas militares para matar a los malos"). Para las niñas la identidad subjetiva pasa por la relación con el otro, reflejan una posición pasiva frente a sí misma y los otros, por el contrario los niños ubican una posición activa transmitida a través de acciones y posiciones donde ellos son sujetos. En general, lo que esto nos puede revelar en alguna medida son sus referentes de identidad. Cabe interrogarse ¿A partir de qué imágenes y relaciones ellas y ellos están construyendo su identidad?

En las intervenciones, vemos la necesidad de tener presente otras maneras de relacionarse, dándoles a conocer modelos de identificación no violentos que faciliten el establecimiento de relaciones en las que las acciones que dañen al otro u otra no estén presentes. Así mismo, revisar con ellos y ellas los modelos de identificación del ser hombre y ser mujer que han interiorizado desde su hogar, la escuela y otros espacios de socialización. Esto implica además la construcción de una posición ética y de equidad en las relaciones que establezcan con los demás.

\section{LAS Y LOS JÓVENES DESPLAZADOS}

A través de las intervenciones realizadas hemos encontrado diversos elementos, como la pérdida de imagen de autoridad de los adultos en particular del padre, la extra- valoración de sus vínculos familiares en particular con la madre y el desprecio por el origen campesino.

Existe en ellas y ellos una valoración de la presencia del amor y el buen trato cuando encuentran personas que se relacionan con ellos y ellas de manera diferente a la violenta. Igualmente rechazan que se les regañe y se les prohiba en exceso. De esto se puede construir dos hipótesis, lo que les molesta no es que les impongan limites, sino que 
lo hagan en exceso. La otra hipótesis es que por estar en la adolescencia los/as jóvenes rechazan a quienes representan la autoridad como una forma de ganar independencia.

El desplazamiento involucra a los jóvenes en otra dinámica, la ciudad deslumbra, les ofrece otras oportunidades que les alejan de su identidad campesina. Esto les hace tener una imagen de futuro donde identificamos dos tendencias, la primera se centra en lo urbano, comienzan a imaginar su vida rodeados de la ciudad, la segunda, se centra en la imagen que añora aquello que perdieron, la vida rural, y que evidentemente no podrán recuperar.

En la reconstrucción del tejido social, para ellas y ellos resulta de mucha importancia los nuevos vínculos que construyen fuera de la familia, los amigos, los novios-amores. Para las jóvenes el referente de amor se asocia ahora al hombre de la ciudad pues según ellas éstos si valen la pena. Con el agravante de que se vuelve un modelo de hombre que ya no es el "príncipe azul" sino el "príncipe armado". Hay valoración de los vínculos que pueden establecer con sus pares y de las actividades que a veces realizan en el barrio. Igualmente, el lugar donde viven tiene importancia porque les ofrece otras oportunidades de acercarse a la ciudad donde, tanto ellas como ellos, ubican posibilidades de salir adelante y un futuro mejor.

\section{MUJERES Y HOMBRES JÓVENES EN EL CONFLICTO URBANO}

Hemos observado que la mayoría de jóvenes mujeres y hombres, tienen una gran valoración de figuras masculinas cuyas características son la fuerza, la capacidad de burlar la ley, de burlar la muerte, la capacidad de tener dinero y mujeres; a su vez, admiran aquellos personajes del barrio que hacen parte de bandas armadas. Las chicas admiran a mujeres bellas y capaces de ser deseadas por esos hombres fuertes y admirados por la colectividad. Para ellas el poder gira en torno al ser capaces de conquistar a un hombre con esas características; a diferencia de los chicos para quienes el poder está articulado a su capacidad de intimidar al semejante por medio de la fuerza. 
Hay una diferencia notoria en el modo como chicas y chicos resuelven los conflictos. La tendencia de los hombres es utilizar el golpe, mientras en el caso de las mujeres, si bien también utilizan esa forma, prefieren el insulto verbal, el excluir a la amiga, ignorarla o hablar mal de ella con el fin de dañar su imagen.

Para los muchachos, la muerte siempre está asociada a los homicidios y a la guerra, pero también a otras significaciones como una especie de descanso frente a la vida que se torna dura y tediosa, burlar la muerte y jugar con ella se constituye en un valor.

Si bien el contexto justifica la violencia y facilita que esa disposición humana se exacerbe y se promueva, ello no exime a cada persona, independientemente de la edad, a formularse una pregunta por la responsabilidad que cada uno y una tiene en los actos que realiza. Claro que para preguntarse por los actos es necesario que la persona empiece a sentir incomodidad con su modo de ser, ahora bien, hay que diferenciar la culpabilidad de la responsabilidad. La responsabilidad promueve el deseo de transformación, la culpa supone que la persona siente vergüenza y a su vez un profundo desprecio hacia si misma.

\section{El trabajo de GÉNERO de la Corporación COMO ALTERNATIVA PACIFISTA}

Nuestra organización es una de las miles de iniciativas de la sociedad civil, que cree en la vida digna, la justicia y la equidad para las mujeres y hombres de Colombia. Nuestro trabajo no esta referido exclusivamente a los efectos del conflicto armado y la guerra, pues nunca hemos creído en abordar las consecuencias de los problemas sino en ir directamente sobre las causas que soportan los fenómenos de inequidad entre los géneros, las exclusiones, la pobreza, la dominación, el consumismo, la degradación del medio ambiente. 
Como feministas hemos cuestionado desde el origen de nuestra organización, el modelo o esquema androcéntrico que rige las relaciones del planeta y que tiene miles de formas de manifestación, esquema generador de violencias, actitudes y actos des-humanizados que dañan y destruyen la naturaleza, el tejido de relaciones sociales y a las personas mujeres y hombres de todas las edades y culturas.

Estamos convencidas de que la humanidad se comporta de manera incoherente con su sentido humano, haciendo uso de la violencia y de la desaparición del otro u otra para dirimir y tramitar los conflictos y las diferencias. Esto lo hemos encarnado desde la vivencia de las distintas formas de violencia, subvaloración, exclusión de las mujeres en la sociedad. Por ello, somos sensibles a los efectos de lo que nombramos la raíz o el núcleo de los conflictos armados y la guerra, como máximas formas de expresión de los desencuentros sociales y afirmaciones de búsqueda de poder.

Vamos Mujer, comienza a construir una mirada y postura política clara y se interroga específicamente por la problemática de la guerra y los efectos en las mujeres. En 1995 en los preparativos para participar en la Conferencia en Beijing Mujer, Paz y Desarrollo, en 1996 iniciamos la creación de la iniciativa de paz Ruta Pacífica de las Mujeres Colombianas. Nos vinculamos al trabajo particularmente con la población afectada y desplazada por la guerra, en 1997 cuando participamos como una de las ONG'S testigas en la firma de reconocimiento como comunidad de paz "San Francisco de Asís". A partir de noviembre de 1997, iniciamos la propuesta de capacitación, con mujeres y hombres, en derechos humanos con enfoque de género.

Vamos Mujer viaja al campamento de Pavarandó, como parte de un grupo de organizaciones que integramos la Ruta Pacífica, que quiere hacer un apoyo específico con las mujeres afectadas por el desplazamiento y con niñas y niños, allí nos toca presenciar la masacre que hace que se desplacen más personas. Fuimos directas testigas de: 
- Los actos atroces de la guerra y la actitud no solidaria e insensible del resto de la población Colombiana y del estado, ante una realidad tan dolorosa e inhumana como el desplazamiento forzado.

- El dolor del otro y de la otra, constatar lo que significa perder todos los referentes culturales y afectivos; perder todo a nombre de los actos de barbarie que se justifican en los intereses de la guerra y de las armas.

- Esta población con gran diversidad cultural y con predominio de la cultura negra, no tenía rabia y deseos de venganza a pesar de los hechos tan humillantes y dolorosos.

- En medio de la guerra, los roles reproductivo y doméstico cobraban una dimensión fundamental en la sobrevivencia, las mujeres hacen desde ahí "Resistencia doméstica", "Resistencia pacífica" y se convierten en protagonistas y dinamizadoras de un papel esencial para la vida, que de otra manera no es reconocido, sólo en medio de la emergencia y la guerra. Mientras los hombres estaban dinamizando el rol organizativo como presidentes de comunidad e integrantes del comité encargado de orientar la Comunidad de Paz, las mujeres organizaban la redistribución del escasísimo alimento para cada familia del campamento. Allí hicimos conciencia de que es posible el empoderamiento de las mujeres desde un rol tradicional redimensionado y valorado socialmente.

- Los hombres que expresaban como se juntaban con mujeres paridas o preñadas sólo para garantizar su alimento, pues la comida era prioritariamente para ancianos, ancianas, niños, niñas y mujeres en esta condición. El aumento de nacimientos de niñas y niños se volvió un problema de salud pública y comenzó a promoverse de manera prioritaria el control de la fertilidad de las mujeres. Los hombres se sentían estar como en una cárcel y que no eran nadie, pues estar allí significaba no tener dinero y no ser ya los proveedores de las familias y perder lo que desde este rol les daba estatus y poder para conquistar a las mujeres, pues en el campamento no podían trabajar. 
Todos estos datos nos fueron mostrando como también en la guerra se hace urgente desde un trabajo de elaboración de duelo, de recuperación de la memoria histórica y cultural, de reconstrucción de tejido social, de concreción de los derechos humanos y de fortalecimiento de las formas organizativas comunitarias; la mirada con enfoque de género, para desde allí ubicar alternativas que permitan transformar las problemáticas que afectan a mujeres y hombres de manera diferenciada y de manera común.

\section{METODOLOGÍA DE INTERVENCIÓN EN DUELO Y CON ENFOQUE DE GÉNERO}

Institucionalmente nunca antes habíamos intervenido en una realidad como estas. Nuestro énfasis siempre fueron las mujeres, aunque en un momento de nuestra historia definimos políticamente hacer la excepción para el caso de los hombres y mujeres jóvenes. Pues considerábamos que era clave para lograr transformaciones en mentalidades, subjetividades y actitudes en las relaciones entre los géneros, hacer una fuerte incidencia en las etapas de socialización y formación, pues los adultos y adultas por estar ya estructurados culturalmente, hacen más dificultoso y lento cualquier cambio de estas dimensiones.

A partir de vivir la realidad del desplazamiento forzado, constatamos la urgencia de apoyar con un trabajo desde el enfoque de género, que incidiera en la realidad de la guerra y en la manera particular que afecta a las mujeres y a los hombres de diferentes culturas y edades. A partir de allí, se nos constituye un reto poner nuestra metodología y pedagogía de género al servicio de afectar positivamente la realidad de mujeres y hombres que viven en condiciones de guerra, en el sentido de aportar a reconstruir identidades personales, culturales y el tejido social, buscando propiciar relaciones equitativas, de respeto y dignidad, de empoderamiento y acceso a igualdad de oportunidades, por parte de mujeres y hombres. 
Para Vamos Mujer, la guerra, el conflicto en todas sus manifestaciones y efectos, se constituyen en territorio o escenario para re-interpretar problemáticas y re- crear formas de intervenir a la luz de nuestra misión institucional: propiciar relaciones más humanas, justas, equitativas y éticas entre mujeres y hombres. Paradójicamente, realidades tan duras, que quiebran a las personas y en este caso, afectan tan profundamente las identidades personales de mujeres y hombres, posibilita un ámbito para imaginar y re-crear el ejercicio pedagógico de género en la doble vía de la de-construcción, construcción, de nuevas identidades, mentalidades, subjetividades, actitudes, roles, papeles y formas de relación entre ambos géneros y de estos con el mundo que les rodea.

No se trata de que las personas en medio del dolor se hagan preguntas por la existencia, se trata de que puedan conversar de lo que de otra manera jamás conversarían, de cómo vivimos los hechos, de cómo nos afectan como personas y como géneros, de cómo los enfrentamos desde nuestros seres y cuerpos, imaginarios, maneras de representar, expectativas, deseos y potencialidades, de cómo estas maneras nos cierran puertas para la interrelación cotidiana, nos hacen agresivos y agresivas, nos convocan al permanente desencuentro, a las violencias.

La propuesta metodológica y el tipo de problemática a atender, ha exigido personas talleristas con un perfil profesional, con énfasis en el manejo de situaciones conflictivas, en el manejo psicosocial con enfoque de género, en la elaboración del duelo, en el fortalecimiento cultural y grupal, en la negociación y en la elaboración de proyectos para fortalecer la esperanza y las formas propias de organización de mujeres y hombres. Este trabajo interdisciplinario posibilita intervenciones que involucran aspectos de lo subjetivo, de lo cultural social y del orden de las mentalidades y de lo simbólico.

El trabajo se ha realizado en tres niveles: Las organizaciones contrapartes (organizaciones que apoyan y realizan el trabajo directo con los desplazados en las cinco regiones), la población desplazada de 
mujeres y hombres adultos y la población de mujeres y hombres jóvenes desplazados. Con las organizaciones contrapartes, en la vía de que ellas ganaran herramientas metodológicas y pedagógicas con enfoque de género, para atender, el duelo, reconstruir la memoria cultural, fortalecer la organización comunitaria en acciones referidas a este grupo de población y en acciones en el marco de la aplicación de los derechos humanos, es decir de lograr hacer verdad, justicia y reparación. Con la población adulta y juvenil, en la vía de que pudieran tramitar desde un enfoque de género estos mismos asuntos.

Pedagogía de GÉNero

En cada evento pedagógico se ha trabajado a partir de ejercicios que hacen posible un conjunto de asuntos en las personas:

- Hacen posible apaciguar la angustia, nombrar los miedos.

- Movilizan posiciones subjetivas.

- Construyen posiciones de dignidad en las personas.

- Permiten el trabajo desde sus emociones y potencian su fortaleza creativa y estética.

- Posibilitan el análisis de situaciones, repensar las causas y los efectos de ellas en las subjetividades, mentalidades y actitudes, hacen posible des-aprender- aprender, de-construir. Permiten moverse de situaciones aparentemente naturales para ellos y ellas o de situaciones impuestas por la cultura, la crianza, la socialización.

- Permiten herramientas e información sobre los derechos humanos para tramitar sus necesidades y propuestas. 


\section{Las PROpuest as y QUeHACERES DE PAZ \\ DE LAS MUJERES FEMINIST AS Y POPULARES.}

Coincidimos con lo que acertadamente dijo Martha López en un encuentro de mujeres. "Para nosotras la paz entre los seres humanos, entre mujeres y hombres, quienes viven próximos unos a otros, no es un estado natural, por eso la paz tiene que ser instituida, hay que establecerla lo cual significa sentar su normatividad y que se convierta por fuerza en ley moral o fuerza moral o psicológica equivalente a la fuerza física, esto hará que el estado de derecho sea también un estado de justicia".

LA RUTA PACÍFICA DE LAS MUJERES COLOMBIANAS, INICIATIVA PACIFISTA, CONSTRUCTORA DE EQUIDAD, SOSTENIBILIDAD Y PAZ

Las mujeres que confluimos en La Ruta Pacífica pensamos y sentimos que el desarrollo de la guerra que vive Colombia atenta contra nuestra dignidad y degrada nuestras posibilidades de existencia, la de nuestros hijos, compañeros, familiares y amigos, así como las de las generaciones por venir.

Hemos rescatado un discurso y las propuestas pacifistas que propenden la convivencia pacífica con todos los seres de la naturaleza, por eso le planteamos al país que se debe parar la guerra, y colocarle límites colectivos a la lógica en la cual, ésta se apoya. Sabemos que no hay futuro posible y viable para las nuevas generaciones, si las presentes no acumulan herramientas y habilidades de todo tipo en la tramitación pacífica de los conflictos ya sean familiares, sociales o políticos, si no aprendemos a respetar la naturaleza, superando la relación de dominio que la depreda y pone en duda la continuidad de la vida en el planeta.

La Ruta Pacífica representa el empeño, el empuje, la solidaridad, la fuerza de muchas mujeres para poner límites a la locura de esta guerra. No es la única iniciativa de Paz construida desde las mujeres, 
existen otras, todas ellas necesarias y bienvenidas porque los esfuerzos por lograr la paz deben ser muchos, múltiples, diversos.

\section{¿QUÉ ES LA RUtA?}

Esta iniciativa nace en 1995 en el marco del análisis de la problemática de violencia sexual sobre las mujeres generada en zonas de conflicto, en específico en el corregimiento de Pueblo Nuevo Urabá en donde $90 \%$ de las mujeres fueron violadas o abusadas sexualmente por los diferentes actores armados que se mueven allí.

La Ruta es una propuesta política feminista, que propugna por la tramitación negociada de los conflictos. Nos declaramos pacifistas, antibélicas y constructoras de una ética de la no violencia, en la que la justicia, la paz, la equidad, la tolerancia, la autonomía, la libertad y el reconocimiento del otro, son principios fundamentales.

Para llevar a cabo nuestro proyecto, nos entrelazamos en puntos focales y logramos la confluencia de diversos sectores: campesinas, indígenas, afro-colombianas, intelectuales, amas de casa, mujeres jóvenes, viejas, mujeres populares y profesionales. Para organizar el trabajo se ha conformado un Equipo Nacional Coordinador que se reúne para organizar y preparar nuestras acciones y reflexiones ${ }^{2}$.

2. Este equipo esta integrado por la Mesa de Trabajo Mujer de Medellín, la Escuela Nacional Sindical (Medellín), la Casa de la Mujer (Bogotá), Comunitar (Popayán), la Red Nacional de Mujeres (Quibdó), la Corporación Nuevo Arco Iris (Putumayo), la Red Nacional de Mujeres (Pereira), la Red Nacional de Mujeres (Cali), la Red Nacional de Mujeres (Cartagena), la Corporación Mujeres que Crean (Medellín), la Corporación Vamos Mujer (Medellín), Mujer y Futuro (Bucaramanga), la Corporación Combos (Medellín) y la Corporación Convivamos (Medellín). 


\section{Propuest AS y APUEST AS De la Ruta Pacífica}

- Apoyar las medidas internacionales para la disminución del armamentismo.

- Que quede explícito el compromiso del Estado de disminuir el presupuesto de guerra y aumento del presupuesto de inversión social.

- Reforma en las fuerzas armadas para garantizar un orden público democrático.

- Reformular la formación militar, orientada a fortalecer el desarrollo de la Paz en el país y a la protección de la Ciudadanía, partiendo del principio de construir una sociedad civilista, y no guerrerista.

- Respetar la objeción de conciencia. El servicio militar obligatorio debe ser reemplazado por el servicio social que beneficie a la población, propiciando la profesionalización de las fuerzas armadas.

- Velar por la no incorporación ni reclutamiento de menores en las filas de los diferentes ejércitos.

- Por un país libre, donde los derechos humanos se respeten y nuestras futuras generaciones puedan disfrutarlos vital y plenamente.

- Igualdad de oportunidades para las mujeres hacia el logro de la equidad.

- Fortalecer la solidaridad- sororidad entre las mujeres.

- Fortalecer alianzas nacionales y regionales entre las diferentes iniciativas de mujeres por la paz.

- Consideramos que la violación de las mujeres en el contexto de la guerra, por los diversos actores armados, debe ser considerado un Crimen de Lesa Humanidad. 
- Realizar diálogos regionales, veredales y barriales, en los cuales todas y todos podamos aportar y trabajar por un país equitativo y vivible para quienes lo habitamos.

- Convertir los actos agresivos en reflexiones que propicien la paz, mejorando las formas de relación entre hombres y mujeres buscando el diálogo y la negociación también en los espacios cotidianos.

- Convocar a los actores de la guerra: paramilitares, "convivir", narcotráfico, guerrilla y ejército a que se desarmen e inviertan su empeño, en trabajo que apoye el desarrollo de las comunidades.

- Contribuir a la construcción de una propuesta de Desarrollo Humano Sostenible que propugne por un estilo de vida no consumista, un desarrollo que respete el equilibrio ecológico, y en el cual las mujeres y los hombres compartamos equitativamente las responsabilidades y beneficios del desarrollo.

- Llamar a la responsabilidad y compromiso de los empresarios y dueños de la tierra, para que consideren una redistribución de los recursos y poder así generar una reforma agraria negociada que no se haga por la vía de la barbarie a sangre y fuego.

- Convocar a las multinacionales a no exacerbar más el conflicto armado aliándose con los diversos actores armados, que sus inversiones tengan en cuenta la situación social y política de cada zona, propugnando por apuestas de desarrollo que faciliten la equidad y la salida negociada al conflicto.

- Consideramos que a través de la participación ciudadana de las mujeres aportamos un granito de arena a la pacificación de nuestras comunidades. Estamos dispuestas a contribuir con alternativas, dialogo y apoyo mutuo, para que la paz sea una construcción real y posible.

- Nos comprometemos a multiplicar día a día, los ejemplos y esfuerzos de convivencia y solidaridad, empezando por la casa, la familia, la pareja, hasta la vereda, la ciudad y el país. 
- Nos comprometemos en este proceso a participar activamente en los comités de impulso de la Asamblea Permanente de la Sociedad Civil.

- Desde la sociedad civil llevar a cabo acciones que presionen la negociación del conflicto armado que vive el país, exigiendo el pleno respeto al Derecho Internacional Humanitario.

- Trabajar por la convivencia pacífica desde una ética de la cooperación y la solidaridad y una pedagogía de la No Violencia.

- Ser veedoras en la negociación del conflicto armado del respeto por nuestros Derechos Humanos, Sexuales y Reproductivos.

- Que el Estado y el gobierno colombiano se comprometa seriamente a promover, difundir y establecer estrategias para el respeto de los Derechos Humanos y el Derecho Internacional Humanitario.

- Respeto a las decisiones de la población civil, respeto a nuestra posición civilista de autonomía (Neutralidad activa) frente a todos los actores de la guerra y las diferentes formas de resistencia pacifica, exigiendo nuestro derecho a no ser involucradas e involucrados en la guerra por ninguno.

- Rechazamos la decisión del Estado de permitir las asociaciones "Convivir" porque atentan contra la estrategia de humanización de la guerra, las llamadas Cooperativas de vigilancia ciudadana, no son más que nuevos grupos paramilitares.

- Proponemos fortalecer los mecanismos ágiles de justicia (acciones de tutela y acciones populares).

- Buscar la solidaridad internacional que permita desarrollar una labor de difusión que genere una corriente que propugne por la solución pacífica del conflicto armado en Colombia.

- Fomentar la conformación de una Red Internacional de ONGs de mujeres y feministas que apoye y haga seguimiento a las propuestas de paz en Colombia, y que tiendan a la creación de lazos de solidaridad con mujeres y hombres de otros países del mundo. 
Impulsar la conformación de una Veeduría Internacional compuesta por Estados amigos de Colombia, ONGs, así como por mujeres con experiencia en la negociación de conflictos armados, que haga el papel de "Amigables componedores".

- Impulsar una estrategia de comunicación, difusión, cuestionar el rol guerrerista de los medios colombianos, realizar una campaña de visibilización de nuestra propuestas y trabajos por la vida, a través de los medios de comunicación.

- Organizar y realizar una próxima Ruta Pacífica en el 2001, a una ciudad de frontera al Sur del país; en la que convoquemos al movimiento internacional de mujeres a llegar al núcleo del conflicto armado, así como este año llegamos en la Marcha Mundial del Pan y las Rosas al núcleo del capitalismo (New York).

\section{Las Mujeres DE NeGRO}

Somos un grupo de mujeres de distintas regiones y ciudades de Colombia, de la "Ruta pacífica de las mujeres de Colombia" y de la "Cadena de mujeres contra la guerra y por la paz del Magdalena Medio", que, en silencio, vestidas de negro y con flores y mariposas amarillas, manifestamos públicamente todos los martes de fin de mes, nuestro NO a la guerra y a las distintas violencias.

Nos sumamos solidariamente a las mujeres y feministas pacifistas Israelíes, Palestinas, Norteamericanas, Yugoslavas, Italianas que se oponen a las guerras y al armamentismo. Vestimos de negro por todas las víctimas del conflicto armado, conocidas y desconocidas, por las masacres, por el irrespeto a la población civil, por las minas quiebrapartas, por las desapariciones forzadas, por los secuestros, por la afectación de la vida, los afectos y el cuerpo de las mujeres con la practica de la violación, el trato como botín de guerra, la seducción y control del amor de las mujeres, los escarnios públicos. De negro y en silencio protestamos por la impunidad, por las políticas y prácticas de todos los ejércitos cuyos argumentos son la fuerza, las violencias, la violación de los Derechos Humanos y la violación del Derecho Internacional Humanitario. 
Escogemos el silencio como acto de repudio a la palabra de los medios de comunicación que presentan las noticias del dolor de la guerra, como hechos sensacionalistas y amarillistas no posibilitando que la población civil se informe, tome conciencia y actúe no violentamente frente a las atrocidades y la barbarie de la guerra. A través de los símbolos que portamos, hacemos visible nuestra postura de defensa de la vida digna e impulsamos acciones y valores de no violencia, de solidaridad, de hacer verdad, justicia y reparación sobre los actos atroces de todos los actores armados sobre las mujeres, los hombres, los y las jóvenes, los y las niñas.

Para finalizar, reafirmamos la urgencia de crear redes de solidaridad, apoyo y protección, entre hermanos y hermanas de los distintos lugares del planeta, como posibilidad de condolernos con los otros y otras, sentir que nuestro país es uno sólo y que necesita seguir vivo, sobre todo necesitan seguir vivas las alternativas y experiencias no violentas.

\section{BIBLIOGRAFÍA}

Córdoba, M., 2000, Las mujeres en el conflicto armado, ponencia, Seminario Taller "Una Visión de los Efectos del Conflicto Armado Urbano sobre la Vida de las Mujeres", realizado por la Ruta Pacifica de las Mujeres Colombianas, coordinación Medellín y la Corporación Vamos Mujer.

Corporación de Promoción Popular, IPC, 1999, Antioquía fin de milenio: ¿Terminará la crisis del Derecho Humanitario?

Corporación Vamos Mujer, Cartillas sobre la Experiencia de Capacitación en Derechos Humanos con Enfoque de Género, con Mujeres y Hombres Desplazados por el Conflicto Armado en Cinco Regiones del País.

La Ruta Pacífica, 2000, Documentos, Libro de Sistematización de la Experiencia.

Mazo López, C., 2000.

Experiencia de Capacitación con Enfoque de Género, en Derechos Humanos con Mujeres y Hombres Desplazados por la Guerra, en la Vía de Devolverles Algunas Luces de Esperanza como Sujetos de Derecho, ponencia realizada para el 
Seminario Taller: Experiencias Educativas que Aportan a la Construcción de Comunidad en Zonas de Conflicto.

Los Duelos Causados por la Guerra y por el Desplazamiento Forzado en Nuestro País, ponencia realizada para el Evento Interdisciplinario en Atención en Duelo, Medellín y Bucaramanga.

Una Mirada a la Guerra por la Vida, memorias del evento realizado por la Organización Femenina Popular de Barrancamermeja.

Mejía, M., 2000, Implicaciones subjetivas del conflicto armado en mujeres y hombres preadolecentes: Un enfoque de intervención, ponencia, Seminario Taller "Una Visión de los Efectos del Conflicto Armado Urbano sobre la Vida de las Mujeres", realizado por la Ruta Pacifica de las Mujeres Colombianas, coordinación Medellín y la Corporación Vamos Mujer.

Ospina W., 1999, La Franja Amarilla.

Tamayo, L., Cruz Roja Intenacional-Bogotá, información diversa. 


\title{
ChristianA GEORGE
}

\section{Engendering the Peace Process IN AFRICA}

\begin{abstract}
"Women ... are rarely consulted during the political process of peace negotiations, yet they are often the ones who keep their communities alive - emotionally and physically - during the times of war."
\end{abstract}

(Women's Commission for Refugee Women and Children, 1995)

\section{Processus de paIX EN AfRIQUe}

Inspirées par la plate-forme d'action de Pékin, les femmes d'Afrique sont plus que jamais déterminées à participer activement aux nombreux processus de paix et à ne plus demeurer des victimes passives de la guerre. Dans cette détermination renouvelée, les femmes africaines ont préféré préconiser et influencer les lignes de conduite afin d'aider à résoudre les problèmes à la base au lieu d'utiliser des mesures «bouchetrous» dans des situations d'urgence. Ces désirs se sont traduits aujour d'hui par des actions à travers toute l'Afrique; de nombreux groupes de femmes, au niveau national, régional et sous-régional, militent active ment pour la paix et participent à des négociations de paix de haut niveau. Cet article est destiné à souligner l'engagement de Femmes Africa Solidarité (FAS) dans la création du processus de paix en Afrique. 


\section{INTRODUCTION}

At the threshold of a new millennium where development is flourishing in all regions of the earth, Africa is a continent in turmoil experiencing poverty, illiteracy, corruption, famine, debt and an explosion of internal conflicts whose effects are most often borne by women and children.

Women in war-torn regions of the continent have seen their husbands, children, relatives and friends blasted or hacked. They have had their homes and farms torched and livestock stolen. Many have been raped, some repeatedly. A significant number were impregnated by the very men who murdered their husbands and children. They have given birth to unwanted children. More than any other group, they live in life-threatening situations marked by fear, insecurity, trauma and helplessness. To their traditional roles of house wives and care takers has been added the role of breadwinners, a role most of them are ill-prepared to assume. Thus women bear a disproportionate share of the negative impact of war.

Furthermore their children have been particularly victimised by these conflicts. They are orphaned, the boys are recruited into the army as child soldiers, exposed to drug use and abuse. Usually deprived of an education or training in marketable skills, the young recruits who make up these armies often find that soldiering is the only occupation for which they are equipped. The girls are raped, and exposed to prostitution as well as HIV/AIDS.

In view of this situation, African women have realised that they can no longer be passive victims of conflicts. They have come to the conclusion that while the peace process tends to focus on bringing warring factions together, room should be made for women representatives who will be responsible for much of post war social rehabilitation. Their representation at the negotiating table has thus become imperative. 
Women insist that greater recognition and visibility should be given to them and their work by supporting their participation in governance mechanisms. A proper balance could then be restored and democracy could prevail, which will be a vital process for establishing an environment conducive to durable peace and sustainable development in Africa.

These desires have been translated into action as today, throughout Africa, many national, subregional and regional women's groups are actively advocating peace and creating alternative communication networks that are opening new spaces for non-violent conflict resolution and new forms of solidarity. African women have preferred these forms of conflict management to militating for the implementation of humanitarian instruments of law, which in their view insists on conducive environment for war and does insist on building sustainable peace. To this end African women, sponsored by UNESCO, came together in Zanzibar to elaborate a culture of peace at the Pan-African Women's Conference on a Culture of Peace entitled "Women organise for Peace and Non-violence in Africa" which was held in Zanzibar, United Republic of Tanzania on 17-20 May 1999.

Other African women's organisations, individually and collectively, have seized the opportunity created by the Beijing process to come together for effective debates and mobilisation. One such organisations is Femmes Africa Solidarité (FAS) based in Geneva.

\section{The Role of Femmes Africa Solidarité (FAS)}

Femmes Africa Solidarité (FAS) is a women's organisation founded in June 1996 by women leaders from various African countries representing different professions. Since its inception in 1996, FAS has been working to promote the leading role of women in the prevention, management and resolution of conflicts on the African continent. It does so through advocacy to bring women's concerns to the 
attention of national, regional and international bodies and by facilitating dialogue among women groups.

FAS believes that political crises in Africa that turn into internal wars derive mainly from the absence of good governance and failure to respect human rights and rule of law. Denial of participation and politics of exclusion further add to the multiple factors and forces that cause conflict and political instability on the continent. It is important to develop more comprehensive policies and practices for conflict prevention and management in order to strengthen capacity to manage conflict at national and regional levels.

To this end FAS advocates the involvement of women in the peace process at national level, notably through peace and solidarity missions. Such missions have been carried out in Liberia, Sierra Leone and Burundi. This advocacy and lobbying programme targets local governments, political parties, diplomatic corps, UN and OAU representatives and the media. Another specific characteristic of this strategy is the use of the experience and influence of African women leaders to sensitise these actors to women's best practices so that their role can be visible and fully recognised.

This forceful strategy enables local women NGOs to interact with different actors involved in the decision-making process in order to adequately involve women, mainstream gender into policies and programs, and get support from these actors.

As an advocacy network dealing with peace, gender and development, FAS targeted four main institutions at regional level. These are the Organisation of African Unity (OAU); the Economic Commission for Africa (ECA); the African Development Bank $(\mathrm{ADB})$ and the African Commission on Human and Peoples' Rights (ACEPR). FAS also works with other sub-regional institutions like the Economic Community of West African States (ECOWAS), The Intergovernmental Authority for Development (IGAD) and the South African Development Committee (SADC). 


\section{FAS ADVOCACY ON PEACE}

Facing African women's growing involvement for peace and their strong determination to be involved in political decision-making in order to help solve problems at source instead of using stop-gap measures in emergency situations, FAS uses advocacy and capacity building as its main strategies to facilitate the participation of women in the various peace processes and to strengthen women's position and influence. Women leaders and women organisations are thus introduced to the existing mechanisms at regional and continental levels and they are also trained in negotiating techniques. In this regard FAS facilitates and brings together other women organisations who work at the grass roots and national levels to form effective platforms for advocacy. This has been achieved by:

- mobilising local women's NGOs involved in the peace process and encouraging their networking, and facilitating the establishment of strong partnerships between these groups and peace and development bodies at all levels;

- supporting women's NGOs attending the sessions of the governing bodies of AWCPD, OAU, ECA, ADB and ACPPR to better understand the proceedings of those different bodies, improve knowledge of their mechanisms and functions and translate them to the grassroots level ;

- facilitating the creation of a women's caucus within these institutions which will serve as a platform for local NGOs to meet regularly to exchange information, hold briefings and formulate their agenda to be presented through these mechanisms;

- strengthening women's organisations within the caucus by providing them the necessary advocacy techniques and tools, and making use of press releases and daily meetings to mobilise public and political support; 
- sensitising these institutions to the role of women in peace and development, and stressing the importance for African States to ratify and implement legal instruments addressing women's human rights;

- monitoring and evaluating the progress made towards the implementation of the various Platforms of Action addressing the empowerment of women adopted by African States;

- organising campaigns through the media and sensitising the public to the role of women and their NGOs' best practices in the peace process;

- building partnerships with women from other continents to support these campaigns;

- collecting data, statistics and evidence of women's best practices and disseminating this information ;

- raising funds to support women's initiatives on conflict resolution and peace building.

\section{ACHIEVEMENTS OF FAS ADVOCACY}

\section{Advocacy Campaign: Engendering the Peace Process}

FAS has lobbied for and obtained institutional change in international, regional and national bodies. It participated in the campaign organised by the African women's peace movement which led to the creation of the African Women Committee on Peace and Development (AWCPD) in April 1998 to ensure women's participation in the activities of the OAU's central organ, in particular through the Mechanism. of Conflict Prevention, Management and Resolution. It is meant to work in close 
co-operation with the OAU's Women's Unit and the ECA's African Centre for Women. To bring women's voices and concerns to the ongoing peace process in Burundi, FAS also successfully advocated the participation of Burundian women at the peace negotiations which are currently being held in Arusha, at which they were granted observer status.

\section{Violence against Women}

FAS has participated in the elaboration of legal instruments to protect women's human rights. In this regard, FAS has supported women's participation at the UN Commission on the Status of Women in New York, which is in charge of drafting the optional protocol to the Convention on the Elimination of all forms of Discrimination Against Women (CEDAW). Also at regional level, FAS has successfully campaigned for the appointment of a Special Rapporteur for women's rights at the ACUPR, this was accomplished in April 1998. It also successfully lobbied for the inclusion of more women members in the Commission, which has brought the number of women from two to four during the OAU Summit in June 1999 in Algiers; and also for the elaboration of an additional protocol to the African Charter on Human and Peoples' Rights for the establishment of an African Court of Human Rights, which is pending ratification at the OAU level, as well as an additional protocol on Women's Human Rights.

FAS has also intervened at the UN Commission on Human Rights and at its Sub-commission regarding the situation of women in armed conflict, especially in Sierra Leone, during the 1998, 1999 and 2000 sessions. These interventions led to the visit of the High Commissioner on Human Rights to Sierra Leone and the creation of a tribunal to investigate the crimes perpetrated during the conflict. 


\section{Solidarity and Peace Missions}

FAS sent several high-level delegations to visit Burundi in December 1997, Sierra Leone in February 1997, Liberia in July 1997 and Ethiopia and Eritrea in September 1999. The missions were aimed at encouraging and supporting women's peace initiatives in these countries; sensitising the different actors involved in the negotiations to the need to involve women in the decision-making process on peace; and sharing experiences on African women's initiatives on conflict management and resolution.

\section{Capacity Building}

FAS has organised training workshops and fostered an exchange of experience and information among women and their associations in many parts of Africa, especially in Burundi in December 1997; two training sessions in Liberia in July 1997, in Sierra Leone in February 1997 and in the Great Lakes region in March 1998. Such training workshops focused on civic education, conflict resolution and negotiation techniques, as well as leadership building. FAS has also built national women's networks in the Great Lakes and Mano River regions, through the creation of sub-regional networks such as Femmes et Paix and the Mano River Women's Peace Network.

\section{Democratisation Process}

FAS has successfully conducted women-only election observer missions to Liberia in 1997, designed to assist the electoral process as a whole. This mission was carried out in four phases. The first phase was a solidarity mission as well as a training programme on civic education to support the women. This was followed by an election observer mission. The third phase was an evaluation programme which 
was combined with a training session on advocacy and techniques of negotiation; and the final phase centred on the promotion of gender issues into government policies and programmes.

\section{Communication}

FAS promotes communication, with a view to maintaining contacts between women and the international community and building partnerships. To this end, FAS has developed a Web site www. fasngo. org which offers information on women's peace activities and makes available a "Leadership Bank" on women leaders working for gender equality, peace and development in Africa. FAS also publishes, twice yearly, an advocacy newsletter, FAS Advocacy News, which reports on and analyses the role of women in peace initiatives and monitors progress in gender, peace, development and related issues. The various missions of FAS are also published in the form of books. During its previous programme, FAS published four mission reports. The first one addressed the democratic process in Liberia and the second one was devoted to Women's Best Practices in the Sierra Leone peace process; the third and fourth ones were on Women's Best Practices in Burundi and the Mano River Union States of Guinea, Liberia and Sierra Leone. These publications have been widely distributed for information purposes to women's NGOs, governments and OAU Member States. 


\section{CONSTRAINTS AND LIMITATIONS}

African women have joined the struggle to achieve peace and development, they have mobilized to get recognition and visibility, they have created those institutional mechanisms needed for the advancement of women. Still, more needs to be done, particularly in order to place more women in the seats of power where decisions are made on war and peace, military spending and policy.

Some of the constraints they face are due to the fact that:

- Most of the time, limited resources are put into efforts which deal directly with those who bear guns and priority is not given to long-term initiatives aimed at reconciliation.

- There is resistance among men to seeing women at the negotiating table on the pretext that they are not party to the conflict, in other words, because they have not themselves taken up arms; another argument is that in negotiations, women are by nature more conciliatory. It is clear that the main reason for this resistance is the desire to avoid sharing the "pie", which the men consider exclusively theirs.

- When women have succeeded in removing the barriers and participating in negotiations, after a peace agreement is reached they are excluded from the governance mechanisms. The usual rhetoric is that now that they have made peace they should go back to their families or do community work.

- Women do not have access to the resources that facilitate monitoring, for example, of arms flows.

- Competition among the members about the resources available weakens the Movement.

- The spread of HIV/AIDS in Africa, which is diminishing the human and financial resources. 


\section{THE WAY FORWARD}

In conclusion, in order to remove the above-mentioned barriers, we need to find new strategies. These include:

- Developing new ways and means of mobilising funds, for example, by attracting private funds for women's initiatives in post-conflict reconstruction;

- Building strategic alliances between women's mechanisms for peace, for example by establishing institutional links between the AWCPD, WAWA and MRWPN;

- Supporting existing networks and creating a space for dialogue and discussion for consensus building, for example by organising a consultation with NGOs on issues such as disarmament or violence against women ;

- Looking into a regional approach for effective conflict resolution, for example by organising regional consultations among women's groups;

- Sensitising more men to gender issues and promoting a culture of peace for an effective partnership, for example by establishing a permanent dialogue with the leaders at the OAU Central Organ and including more men in the Movements programmes;

- Monitoring the mechanisms dealing with peace processes, for example by understanding the IGAD and ECOWAS systems in order to promote women's leadership role in their councils of elders in early warning and in peace missions;

- Building the capacity of national peace committees, for example by providing training to the Gabon National Peace Commission and sharing experiences to enable it to promote effective conflict prevention in a country surrounded by neighbours in conflict, 
- Putting such issues as HIV /AIDS on the agenda and advocate its inclusion on the African Leaders' Agenda;

- Using the media as a preventive tool in a conflict setting, for example with the creation of an African women's radio station, which would promote a culture of peace and tolerance.

Ladies and gentlemen, it is difficult to measure the direct results of women's peace movements in Africa but clearly they have had a major impact in sensitising public opinion and pressuring governments and international bodies. However, concerted efforts need to be made to consolidate gains from initiatives already started by women groups instead of starting the process all over again. The participation of women in the Burundian peace process has suffered a major setback because it is now being promoted by UN agencies that do not take the initiatives already started by women groups into account.

These initiatives will also be more effective if funding agents concentrate on ongoing initiatives to see them to a fruitful end instead of changing their areas of priority with the ever dynamic international discourse; all the more so since such initiatives must be preceded by intensive sensitisation programmes on both men and women in order to open the way for advocacy and capacity building programmes.

Finally, neither Femmes Africa Solidarité nor any other women's organisation can claim to have the solutions to conflicts in Africa. As you continue your various researches especially in the conflict zones of Africa, we will be glad to brainstorm with you on more effective ways and means of conflict management, effective ways and means which take the views of all affected groups into consideration. 


\section{ABSTRACTS}

\section{FENNEKE REYSOO}

\section{SITUATIONS OF ARMED CONFLICTS \\ AS GENDER RELATIONS ANALYSERS}

Armed conflicts are in the headlines. Yet the meaning of these conflicts for the different social actors involved, especially for civil populations, has only slowly emerged as a field for research. Gender disaggregated social roles and responsibilities can change dramatically in a situation where all the usual social relations are disrupted. During this colloquium, we intend to consider war as a deep social breaking and as gender relations analyser.

In the introduction part, gender's structuring power is considered. Indeed, gender notions and norms are used to deepen antagonisms between the parties at war, and allow to build an Us category, whose crime we understand, and an Others category, whose rapes and torture we abhor. In the latter we see merciless acts committed by "male" aggressors, and in the former "female" victims who are only waiting for revenge. The production of the Other-ennemy is even more efficient as it is built on gender and sexuality norms, for it gives whole groups a sex and a hierarchy. 


\section{AMNEH BADRAN \\ Palestinian - IsRaeli Women Peace Initiatives AND POWER RElations}

Palestinian - Israeli women peace initiatives publicly started more than a decade ago. Women's dialogue led to the first published political position paper made jointly by the two sides. Dialogue between prominent political activists on the two sides also opened the way for the first institutionalised work based on a continuously under development political principle, the birth of the Jerusalem Link.

Yet power relations between both sides and within each community have always determined, to a great extent, the process of roles shaping in the women's quest for conflict transformation. In this regard, women's politics has been very much connected to the political positions of their parties.

This paper intends to discuss these issues, with more focus on the Palestinian side.

\section{EUgÉNIE Aw-NDiAYE}

\section{RELATIONS BETWEen MEN AND WOMEN: \\ ARe the Crises in Africa RoOts of Change?}

In conflict situations, African women are often associated to the reconciliation and peace symbol. Their specific suffering and their nurturing role are connected to their statute in the African societies and explain this image. Yet women are part of an environment and a his tory that place them at the heart of the conflict. However, their experiences entail a different relation with men and society, and leads them to become real citizens, what most development experts are not aware of. 


\section{SUSANNE SCHMEIDL}

\section{GENDER AND EARLY WARNING}

This paper argues that the introduction of gender into early warning will lead to more practical, realistic and usable early warning approaches, especially if early warning is understood as a flexible system that is sensitive to the diverse situations or on the ground necessitating customised solution. A gender-sensitive approach can enhance early warning models in their basic assumption (what we consider as important or not and the questions we are asking), in their modelling (incorporating gender-sensitive indicators), and in the implementation as well (larger variety of responses options). In addition to presenting the arguments as to why a gender perspective would improve early warning in general and early warning models in particular, the paper presents suggestions for gender-sensitive indicators.

\section{Fanta Coulibaly Coumaré}

\section{Situations of ARMed Conflicts betweEn Natural Resources Exploiters in the Sudan-SaHel Zone: The Malian Case}

This presentation means to present how the anarchic use of natural resources is the main source of conflict in the Sahelian regions. Scarcity and a bad management of natural resources cause conflicts between the different Sahelian countries, and between neighbour communities as well. Some factors (intensive exploitation of combustible materials, endemic drought, ...) make the living conditions ever more difficult. The introduction of new energetic technologies, of decentralised management structures, together with women's involvement may help appease the tensions and prevent conflicts. 


\section{MONIKA KAEMPF}

\section{IMPACT OF WAR ON WOMEN}

The ICRC is an independant humanitarian organisation whose purpose is to protect and assist the victims from wars and internal tensions. The ICRC is active in 80 countries. International humanitarian law has granted equal protection measures for women and men. In certains cases, women's specific needs call for particular protection measures. This paper presents different concrete actions focusing on women's needs.

\section{Magdala Velazquez Toro}

\section{Feminist Reflections on War, Peace and Women, IN A GENDER APPROACH}

In this presentation the author considers war and peace from an historical and feminist point of view. After a brief overview of the history of pacifist and feminist movements, she deconstructs patriarchy and men's socialisation models in certain societies. At the same time she proposes alternative models to the existing stereotypes concerning masculinity and femininity. Some of these models can be seen in the so called "post-modern" war where the many and flexible discursive spaces allow individuals to find a motivation for their individualised participation. Then participating in a war becomes a matter of negociation mainly based on the construction/deconstruction of gender categories. 


\section{DinORA Aguiñada DERAS}

\section{A FEMINIST LOOK ON WOMEN'S PARTICIPATION IN WAR}

This paper deals with the reconstruction of the feminine identity of ex-fighting women who have taken part in the guerrilla, who have come back to villages and who are refugees. This reconstruction is based on substantial transgressions of traditional norms with regard to sexuality, maternity and mourning.

\section{Goretti NDACAYISABA}

Impact of Conflict on the Men-Women Relations. The Case of Burundi

Burundi's recent history is punctuated with political crises and violent conflicts. Armed conflicts deeply alter human relations. Women, children and elders who are not fighting are continually on the road in search of quiet places. In this exodus, the traditional relations between men and women are altered. Mainly with NGOs are women - most of whom have to ensure their families' survival without a man in a good condition - able to set up support structure.

\section{Alla Kuvatova}

\section{CONSEQUENCES AND IMPACT OF THE CiVIL WAR:}

GENDER ISSUES IN T AJIKIST AN

The impact of the civil war on Tajikistan was enormous and its consequences will continue to be felt for a long time. The gender gap widened during this period (1992-1997) in all spheres - 
economic, political, cultural, family life. Gender roles in the Tajik society are changing, but the traditional view is still strong. Negative social phenomenon such as criminality, violence, polygamy are expanding. Increased women's involvement in NGOs has a transforming power.

\section{ANNEMIEK RICHTERS}

Gender Violence, Health and Healing in Situations of Ethno-national Conflicts: The Cases of the FORMER YUgOSLAVIA AND TAJIKISTAN

This intervention is related to the experiences the author had in the former Yugoslavia and Tajikistan when she worked on the issue of gender violence. Gender violence is considered in all its interpersonal, sociocultural, economic and political complexity. The complexity of this phenomenon calls for therapeutic and preventive measures that take the whole scope of these factors into account. Setting up approaches and health projects to treat the traumas resulting from a conflict implies a holist view of the problem. In these conditions health promotion cannot go without considering these issues as women's fundamental rights issues.

\section{Micheline Centlivres-Demont}

Fighting Men, Discreet Women:

Aspects of Subordinate Resist ance in the Afghan CONFLICT AND EXILE

Unlike the anglo-afghan wars of the 19 th Century that aroused women's tradition for resistance, the never ending Afghan conflict which began as a coup d'Etat in April 1978, generated few heroic 
female warriors. The islamic and traditional nature of the Afghan resistance movement may be part of the reason. In this conflict Afghan women seem to have been mainly victims, which was used for propaganda purposes by the parties.

In refugee camps in Pakistan, the "management" of women, particularly that of widows without family support, triggered conflicts between well known Afghans and experts from international Organisations.

But it would be erroneous to consider that relations between men and women in the Afghan conflict merely represent a relationship of subordination going from the authority of some to the passivity of others. Women discreetly resisted to both the common adversary and the situation that was imposed on them.

\section{Clara Inés Mazo LóPez}

\section{Considering the Colombian ARMed Conflict FROM WOMEN'S ACTIONS, SYMBOLS AND PROPOSITIONS}

The internal Colombian armed conflict is currently annihilating those positive transformations that women had managed to introduce. Gender roles and values on which discrimination, exclusion and violence against women are based are currently gaining ground. The logic of war reinforces the view of domination and heroism as male features and submission and discretion as female features. Peace talks are being conducted while the war is going on. Negotiation too is a patriarcal process in which agreements are only signed by men. The bulk of the population does not take part in this political exercise either. Some women are directly and in several ways involved in the conflict. But we, organised women, are fighting war and the settlement of conflicts and differences with weapons and death. This paper presents the concrete actions of several women's groups who 
are pulling through and showing that other possible logics do exist, allowing the reconstruction of "sustainable" lifestyles, unlike the logic of war.

\section{CHRistiana GEORGE}

Engendering the Peace Process in Africa

Inspired by the Beijing platform for Action, Women in Africa are evermore determined to actively participate in the various peace processes and no longer remain as passive victims of war. In this renewed determination, African women have preferred to advocate and influence policies so as to help solve problems at the source instead of using stop-gap measures in emergency situations. These desires have been translated into action as today, throughout Africa, many national, sub-regional and regional women's groups are actively advocating peace and participating in peace negotiations at high levels. This paper will highlight the involvement of Femmes Africa Solidarite (FAS) in the peace process engendering in Africa. 


\title{
RESÚMENES
}

\section{FENNEKE REYSOO}

\author{
SITUACIONES DE CONFLICTO ARMADO \\ COMO ANALIZADORES DE LAS RELACIONES DE GÉNERO
}

Los conflictos armados están en la primera plana de la actualidad. Sin embargo, la trascendencia de dichos conflictos para los diferentes actores sociales implicados, principalmente para las poblaciones civiles, ha sido sólo progresivamente objeto de investigaciones. Los roles y responsabilidades sociales diferenciados por sexo, pueden cambiar drásticamente luego de una situación en donde todas las relaciones sociales habituales han sido trastornadas. En este coloquio nos proponemos abordar la guerra como ruptura social profunda y analizador de las relaciones de género.

En la introducción, se hace una reflexión sobre el poder estructurante de género. En efecto, las nociones y normas de género son utilizadas para envenenar los antagonismos entre las partes en guerra, permitiendo construir la categoría de un Nosotros, en el que comprendemos los crímenes cometidos, y la categoría del Otro, en el que aborrecemos las violaciones y las torturas. En éstos últimos, vemos los actos sin piedad de los agresores "masculinos" y en los primeros, las víctimas "femeninas" que solamente piden venganza. La producción del Otro-enemigo parece ser aún más eficaz cuando se construye sobre las normas de género y sexualidad, ya que ella asigna un sexo a los grupos enteros y una jerarquización entre ellos. 


\section{AMNEH BADRAN \\ INICIATIVAS FEMENINAS DE PAZ PALESTINO-ISRAELÍES \\ Y RELACIONES DE PODER}

Las iniciativas femeninas de paz palestino-israelíes comenzaron públicamente hace más de una década. El diálogo de las mujeres condujo a la primera publicación, realizada conjuntamente entre las dos partes, de un documento sobre la posición política. El diálogo entre prominentes activistas políticas de las dos partes también abrió el camino hacia el primer trabajo institucionalizado basado en principios políticos en continuo desarrollo que dio origen al "Jesuralem Link".

El hecho de decir esto no debe hacernos olvidar que las relaciones de poder entre ambas partes, así como al interior de cada comunidad han siempre influido, en gran medida, sobre el proceso de configuración de papeles de las mujeres en busca de la transformación del conflicto. Las políticas de las mujeres han estado muy relacionadas a las políticas de sus naciones. El objetivo del trabajo consiste en analizar estos temas, con un énfasis particular en el lado palestino.

\section{EUgÉNIE Aw-NDiAYE}

\section{RELACIONES HOMBRES-MUJERES:}

LAS CRISIS EN AFRICA ¿SON LOS FERMENTOS DEL CAMBIO?

En situación de conflicto, las mujeres africanas están a menudo asociadas al símbolo de la paz, de la reconciliación. Los sufrimientos específicos que son los suyos, su rol alimenticio, ligado a su posición en la sociedades africanas, explican esta imagen. Ahora bien, pese a que las mujeres forman parte de un entorno y de una historia que las sitúan en el corazón de los conflictos, sus experiencias las conducen a otra relación con los hombres y la sociedad, a un futuro ciudadano, casi siempre ignorado por los expertos en desarrollo. 


\section{SUSANNE SCHMEIDL}

\section{GÉNERO Y ALERTA TEMPRANA DE CONFLICTOS}

El presente trabajo plantea que la introducción de género en la alerta temprana de conflictos conducirá a un enfoque de alerta temprana más práctico, realista y útil, particularmente si la alerta temprana es entendida como un sistema flexible, sensible a las diversas situaciones o en base a la necesidad de una solución personalizada. Un enfoque sensible a la dimensión de género, puede reforzar los modelos de alerta temprana respecto a sus aspectos básicos (qué considerar como importante o no y las preguntas que se hace), en cuanto al modelo mismo (incorporando indicadores con perspectiva de género) y así como en su aplicación e implementación (ampliando la gama de respuestas posibles). Además de presentar argumentos sobre la manera de cómo un enfoque de género podría mejorar las prevenciones tempranas en general y los modelos de alerta temprana en particular, este artículo presenta también algunas propuestas de indicadores con perspectivas de género.

\section{Fanta Coulibaly Coumaré}

\section{LAS SITUACIONES DE CONFLICTO ARMADO}

ENTRE LOS EXPLOTADORES DE RECURSOS NATURALES.

EL CASO DE LAS ZONAS SAHELIANAS, MALI

Esta intervención se propone reflexionar sobre la utilización anárquica de los recursos naturales como la principal fuente de conflicto en las zonas sahelianas. La escasez e inadecuada gestión de los recursos naturales son causas de conflictos, no sólo entre los diferentes países sahelianos sino entre comunidades vecinas. Un cierto número de factores (explotación intensiva de las fuentes de combustible, sequía endémica, etc.) vuelven de más en más difícil las condiciones de 
supervivencia. La introducción de nuevas tecnologías energéticas, de estructuras descentralizadas de gestión y la implicación de las mujeres, pueden ayudar a atenuar las tensiones y prevenir el estallido de conflictos.

\section{MONIKA KAEMPF}

\section{EL IMPACTO DE LA GUERRA EN LAS MUJERES}

El CICR es una organización humanitaria independiente, trabaja en 80 países y tiene como objetivo proteger y asistir a las víctimas de las guerras y tensiones internas. La ley humanitaria internacional acuerda medidas de protección a las mujeres iguales a las de los hombres. Sin embargo, en ciertos casos, las necesidades específicas de las mujeres inducen a medidas particulares de protección. Esta exposición presenta un número de acciones en donde trabaja el CICR, teniendo como mira particularmente las necesidades de las mujeres.

\section{Magdala VelazQuez Toro}

REFLEXIONES FEMINIST AS EN TORNO A LA GUERRA, LA PAZ Y LAS MUJERES, DESDE UNA PERSPECTIVA DE GÉNERO. EL CASO DE COLOMBIA

La autora aborda la guerra y la paz desde un punto de vista histórico y feminista. Después de una breve mirada histórica de los movimientos pacifistas y feministas, se consagra a una desconstrucción del patriarcado y de la socialización de los hombres en un cierto número de sociedades. Haciendo ello, propone modelos alternativos de estereotipos existentes sobre la masculinidad y la feminidad. Algunos de esos modelos se observan en la guerra llamada "postmoderna" en donde los múltiples y flexibles espacios de reflexión permiten a los individuos encontrar allí una motivación de partici- 
pación individualizada. La participación en la guerra se vuelve así una cuestión de negociación basada mayormente en la construcción/desconstrucción de las categorías de género.

\section{DinORA AguiñadA}

UNA MIRADA FEMINISTA SOBRE LA PARTICIPACIÓN

DE LAS MUJERES EN LA GUERRA. El CASO DE El SALVADOR

La exposición analiza la reconstrucción de la identidad femenina de las mujeres excombatientes, colaboradoras de la guerrilla, repobladoras y refugiadas. Ello a partir de la recuperación de las rupturas substanciales de las normas tradicionales del comportamiento exigido a las mujeres respecto a la sexualidad, maternidad y procesos de duelo.

\section{GORETTI NDACAYISABA}

\section{IMPACTO DEL CONFLICTO SOBRE LAS RELACIONES HOMBRES-MUJERES. EL CASO DE BURUNDI}

Burundi tiene una historia reciente marcada por las crisis políticas y los conflictos violentos. Los conflictos armados afectan profundamente las relaciones humanas. Las mujeres, niños y ancianos, en tanto no forman parte del efectivo de combatientes, se encuentran continuamente sobre la ruta buscando espacios de tranquilidad. En este éxodo, las relaciones tradicionales entre hombres y mujeres se ven transformadas. Particularmente, es por intermedio de las ONGs que las mujeres -de las cuales la mayoría debe asegurar la supervivencia de su familia sin la presencia de un hombre trabajador- son capaces de instaurar las estructuras de apoyo. 


\section{Alla Kuvatova}

IMPACTO Y CONSECUENCIAS DE LA GUERRA CIVIL :

LA CUESTIÓN DE GÉNERO EN TAJIKISTAN

El impacto de la guerra civil en Tajikistan ha sido enorme y sus consecuencias continuarán sintiéndose por un tiempo considerable. Durante el periodo 1992-1997, el vacío de género se amplió en todas las esferas (económica, política, cultural y familiar). Los roles de los géneros en la sociedad tajica están cambiando, aunque el punto de vista tradicional todavía es muy fuerte. Los fenómenos sociales negativos (criminalidad, violencia, poligamia) han crecido. La intensificación del compromiso de las mujeres en las ONGs tiene un poder transformador.

\section{ANNEMIEK RicHTERS}

\section{VIOLENCIA DE GÉNERO, TRAUMA Y TRATAMIENTO \\ EN SITUACIONES DE CONFLICTOS ETNO-NATIONAL. LOS CASOS DE EX-YUGOSLAVIA Y TAJIKISTAN.}

Esta intervención relata las experiencias de la autora en ex-Yugoslavia y Tajikistan de su trabajo sobre la cuestión de la violencia de género. La violencia de género es estudiada en toda su complejidad interpersonal, socio-cultural, económica y política. La complejidad del fenómeno requiere respuestas terapéuticas y preventivas que tengan en cuenta el espectro entero de esos factores. La instauración de enfoques y proyectos de salud para el tratamiento de traumatismos causados por un conflicto necesita una visión holística. En estos casos, la promoción de la salud no se puede hacer sin abordarla como cuestión de derechos fundamentales de las mujeres. 


\title{
Micheline Centlivres-Demont
}

\author{
HOMBRES COMBATIENTES, MUJERES DISCRETAS: \\ ASPECTOS DE LAS RESISTENCIAS SUBALTERNAS \\ EN EL CONFLICTO Y EL EXILIO AFGANO
}

Contrariamente a las tradiciones de resistencia femenina durante las guerras anglo-afganas del siglo XIX, el interminable conflicto afgano que comienza con el golpe de Estado de abril de 1978, ha suscitado pocas proezas bélicas femeninas. El carácter islámico y tradicional de la resistencia afgana tiene posiblemente algo que ver en ello. En este conflicto, las mujeres afganas parecen haber sido ante todo víctimas, condición que ha sido, por lo demás, utilizada por los partidos con fines propagandísticos.

En los campos de refugiados de Pakistán, la "gestión" de las mujeres, en particular de las viudas sin apoyo familiar, ha provocado un conflicto entre los notables afganos y los expertos de las organizaciones internacionales. No obstante, sería erróneo considerar las relaciones hombre-mujer dentro del conflicto afgano como una simple relación de subordinación entre la autoridad de unos y la pasividad de otros. La resistencia discreta de las mujeres se ha ejercido tanto contra el adversario común como contra la situación que se les ha inputado.

\section{Clara Inés Mazo Lopez}

UNA MIRADA AL CONFLICTO ARMADO COLOMBIANO

DESDE LA PALABRA, LAS ACCIONES, LOS SÍMBOLOS

Y LAS PROPUEST AS CONSTRUIDAS POR LAS MUJERES

El conflicto armado interno en Colombia está generando un retroceso alarmante en los logros obtenidos por el movimiento social de las mujeres. Se han agudizado los roles, valores, subjetividades, men- 
talidades y actitudes de género que hacen que la discriminación, la exclusión y la violencia contra las mujeres sea cada vez mayor. Lo masculino y lo femenino se reafirman en la lógica guerrera del predominio del uno (lo masculino) sobre el otro (lo femenino), del heroísmo del uno (lo masculino) y la invisibilización-desaparición del otro (lo femenino). Actualmente se ha optado por negociar la Paz en medio del conflicto, claro acto patriarcal en el que sólo se pactan acuerdos entre hombres. En este ejercicio político tampoco esta participando la gran diversidad de población civil del país. Si bien existen mujeres involucradas directamente y de diversas maneras en el conflicto armado, las mujeres organizadas nos oponemos a la guerra, a la tramitación de los conflictos y diferencias por la vía armada, la desaparición y la muerte. Este trabajo presenta las acciones de varios grupos de mujeres que tratamos de rescatar y dar a conocer otras lógicas no belicosas para reconstruir propuestas de vida sostenibles.

\section{Christiana George}

\section{GENERANDO EL PROCESO DE PAZ EN AFRICA}

Inspiradas por la plataforma de acción de Pekín, las mujeres de Africa están más que nunca decididas a participar activamente en los diferentes procesos de paz y a no considerarse más como víctimas pasivas de la guerra. En esta renovada determinación, las mujeres africanas han preferido optar por defender e influenciar las políticas, en tanto ayuden a resolver los problemas de raíz en lugar de recurrir a medidas provisorias en situaciones de emergencia. Estas aspiraciones se han traducido en acciones, hoy en día a través de todo Africa, muchos grupos a nivel nacional, regional y sub-regional se encuentran defendiendo activamente la paz y participando en negociaciones de paz de alto nivel. Este artículo resalta el compromiso de las mujeres de "Mujeres Africa Solidaridad" (MAS) en la generación del proceso de paz en Africa. 